Portland State University

PDXScholar

Summer 9-8-2017

\title{
Intraminority Support For and Participation In Race- Based Collective Action Movements: an Intersectional Perspective
}

Jaboa Shawntaé Lake Portland State University

Follow this and additional works at: https://pdxscholar.library.pdx.edu/open_access_etds

Part of the Gender, Race, Sexuality, and Ethnicity in Communication Commons, and the Social Psychology Commons

Let us know how access to this document benefits you.

\section{Recommended Citation}

Lake, Jaboa Shawntaé, "Intraminority Support For and Participation In Race-Based Collective Action Movements: an Intersectional Perspective" (2017). Dissertations and Theses. Paper 3886.

https://doi.org/10.15760/etd.5774

This Thesis is brought to you for free and open access. It has been accepted for inclusion in Dissertations and Theses by an authorized administrator of PDXScholar. Please contact us if we can make this document more accessible: pdxscholar@pdx.edu. 
Intraminority Support for and Participation in Race-Based Collective Action Movements:

An Intersectional Perspective

by

Jaboa Shawntaé Lake

A thesis submitted in partial fulfillment of the

requirements for the degree of

\section{Master of Science}

in

Psychology

Thesis Committee:

Kimberly Barsamian Kahn, Chair

Eric Mankowski

Cynthia Mohr

Portland State University

2017 
C2017 Jaboa Shawntaé Lake 


\begin{abstract}
Due to high profile police shootings, collective action movements addressing racial bias in policing, such as the Black Lives Matter (BLM) movement, have come to the forefront of societal concern. Though these movements and actions directly address police use of force against Black people, a number of non-Black racial minority individuals and organizations have declared solidarity and joined in protests with BLM. This study takes an intersectional approach to examine racial intraminority attitudes (i.e., racial minorities' attitudes toward other racial minority outgroups) toward support for and participation in protests against police excessive use of force and the BLM movement, through its relationship with modern racist beliefs and racial centrality. Participants completed a survey assessing perspectives on policing, racial protests, and BLM, along with racial identity measures. Results show significant differences in both support for and participation in protests and BLM, with women and Black people reporting higher in both outcomes than men and other racial groups, respectively. Within some racial groups, women show higher overall support for (Latinx, White) and participation in (Black, White) protests and BLM than men in the same racial group, though these differences were not found for other groups. Within each intersecting race and gender group, these effects were mediated by levels of modern racism, highlighting a common factor between all groups and an important point of possible malleability and intervention. Further, the relationship between race and gender identities and modern racism was moderated by racial centrality for some groups (Black and Latina women), though this relationship was
\end{abstract}


again not universally found. By examining within group differences, this study highlights the importance of taking an intersectional approach to understand intraminority attitudes and relations as they pertain to participation in collective action movements towards social change. This study has implications for the generalizability of a number of social psychological theories on minority-minority intergroup race relations (i.e., Black-Latinx), as much of the past literature focuses on majority-minority intergroup relations (i.e., Black-White). Additionally, results from this study may provide useful information for community organizers and social justice activists in promoting intergroup collaboration and coalition building towards more equitable social change that is both more tailored for specific groups and more generalizable across groups. 


\section{Table of Contents}

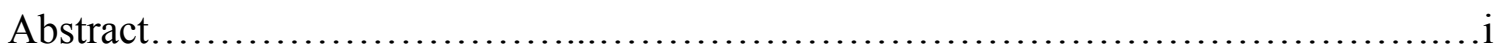

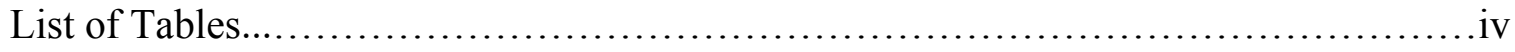

List of Figures................................................................

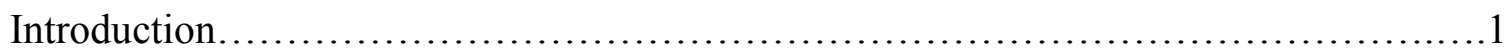

Racial protests and the Black Lives Matter movement..............................4

Collective action and behavior................................................

Intergroup relations....................................................... 16

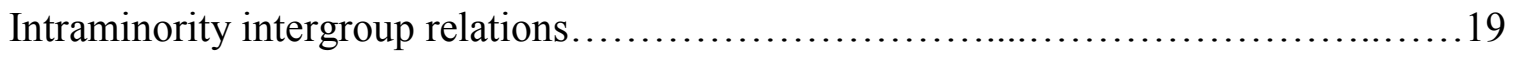

Multiple intersecting identities............................................... 30

Expressions and predictors of racism.......................................... 37

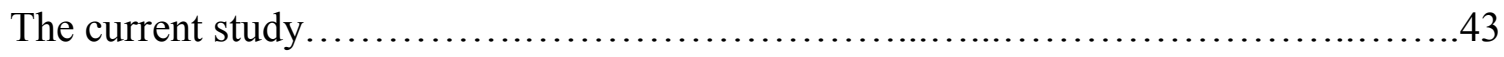

Hypotheses..............................................................45

Method....................................................................49

Analyses and results......................................................55

General discussion...................................................... 73

Tables.................................................................. 99

Figures....................................................................... 111

References..................................................................... 117

Appendix A: List of measures used in analyses............................... 150

Appendix B: Conceptual model and statistical diagrams..........................159

Appendix C: Results from previously conducted EFA and CFAs................... 162 
Table 1. Participant demographics.

Table 2. Participant gender demographics by race.

Table 3. 2 (Gender) x 4 (Race) Factorial ANOVA results for support for protests and the Black Lives Matter Movement.

Table 4. Means and mean differences in support for protests and the Black Lives Matter movement by racial group from Tukey's HSD post-hocs. 100

Table 5. Means and differences in support for protests and the Black Lives Matter movement by gender group within race from post-hoc t-tests.

Table 6. Means and mean differences in participation in protests and the Black Lives Matter movement by racial group.

Table 7. Means and mean differences in participation in protests and the Black Lives Matter movement by racial group from Tukey's HSD post-hocs.

Table 8. Means and differences for participation in protests and the Black Lives Matter movement by gender group within race from post-hoc t-tests.....

Table 9. Model summaries for Equation 1 for each intersecting race and gender group

Table 10. Results from Equation 1 for each intersecting race and gender group

Table 11. Model summaries for Equation 2 for each intersecting race and gender group.

Table 12. Results from Equation 2 for each intersecting race and gender group.

Table 13. Model summaries for Equation 3 for each intersecting race and gender group.

Table 14. Results from Equation 3 for each intersecting race and gender group. 104

Table 15. z-scores comparing the equality of coefficients for race and gender identity predicting modern racism in Equation 1 between intersecting race and gender groups.

Table 16. z-scores comparing the equality of coefficients for racial centrality predicting modern racism in Equation 1 between intersecting race and gender groups. 106 
Table 17. z-scores comparing the equality of coefficients for the interaction of race and gender identity and racial centrality predicting modern racism in Equation 1 between intersecting race and gender groups.

Table 18. z-scores comparing the equality of coefficients for modern racism predicting support for protests and the Black Lives Matter movement in Equation 2 between intersecting race and gender groups.......................................... 106

Table 19. z-scores comparing the equality of coefficients for modern racism predicting participation in protests and the Black Lives Matter movement in Equation 2 between intersecting race and gender groups.

Table 20. z-scores comparing the equality of coefficients for race and gender identity predicting support for protests and the Black Lives Matter movement in Equation 3 between intersecting race and gender groups.

Table 21. z-scores comparing the equality of coefficients for racial centrality predicting support for protests and the Black Lives Matter movement in Equation 3 between intersecting race and gender groups.

Table 22. z-scores comparing the equality of coefficients for the interaction of race and gender identity and racial centrality predicting support for protests and the Black Lives Matter movement in Equation 3 between intersecting race and gender groups.

Table 23. z-scores comparing the equality of coefficients for modern racism predicting support for protests and the Black Lives Matter movement in Equation 3 between intersecting race and gender groups.

Table 24. z-scores comparing the equality of coefficients for race and gender identity predicting participation in protests and the Black Lives Matter movement in Equation 3 between intersecting race and gender groups. 108

Table 25. z-scores comparing the equality of coefficients for racial centrality predicting participation in protests and the Black Lives Matter movement in Equation 3 between intersecting race and gender groups...

Table 26. z-scores comparing the equality of coefficients for the interaction of race and gender identity and racial centrality predicting participation in protests and the Black Lives Matter movement in Equation 3 between intersecting race and gender groups

Table 27. z-scores comparing the equality of coefficients for modern racism predicting participation in protests and the Black Lives Matter movement in Equation 3 between intersecting race and gender groups.

Table 28. Bivariate correlations between variables. 


\section{List of Figures}

Figure 1. Racial group differences in support for protests and the Black Lives Matter Movement (Hypothesis 1a)............................................... 111

Figure 2. Racial group differences in participation in protests and the Black Lives Matter movement (Hypothesis 1a) ................................................. 112

Figure 3. Racial group differences in support for protests and the Black Lives Matter movement (Hypothesis 1a) ..................................................... 113

Figure 4. Gender group differences in participation in protests and the Black Lives Matter movement (Hypothesis 1a) ............................................. 114

Figure 5. Intersecting racial and gender differences in support for protests and the Black Lives Matter movement (Hypothesis 1b) ................................... 115

Figure 6. Intersecting racial and gender differences in participation in protests and the Black Lives Matter movement (Hypothesis 1b) ................................ 116 


\section{Introduction}

Though there has been a historical trend of police violence towards racial minorities (see Kahn \& Martin, 2016 for a review), recent increases in public awareness of racial bias in policing and excessive use of force by police officers against Black people have spurred a number of social justice and collective action responses, including protests and the emergence of the Black Lives Matter (BLM) movement. From these and other public reactions, improving community-police relations and addressing bias in policing and other institutions have come to the forefront as topics of major societal concern. In this societal discourse, certain social identities have become explicit representations of calls for action and police reform, while other social group perspectives are less represented. For example, many refer to Malcolm X or Huey Newton when referencing leadership in the Black Panther movement of the 1960s and 1970s, yet over half of the active members, many of whom also held long-term leadership roles, such as Elaine Brown, were women, and often queer women, such as Angela Davis (Brown, 1992). Currently, DeRay Mckesson and Shaun King, two Black men, are often portrayed as the pioneers of the Black Lives Matter movement, while the movement and network was created and initially mobilized by three Black queer women: Alicia Garza, Opal Tometi, and Patrisse Cullors (Black Lives Matter, 2016). From these and other examples, we can see the contributions that women of color specifically make to the mobilization of various racial justice movements.

Most existing empirical literature has focused on perceptions and attitudes held by majority group members (i.e. White, for race in the US) towards minority groups and 
group members. Intra-minority attitudes and relations (i.e., racial minorities' attitudes toward other racial minority outgroups) have been less explored (Richeson \& Sommers, 2016), and even less as they relate to collective action and behavior (Wright, 2003). Additionally, the role of intersecting identities has been understudied in social psychological literature (Goff \& Kahn, 2013). By exploring these differences and similarities between these understudied groups in this way, this study informs researchers, applied organizers, and other people whose work addresses social issues that are either more group-specific or more generalizable across groups.

Using cross-sectional survey data, this study takes an intersectional approach by examining the independent and interactive influences of individual social identities (race and gender) as they relate to intraminority support for and participation in a current and prominent collective action movement in response to perceived racial bias in policing against Black individuals, Black Lives Matter. Drawing from existing theories and literature, this study further incorporates the influences of racial identity centrality and social attitudes towards racism as predictors of both support for and participation in protests and BLM. That is, this thesis asks, how do an individual's race and gender influence support for and participation in BLM, and are these effects influenced by racial identity centrality and beliefs about racism?

After further setting the social context regarding collective action responses to shootings of and use of force against Black people by police officers, this paper will first define and summarize the existing literature on collective action engagement and political participation, which serve as the dependent variables of interest in the current study. This 
paper will then examine the social psychological literature on intergroup relations, and then, more specifically, on intraminority intergroup relations. Next, intersectionality and its academic trends are explored, while providing historical and current examples of the role of intersecting identities in engagement with past and current collective action movements. To close the introduction, a brief review of the social psychological literature on racism and modern racist beliefs are provided, as both constructs represent key variables in the analyses. Together, this background provides context for the current study's hypotheses that focus on the role of race and gender identities, identification with one's racial group, and beliefs about modern racism on support for and participation in BLM. 


\section{Racial protests and the Black Lives Matter movement}

Recent high-profile cases of shootings of unarmed Black men by police officers have increased societal concern for the issue of racial bias in policing. Though police use

of force against racial minorities has been present and pervasive throughout the history of the United States, some credit the role of technology and social media (i.e. camera phones and online video streaming) in aiding in the creation and mobilization of current social movements that address these and other instances of state violence (Safdar, 2016). Arguably, the most well-known recent movement which seeks to combat these issues is the Black Lives Matter movement. The BLM movement stemmed from the 2012 shooting and death of 17-year-old Trayvon Martin by law-enforcement vigilante George Zimmerman (Black Lives Matter, 2016). This sparked a number of protests nationally and internationally after Zimmerman was acquitted of the charges resulting from the incident.

Over the last few years, a number of other police shooting incidents involving African American males gained wide media attention, such as that of Michael Brown (Ferguson, Missouri in 2014), Tamir Rice (Cleveland, Ohio in 2014), and Walter Scott (North Charleston, South Carolina in 2015), among many others. During this time, the BLM movement began to explicitly address the shooting of and use of lethal force on Black people by police officers. Police shootings totaled almost one thousand deaths across all racial groups in the United States in 2015, with Black people and other racial minorities disproportionately represented in this total (Washington Post, 2016). Overall, $24.2 \%$ of these deaths were of Black people, while Black people only comprise $13.1 \%$ of 
the overall US population (US Census Bureau, 2014), which further exemplifies the disparate outcomes by race in interactions with police. As of the start of 2017, there were 28 official BLM network official chapters across the United States and Canada (Black Lives Matter, 2016), and as of January 2017, over 1,800 BLM demonstrations have taken place across the globe (Elephrame, 2017).

Though the BLM movement has ignited a platform for collective action for Black people, many other racial and ethnic groups have joined the movement in solidarity to address the wider and more global issue of state violence and anti-Blackness. In early 2016, a group of Asian Americans collectively started the "Letter for Black Lives" campaign, for the purpose of better educating their families and communities on pervasive anti-Blackness and the need for the BLM movement by increasing understanding of pervasive discrimination and fostering intraminority alliance (Letters for Black Lives, 2016). The final letter has been translated to dozens of languages and has been shared around the world in both print, audio, and video sign language formats (Meraji, Chow, \& Xu, 2016). Following this campaign, similar letters have been constructed by and for Latinx ${ }^{1}$, Native American, Pacific Islander, and European people in their native languages to also share and discuss with their communities (Letters for Black Lives, 2016).

Other forms of solidarity for the BLM movement have been seen across the world through direct actions and demonstrations, such as from residents in the Palestinian territories and in Cape Town, South Africa. In the Unites States specifically, various

\footnotetext{
${ }^{1}$ Latinx, the gender-inclusive term for people from Latin America or of Latin-American decent, has also been expressed as Latin@, but is argued to be more inclusive of non-binary genders.
} 
racial minority organizations have declared solidarity with BLM, such as La Gente Unida, Unidad Latina en Acción, Last Real Indians, the Council for Native Hawaiian Advancement, GABRIELA USA, Voto Latino, Advancing Justice - Asian Law Caucus, and hundreds of others (APALA, 2016). Though the BLM movement is still a young movement at just over five years old, it has sparked political action and coalition building across racial lines.

To better understand these current social and political movements, how they begin, and how they are sustained in order to create change, social psychological research must put efforts towards expanding the current literature on collective action, intraminority relations and perceptions, and coalition building in response to targeted discrimination. Taking the current racial climate into consideration, especially between racial minority groups, the purpose of this paper and study is to further address this gap in the literature by focusing on how race and gender influence support for and participation in BLM, and how identity and attitudinal factors (racial centrality and modern racism) further influence these outcomes. With this improved understanding of these factors and their influences, results can be used by community organizers and policy makers to increase support for more equitable social justice efforts with more tailored approaches. 


\section{Collective action and behavior}

Examining disparate outcomes between racial groups in interactions with police officers is important for understanding collective action responses to these incidences and improving community-police relations. Many high profile cases of interactions between police and racial minorities which have resulted in the death or serious harm of racial minorities, have sparked protests and public expression of dissatisfaction with the current state of policing. These actions can inform policy makers and researchers alike on the current state of community-police relations. This study focuses on these collective social responses as an important point of examination and a way to better understand intergroup relations in a context heightened by these high profile cases and dissatisfaction with policing practices by marginalized communities.

Public and social responses to pervasive and systemic racial discrimination have manifested in various ways, such as through target-specific direct actions or the creation of wider social movements. Social movements tend to be relatively rare occurrences, often due to obstacles that derail the process necessary to produce interest in disrupting the current social structures and institutions (Wright, 2003). Collective actions and behaviors, which are more common, occur when a member of a group "is acting as a representative of the group and the action is directed at improving the conditions of the entire group" (Wright, Taylor, \& Moghaddam, 1990). Social movements are, then, a product of collective actions and behaviors that are sustained, disruptive, and organized by a large group of people, rather than an individual (McAdam, McCarthy, \& Zald, 1996; Mueller \& Tarrow, 1995). 
There are established bodies of literature on collective action movements and political activism present in sociology (Morris, 1992; Oliver, Marwell, \& Teixeira, 1985), economics (Commons \& Parsons, 1950; Sandler \& Hartley, 2001), and political science (Muller \& Opp, 1986), while much of the psychological literature focuses more on collective action as individual level behaviors. Psychological research on collective action focuses on the conditions under which these behaviors occur, what fosters collective action movements, and the processes underlying them (Becker, Wright, Lubensky, \& Zhou, 2013; Mueller \& Tarrow, 1995; Ostrom, 2000; Wright, 2000). Because previous literature examines how and under what conditions collective behaviors occur, less focus is on who tends to be carrying out these actions and behaviors and how this is influenced by individual-level factors. That is, less is known about who is actually engaging in collective actions and mobilizing their subsequent movements, a gap that the current study addresses.

\section{Types of action}

There are varying types of responses by group members in response to their own group's disadvantage in society. These include individual action or mobility, collective actions or behaviors, or inaction. These actions aim to improve an individual and/or groups status within society, but differ in their goals, processes, and desired outcomes. Individual Action or Mobility

Individual action occurs when members of a low status group focus on improving their own personal outcomes, rather than the outcomes or position of their entire group. Social Identity Theory's discussion of individual mobility and social change (Tajfel \& 
Turner, 1979) theorizes that members of low status groups can either attempt to leave their group in favor of becoming a member of a higher status outgroup (if possible, e.g., when boundaries are permeable), or raise the status of the whole group by striving towards social change. Individual mobility, then, requires a person to psychologically or physically distance themselves from the group in order to achieve a higher status for themselves (Wright, 2003).

When in poverty, people may choose individual mobility to deal with their disadvantaged identity when the social structure is viewed as having group boundaries that are permeable, regardless of whether or not they see the current structure of hierarchies as legitimate (Akfirat, Çömez Polat, \& Yetim, 2015). However, some group boundaries, such as race, are less permeable, making individual mobility from a disadvantaged group less possible. Additionally, an individual does not perceive personal discrimination linked to their group membership, then they may engage in individual actions to confront their disadvantage (Postmes, Spears, \& Lea, 1999).

\section{Collective Actions and Behaviors}

Collective behaviors, or actions by an individual in the interest of the larger, collective group, have been conceptualized under two distinctions: normative vs. nonnormative and reactive vs. strategic (Wright, 2003). Normative expressions of collective action are those that conform to laws and social norms while simultaneously combating them, while non-normative expressions deviate from these (Wright, Taylor, \& Moghaddam, 1990). However, an action is only truly non-normative if the actor is aware that they are acting against convention. An example of a normative approach to collective 
action to better the position of a disadvantaged group would be the efforts and recent success of the push towards the legalization of same-sex marriage. A non-normative approach may look more like raising social awareness and declaring demands during street protests and rallies. Because of the lack of access to power and positions of power oppressed people have, resistance to oppression has often taken the non-normative route towards collective action and behaviors (Collins, 2002), such as various forms of art (Becker, 1974; Doss, 1999), and also by alternative forms of activism, such as self-care as a liberation technique (Heuchan, 2016; Horsham-Brathwaite, 2012; Lorde, 1988).

On the other dimension of collective action, reactive behaviors are described as outbursts, such as riots, often when a disadvantaged group member is faced with severe frustration from their disadvantaged social status. Strategic behaviors label actions that are more based on intention and involve planning, such as pre-organized direct actions and political demonstrations. However, actions that may appear to be reactive, such as riots, may actually be more strategic than they appear, with intentional targets of actions to outgroups who are in positions of power (Reicher, Spears, \& Postmes, 1995). That is, seemingly impulsive actions should not be dismissed as not containing strategy or intention in its methods.

\section{Inaction}

Inaction is when a disadvantaged group member does nothing to improve their individual or collective group position. One theory that may help explain inaction is Relative Deprivation Theory (Crosby, 1976), which describes an affective response to disadvantage in which a person shows negative emotional and stress symptoms, and may 
help explain why individuals chose to not engage in either collective or individual action in a context when their social group is at risk. A person's just world beliefs, a belief system that the world is a just and fair place (Dalbert, Montada, \& Schmitt, 1987), have been found to influence a person's inaction during times of injustice, with people who have high just world beliefs being less likely to engage in collective action, as their perceptions of their own discrimination and injustice against them is clouded by the mediating factor of "all-will-be-well" motivations (Stroebe, 2013). Inaction may also occur as a result of a disadvantaged person's acceptance of their current position, "hopeful patience" that their condition may improve on its own, or perceptions that their position cannot change (Wright, 2003; Wright \& Tropp, 2002). “Angry resignation" may also contribute to inaction, which may occur after past attempts at either individual or collective action that are perceived to be ineffective by the actor (Wright 2003; Wright \& Tropp, 2002).

An individual's internalization of their own oppression, such as internalized racial oppression which is described as an individual's practice of "racist stereotypes, values, images, and ideologies...leading to feelings of self-doubt, disgust, and disrespect for one's race and/or oneself' (Pyke, 2010), may also contribute to inaction (or potentially individual) over collective action as individuals who internalize oppression may blame group members for their own disadvantage, with less consideration of structural or societal influences on the life outcomes of other marginalized group members. Low group identification also predicts inaction during injustice, showing that seeing an identity as more central or important to one's self-concept may influence the extent to 
which a person engages in collective behaviors that benefit others who share said social identity (Stürmer \& Simon, 2004a; Stürmer \& Simon, 2004b; Van Zomeren, Spears, \& Postmes, 2008). Relatedly, the present study incorporates the importance of level of group identification (i.e. racial centrality) in its assessment of collective action support and engagement.

\section{Social identity, identity centrality, and collective action}

Earlier theories of collective action downplayed the role that psychological variables have to contribute to the study of determinants of collective action. For example, the Resource Mobilization Approach posits that structural and organization variables are, instead, key contributors that determine the likelihood of collective action (McCarthy \& Zald, 1977). However, more current research considers collective actions to be a behavioral outcome as a result of psychological factors and processes, as well as structural factors.

Collective actions, as opposed to individual actions, are guided by social or group identities, rather than personal or individual identities. A key in behaviors becoming collective is the psychological process that leads an individual to act in terms of the group, which can result in depersonalization (Wright, 2003). This process is similar to the intergroup end of the interpersonal-intergroup continuum of behavior introduced under Tajfel and Turner's (1986) Social Identity Theory. When social group membership becomes salient, depersonalization occurs, with the self now being perceived not as an individual, but as a member and representative of the group. The individual's thoughts, actions, and motivations become based on perceived prototypical group member actions 
and norms (Wright, 2003). This activation of the "We" over the "I" varies by social context, as a person has many social group memberships, thus many potential selfrepresentations in relation to the salient groups in those contexts (Tajfel \& Turner, 1986; Wright, 2003).

When a particular social identity is made salient, individuals tend to make more intergroup comparisons and, depending on feelings of relative deprivation, engage in more collective actions (Kawakami \& Dion, 1995). Insecurity of one’s social identity arises if the intergroup situation is seen as unstable or illegitimate at a time when social change appears imminent (Finchilescu \& de la Ray, 1991). Identities are sensitive to the current environment and can become politicized. Politicized social identities are formed when the collective group is involved with political protests on behalf of the group (Simon \& Klandermans, 2001). When an identity becomes politicized, a person may experience an 'inner obligation' to engage in collective actions (Stürmer \& Simon, 2004a). Holding a politicized identity itself has been found to have a direct causal effect on civic engagement and collective actions (Simon \& Klandermans, 2001; Stewart \& McDermott, 2004). However, a recent overview examining the role of social identity in predicting participation in protests suggests that holding a particular social identity may not be enough to incite participation, but that close identification with the group (e.g., level of group identification or identity centrality) is also needed to foster the process of a social identity becoming a collective or politicized identity (Klandermans, 2014), an important finding when examining the factors that predict collective behaviors. Collective action participation can, then, be more accurately predicted by a personal 
commitment to the collective group who is the target of injustice, rather than simple social group membership (Thomas, Mayor, \& McGarty, 2012). This study considers the interactional influence of holding a particular social identity and identity centrality by incorporating both of these factors in the analyses to examine their independent and interactional influences on support for race-based collective action and protests.

People with stronger group identification will show more overlapping mental representations of the self and in-group (Coats, Smith, Claypool, \& Banner, 2000). For disadvantaged group members, close identification with the group can serve as a coping mechanism when faced with discrimination (Branscombe \& Ellemers, 1998). Latinx students' level of ethnic identification, (i.e., racial centrality, how strongly they identify with their ethnic group) serves as a group-based coping strategy, which is moderated by perceived discrimination on psychological well-being and engagement in political activism (Cronin, Levin, Branscombe, can Laar, \& Tropp, 2012). Additionally, perceived discrimination was positively associated with subsequent event-specific and global psychological distress after accounting for previous perceptions of discrimination and distress (Sellers \& Shelton, 2003). Similarly, within gender, strength of identification with being a woman was positively associated with both collective and individual (nongroup disparaging) responses, but only collective responses related to broader intentions to engage in collective action for social change (Becker, Barreto, Kahn, \& de Oliveira Laux, 2015). A longitudinal study examining collective action participation by women showed that gender identity centrality directly predicted participation in collective action. 
Gender identity centrality was also found to mediate the influence of gender identity itself in predicting future participation (Kelly \& Breinlinger, 1995). 


\section{Intergroup relations}

Within social psychology, approaches to understanding and evaluating prejudice, discrimination, and, on the other end, solidarity and coalition building, often begin by examining what is known about intergroup relations, or how groups relate and interact with each other. Classic theories of intergroup relations posit general ways to reduce outgroup bias and promote intergroup cooperation. These theories primarily focused on White peoples' interactions with racial minorities, and how to improve White-racial minority relations. For example, Allport's Intergroup Contact Theory (1954) emerged during the era of Jim Crow Laws in the United States, which are a set of laws that legally permitted racial segregation in southern states under the guise of races being "separate but equal" (Alexander, 2010). Allport's (1954) theories of intergroup contact sought to develop methods to reduce prejudice and intergroup conflict by increasing contact between different groups in meaningful ways. Four conditions under which contact should occur were developed as ways to reduce intergroup prejudice: equal status of groups, cooperation among groups, a common goal between groups, and support from institutions or individuals in power.

More recent research examining Allport's four conditions explores how each of these contact conditions differently, and with the interaction of some or all, work to reduce prejudice. In a recent meta-analysis, Pettigrew and Tropp (2006) found important implications for the utility and effectiveness of the four conditions outlined in intergroup contact theory. First, though intergroup contact theory was originally constructed to address racial prejudice, research over the last decades have shown that these methods 
may be useful in reducing prejudice in other domains, such as gender (Thomae \& Viki, 2008; Walch et al., 2012). Second, though prejudice reduction can be seen under Allport's four conditions, each of these conditions are not necessary for prejudice reduction to occur. More specifically, the authors suggest that more attention is needed in researching other underlying factors that contribute to outgroup prejudice, such as intergroup anxiety and authoritarianism. However, in sum, intergroup contact contributes to the reduction of prejudice across various intergroup relations (Pettigrew \& Tropp, 2011).

Another example of classic literature examining intergroup relations is that of the Robber's Cave experiment in the 1950s and 1960s by Muzafer Sherif and colleagues. Based on Allport's work, this series of experiments, which created situations that promoted either competition or coalition between two groups of young boys, validated Sherif's Realistic Group Conflict Theory (RCT). RCT aimed to account for outgroup prejudice in situations of competition for resources, and found that coalitions were formed under circumstances where a common goal between two previously oppositional groups was present (Sherif, 1998; Sherif, 1958; Sherif et al., 1961).

Though these classical studies have provided useful information about intergroup conflict and cooperation, recent research provides further insight about intergroup relations in more specific contexts and across different groups. Since the time of these early social psychological studies, a significant amount of social psychological research has been aimed at examining intergroup relations within race. However, much of this research has focused on majority-minority (i.e., White-Black) intergroup attitudes and 
behaviors, with very little research examining minority-minority relations (i.e. BlackLatinx; Richeson \& Sommers, 2016). Though these previously mentioned theories and studies have provided useful information about intergroup relations and ways to begin to reduce prejudice, more literature examining the similarities and differences between majority-minority and minority-minority relations is needed, especially as the social and cultural contexts continues to shift and become more multicultural in the United States. Moving beyond the White-minority dynamic, we now turn to an examination of existing literature on intraminority intergroup relations. 


\section{Intraminority Intergroup Relations}

The most commonly referenced theories of intergroup relations provide a useful start to examining prejudice, discrimination, and solidarity, but may also be limited in generalizability and assumptions about universality of behaviors and attitudes. Similar to many other countries, the United States is rapidly changing in demographic composition, including race, with a rise in racial minority and mixed-race residents (US Census Bureau, 2014). As the population shifts, it is critical for psychology to take a proactive approach to understanding how research on intergroup relations similarly or differently applies across racial minority groups in this changing context.

In this context, often, empirical studies treat racial minorities as a monolith by grouping them together, though there are known differences in attitudes, beliefs, and social outcomes between racial minority groups. Applying outcomes and findings that might not be generalizable from one group to another which has different histories and social statuses may not be accurate (Ponterotto, 1988). In one example, current social psychological literature on prejudice confrontations to reduce prejudice primarily focuses on confrontation carried out by the target group member or the dominant group member, and not on confrontation behaviors of other racial minority group members (Czopp \& Monteith, 2003; Good, Moss-Racusin, \& Sanchez, 2012; Nier, Gartner, Dovidio, Banker, \& Ward, 2001; Rattan \& Dweck, 2010). Minority-minority relations differ from minority-majority relations, interactions, and alliances in that, though each racial group is distinct, a collective self-representation and common minority status can induce feelings

of common identity and fate, even across domains (Craig \& Richeson, 2014). Within race 
specifically, the results found between majority-minority groups may not be generalizable to intraminority outcomes, as the relations are qualitatively different and sensitive to social context (Richeson \& Sommers, 2016). It is particularly important to examine various racial groups and their outcomes while considering their historical and current differences in social psychological research. There has been a recent call for more contemporary research to develop theory that is either more generalizable, or more specific in order to more fully and accurately understand human behavior in this changing context (Richeson \& Sommers, 2016), a goal that the current study hopes to address.

Aside from distinct historical differences between racial minority groups, current real-world disparities in outcomes across racial minority groups also give support for examining these groups separately. In education, for example, there are stark differences between racial minority groups in opportunity and achievement gaps, with a historical trend of differences in high school graduation rates. In 2014, it was reported that Asian students hold the highest rates for high school graduation $(89.4 \%)$, followed by White students (87.2\%), Hispanic students (76.3\%), Black students $(72.5 \%)$ and Native American students (69.6\%) (NCES, 2015). Disparities between racial minority groups can also be seen in annual household income, with 2014 data showing that Asian households earned the most $(\$ 74,297)$, followed by White $(\$ 60,256)$, Hispanic $(\$ 42,491)$, and Black $(\$ 35,398)$ households (DeNavas-Walt \& Proctor, 2015).

Within race, widely referenced models demonstrate that racial minorities, though they share the superordinate 'minority' group membership, are not perceived in the same 
ways. For example, the Stereotype Content Model (Fiske, Cuddy, Glick, \& Xu, 2002) shows inter- and intra-racial group differences in levels of perceived competence and feelings of warmth in evaluations of these distinct racial groups (by primarily White raters), called the mixed stereotype hypothesis. In this model, Black, Native American, and Hispanic people fall under medium competence and warmth, while Asian people are perceived as being high in competence and medium in warmth, and White people are seen as high in both dimensions. This model shows that not every racial minority group is evaluated with the same criteria. It also emphasizes that these criteria depend on social structures, making the results dependent on specific contexts. For example, though Asian Americans are racial minorities in the United States, the group's marginalization and experiences with structural disadvantage may be overshadowed by simply looking at these educational and income-based assessments, and the presence and endorsement of the "model minority" stereotype. Though the "model minority" stereotype is framed as a positive group-based characteristic, it has had a negative influence on Asian Americans by restricting access to opportunity (Wong \& Halgin, 2006), increasing anti-Asian prejudice (Kohatsu et al., 2011), and influencing treatment by medical professionals (Cheng, Iwamoto, \& McMullen, 2016), among others.

The conclusions from these and other studies that reveal varying attitudes, conditions, and outcomes between racial minority groups further lend to the notion that racial minority group members should not be lumped together in analysis or investigation. The conclusions, assumptions, and implications drawn from these research practices may be inaccurate and, at times, harmful and counterproductive of efforts 
towards equity for different races and combating racism in its many forms. This leads to the current study's focus on separating racial minority groups during analyses, and further by gender within race, in examining outcomes and exploring further variance within these identity domains.

\section{Shared and common identities}

People with multiple disadvantaged identities are lacking power in multiple identity domains. Women and racial minorities as distinct groups share a common status in that neither group holds power in their respective identity domains (gender and race). A number of models and theories have been developed to explain relations between groups with one or many shared traits, experiences, or social circumstances, which may be used to examine intraminority intergroup relations. Like other theories of intergroup relations, at the core of many of these models and theories is Tajfel and Turner's (1986) Social Identity Theory (SIT). Social Identity Theory states that the social groups that a person identifies with make up an important part of their identity, affecting their selfesteem and ultimately behavior. SIT explains intergroup relations and attitudes as they are relevant to a specific context and environment, and how intergroup prejudice and discrimination emerges in these contexts, such as the relative social status of groups, and how belonging to either a low- or high-status group translates to behavior.

SIT states that individuals tend to hold more positive evaluations of an ingroup in order to gain self-esteem (Tajfel \& Turner, 1986). The way a person conceptualizes the ingroup can alter the way they evaluate members of a similar social groups. From this, the Common Ingroup Identity Model (CIIM; Gaertner \& Dovidio, 2000; Gaertner et al., 
1993) was developed with the goal of reducing intergroup prejudice by creating or fostering a common ingroup between individuals who share the same or similar social identities. Within the context of race, studies have found that by inducing more inclusive group representations of members across different racial groups, a cognitive recategorization of the ingroup occurs, which transforms previous representations of the "Us" and "Them" to the more inclusive "We" (Gaertner \& Dovidio, 2005; Nier et al., 2001). This re-categorization of the ingroup, then, may have influence on the outcomes of interracial interaction and reduce prejudice toward the previously seen outgroup.

When applied to race relations, the CIIM is careful to not promote ideas of assimilation, but of multiculturalism. That is, the model does not say that individuals should alter themselves to fit the hegemonic ingroup or group with the most power, but that each subgroup should be valued in their uniqueness, while simultaneously embracing a common superordinate ingroup across subgroups. In this way, the "We" that the CIIM aims to enhance does not require individuals to give up their own specific social group memberships, but is a cognitive re-categorization of what it means to be a part of a superordinate group (Gaertner \& Dovidio, 2005; Nier et al., 2001). This embrace of a superordinate group while valuing the subgroup (i.e. multiculturalism) is similarly echoed in the Mutual Intergroup Differentiation Model (MIID; Hewstone, 1996; Hewstone \& Brown 1986). In this way, unique group identities are not threatened or sacrificed in order to belong to a superordinate group. Research on the MIID shows that this approach is more effective in reducing intergroup prejudice than models that require individuals to 
abandon a subgroup identity to become a member of a superordinate group (Gaertner et al., 1993; Hornsey \& Hogg, 2000; Islam \& Hewstone, 1993; Smith \& Tyler, 1996).

The influence of ingroup boundaries on intergroup attitudes has also been explored at the implicit level. Specifically, recent evidence has been emerging on implicit intergroup attitudes for groups with shared identities. Scroggins and colleagues (2016) showed, through the use of an Implicit Association Task (IAT; Greenwald \& Banaji, 1995), that when non-Black participants categorized Black people into a shared superordinate group, participants showed less immediate pro-White/anti-Black implicit bias, as opposed to participants who did not categorize Black people into a shared superordinate group. This study demonstrated the immediate implicit effects recategorization induced as they apply to interracial intergroup boundaries. However, this study, like many others, collected data from White participants, with Black people as a proxy for the "other" racial minority group. The results from this study are then limited to majority-minority (i.e. White-Black) intergroup relations, and may reveal different results if examined between other racial minority groups.

With a focus on intraminority relations, another recent study measured similar implicit group boundaries, but between different racial minority groups, instead of the majority-minority approach more commonly taken to examining intergroup relations. When pervasive own-group racial discrimination is made salient, a common disadvantaged racial minority identity was activated, which lead to more positive intraminority attitudes. Specifically, when Asian American participants were exposed to pervasive anti-Asian discrimination, participants reported closer levels of 
interdependence with Black Americans and showed less pro-Asian/anti-Black bias on an immediate Asian-Black IAT, as compared to a control group that was not exposed to anti-Asian discrimination (Craig \& Richeson, 2011). Showing that awareness of owngroup pervasive racial discrimination increases intergroup interdependence, it is evident that social psychological factors play a significant role in intraminority relations.

Building from these and other models and theories, additional psychological predictors have been examined as they relate to intraminority intergroup relations and common identity. Group consciousness, or identification with a specific group along with awareness of the group's social position (Gurin, Miller, \& Gurin, 1980; Miller, Gurin, Gurin, \& Malanchuck, 1981), is a significant predictor of political engagement for various racial minority groups. Group consciousness differs from group identification in the idea that simply identifying with a group is not enough to motivate an individual to engage in political participation, but that group identification needs to be paired with a deeper understanding and recognition of the group's conditions in society (Verba \& Nie, 1982). For African Americans, group consciousness has repeatedly been found to be a significant predictor of own-group political participation (Dawson, 1994; Pinderhughes, 1987; Tate, 1994). Using secondary data from the 1999 National Survey on Latinos, group consciousness, which was comprised of perceived own-group discrimination, among other factors, played a significant role in Latinos' perceptions of commonality with African Americans (Sanchez, 2008). Similarly, analyzing data from the 2000 Pilot National Asian American Political Survey and the 1999 National Survey on Latinos, perceived own-group racial discrimination was a significant predictor of panethnic 
consciousness towards the other group for both Asian American and Latino American respondents (Masuoka, 2006). These studies emphasize the use of this information as a tool to further develop intraminority identity and political alliances towards social change. The hypotheses for this study incorporate the suggestions from these previous findings and examines both identity (i.e., racial centrality) and social attitudinal factors about racism (i.e., modern racism) factors beyond simple group identification as predictors of support for and participation in collective action across groups.

\section{Intraminority intergroup relations, collective actions, and solidarity}

Though less is known about minority-minority intergroup relations, especially in the context of social action, the process of supporting or engaging in collective action across racial minority groups can begin to be pieced together by referring to literature on social identity, wider collective identities, and community contexts.

Group-based factors are important indicators of participation in politics and collective action. Intraminority solidarity has intentionally and systemically been discouraged through racial segregation, which creates barriers to coalition building between disadvantaged groups by limiting intergroup contact (Dixon et al. 2015). Racial alienation, or feelings of separation from other racial groups, often who share similar oppressions, influence beliefs about racial stratification and, in turn, increase feelings of threat from groups who share a common status (Bobo \& Hutchings, 1996). These feelings of alienation may then decrease motivation to engage with cross-group collective action movements. An examination on intergroup engagement in collective action showed that people are less likely to engage in collective action behaviors for outgroup 
members (Glasford \& Caraballo, 2016), however, these results may not be generalizable to intraminority relations, as this study measured Latinx students' motivation to engage in collective action for their own group (Latinx/Hispanic), or for majority outgroup members (White/non-Hispanic), who hold more relative power.

Research in political science has demonstrated the role of individual-level resources (i.e., income, education, social status) in a person's ability to engage with politics (Brady, Verba, \& Schlozman, 1995; Verba \& Nie, 1987; Verba, Schlozman, \& Brady, 1995). Racial minorities are less likely to have access to these individual-level resources, and in turn pull political information from their collective groups to ease the individual burden of political participation (Verba \& Nie, 1987). It may be said, then, if members of differing racial minority groups perceive similarities in their marginalization, and develop a stronger identification with a common superordinate ingroup, they may then look to each other for collective political engagement. This process would thus create potential for intraminority coalition building.

Looking at relations between groups who share a disadvantaged social status, collective victimhood and inclusive victim consciousness have been found to promote more positive attitudes about intraminority coalition and engagement in joint collective action (Glasford \& Calcagno, 2012; Vollhardt, 2015). Collective victimhood is described as a common identity shared by groups who are disadvantaged, while inclusive victim consciousness is when members of various disadvantaged or oppressed groups perceive similarities between group victimizations (Vollhardt, 2012). Some studies have found that having a shared victim status may produce negative psychological outcomes, such as 
general well-being and more specific mental health outcomes (Pascoe \& Smart Richman, 2009), along with social outcomes, such as less outgroup trust (Rotella, Richeson, Chiao, $\&$ Bean, 2012). However, inclusive victim consciousness can also produce positive outcomes for long-term social change. When disadvantaged groups perceived a shared victimization, more solidarity between groups towards collective action is created. These outcomes take form as advocacy for and alliances between victimized groups, such as between Black and Latinx sexual minorities (Kaufman, 2003) and between different ethnic immigrant groups (Swarns, 2006).

Collective efficacy, or a community's capacity to combat and prevent violence (Sampson, Raudenbush, \& Earls, 1997), such as state violence, stems from social interactions that foster shared community trust and capacity for collective action (Sabol, Coulton, \& Korbin, 2004), and is a strong and direct predictor of participation in political protests (Grant, Abrams, Robertson, \& Garay, 2015). Once social and systemic change does happen, it is important that communities actively engage with one another to further build resilience in these changing systems for the new systems to sustain and for the communities to thrive, further showing the importance of shared-group solidarity (Magis, 2010).

Overall, one's social identities, group memberships, perceived closeness to groups who may share a similar or shared marginalization, and subsequent community capacity influence intergroup support and solidarity in response to institutional disadvantage. Though taking into account domain-specific identities as they relate to a particular social cause or movement is essential, considering intragroup diversity and the multiplicity of 
identities held by group members may help further explain who engages in actions towards social change and why. By considering intersecting identities (e.g., race and gender together), this study addresses this by examining within-group differences and how they might account for differing amounts of variation in intraminority support and collective behaviors. The literature on intersecting identities, examples of the influence of these identities on collective action engagement, and past and current efforts to support social change is further reviewed in the following section. 


\section{Multiple intersecting identities}

Though stronger self-identification as a group member may incite more engagement with collective action, it may also require individuals to sacrifice other identities to bring attention to a movement's primary goals (Traindis \& Gelfand, 1998), especially when the goals are not inclusive. Intersecting identities are, then, an important factor to consider when exploring who tends to support and participate in race-based collective action movements.

The term "intersectionality" was coined by Kimberlé Crenshaw (1989) to bring attention to the "single axis" framework of looking at race and gender issues in multiple contexts, which further marginalizes people with non-prototypical identities. PurdieVaughns and Eibach (2008) describe this as "intersectional invisibility," which describes the tendency for people who hold multiple marginalized identities (i.e., women of color, queer racial minorities) to be unseen and unrepresented, or "invisible," in many contexts, relative to those with a single marginalized identity, or the "prototypical" group member (i.e. White women, straight men of color). This pattern is present in three identity domains - gender, race, and sexual orientation (androcentrism, ethnocentrism, and heterocentrism, respectively) - though this tendency is also present for other marginalized identities, such as disability status. Though social psychological research that takes intersecting identities into account is on the rise, there are significant improvements that need to be made in including this framework in the research and study of intra- and inter-group relations (Goff \& Kahn, 2013). This study considers the role of intersecting identities and how holding multiple marginalized identities, such as women 
of color, may influence racial attitudes and, subsequently, support for and participation in protests in response to pervasive racial discrimination by police.

\section{Additive vs. interactive approaches}

Early literature considering the role of intersecting identities focused on additive models as a way to better understand a person's experiences with multiple identities. Additive models treat the outcomes of people with multiple marginalized identities as additive to each other, rather than interactive. The additive approach to examining multiple marginalized identities would say that the issues faced by a Black woman, whose race and gender identities are marginalized, are that of women and of Black people added together. From this approach, the "double jeopardy" model was popularized as a way to explain the cumulative disadvantage from each subordinate-group identity (Beale, 1970; Glenn, 1992; Reid 1984). Expanding on this, models of "triple jeopardy" (Louie, 2001) and "multiple jeopardies" (King, 1988) were conceptualized to consider more than two marginalized social identities.

As opposed to an additive model, an interactive model differently examines the outcomes of persons who hold multiple marginalized identities by considering how each of a person's marginalized identities interact jointly, believing that people experience these identities as one. Recent literature shows the importance of using interactive models when considering multiple social identities (marginalized or privileged) over previous additive models. Specifically, evidence comes from the closer examination of racial stereotypes, which have been found to not be equally applied to persons of the same race, but differ based on genders within racial groups (Goff, Thomas, \& Jackson, 2008; Sesko 
\& Biernat, 2010). For example, looking at race and gender together, gendered stereotypes and benevolent sexist attitudes are not equally applied to White and Black women (McMahon \& Kahn, 2016). Similarly, when people are told to think of a Black person, they imagine a man, but imagine a woman when told to think of an Asian person, as Black men, being hyper-masculinized, and Asian women, being hyper-feminized, are more prototypical of their respective racial groups (Schug, Alt, \& Klauer, 2015). These studies describe the unique ways in which people within same racial group are treated differently based on their gender, supporting an interactive analysis.

\section{Intersectionality and collective action}

Research undervalues experiences of people with intersecting identities, with the current psychological understanding of racism as unintentionally sexist, in that it focuses mainly on men, and of sexism as unintentionally racist, focusing on Whites (Goff \& Kahn, 2013). There have been recent calls for psychological scientists to further investigate the roles of intersecting identities on generalizability of widely regarded theory (Goff \& Kahn, 2013), and a push to a methodological shift, when needed, to better account for the experiences at various intersections of identity (Cole, 2009). As explained by freed, formerly enslaved Black woman and activist Sojourner Truth in her famous speech “Ain’t I A Woman?”, people hold intersecting social identities which are prioritized in different social movements, while other important social group memberships are ignored (Stanton, Anthony, \& Gage, 1881). In Truth's case, she spoke of the roles of her marginalized racial identity in the context of the women's suffrage movement, which primarily addressed issues directly relevant to White women (Breines, 
2002; White, 1999). Evidence can also be found in past collective action efforts, in which race-based movements, such as the civil rights movement of the 1960s, primarily addressed issues directly relevant to Black men (Barnett, 1993). Similarly, many women who were members of the Black Panther Party, such as Elaine Brown, Angela Davis, and Roberta Alexander, spoke out about the movement's patriarchal tendencies and lack of inclusion of women's issues, aside from race alone (Bhavnani \& Davis, 1989; Brown, 1992; Spencer, 2016).

A trend reflecting these can be observed, with many notable social movements in the United States widely ignoring the lives of people with multiple marginalized identities (King, 1988). In these cases, Black and other minority women and their intersecting marginalized identities were not acknowledged, thus their unique oppressions were invisible in these movements. Currently, the Black Lives Matter movement addresses these omissions and exclusions in past race-based collective action movements and organizations by explicitly being a women- and femme-centered organization that works towards the liberation of all Black people, despite gender identity, sexual orientation, or other social identities (Black Lives Matter, 2016).

Though examining group differences is important, when applying intersectional theories of social identities to psychological research, one must be careful to not simply rank groups based on particular dimensions, but to recognize that there are underlying qualitative differences between the groups that are not revealed when using quantitative methods (Warner, 2008). To be able to fully understand group differences in results, social contexts such as history and culture must be considered (Goff \& Kahn, 2013). By 
considering these influences, rather than just results from quantitative tests, a better understanding of the processes and phenomena may be examined, such as within this study, where context is critically important to interpreting results and their real-world implications.

Social inclusion is central in creating stronger participation in collective action movements. Identification with a smaller subgroup is a stronger predictor of participation in human rights activities than sole identification with the larger superordinate group (Condor, 1986; Simon et al., 1998). Black feminist literature concludes that, because of the intersections of both an oppressed gender and an oppressed racial identity, Black women are in a unique position which leads them to be more aware of oppressive systems, have a more critical social theory, and ultimately be more involved in political activism compared to others with a singular or no oppressed race or gender identities (Collins, 1989). However, this intersection of identities and its role in increasing critical consciousness, or the psychological process that oppressed people recognize their own social status and become motivated to take actions towards social change (Freire, 1970; Watts \& Hipolito-Delgado, 2015), and political activism, has not been explored empirically. Current social psychological literature lacks content on the concept of critical consciousness altogether, let alone as a mediating variable between identity factors and collective behaviors, which the current study proposes. Though direct measures of critical consciousness are not included in this study, by incorporating both racial identity centrality and modern racist beliefs as predictors of political participation, 
this study contributes to the literature examining the components of critical consciousness as predictors of social attitudes and behaviors.

Research on social activism often takes a singular identity approach, which focuses on one social identity, often central to the social issue (Greenwood, 2012). There are two assumptions of identity-based models of social activism: 1) that motivations are based on one's own relevant disadvantaged identity in the context and 2) the previously mentioned feelings of coalition with other groups who face similar disadvantage are present (Curtin, Kende, \& Kende, 2016). However, taking an intersectional approach to motivations for activism, it is also important to consider the influence of those who hold both advantaged and disadvantaged identities simultaneously, such as being both Black and a man. Qualitative interviews conducted in both the Unites States and in Hungary have demonstrated that ally activism is fostered by both holding a disadvantaged and advantaged identity, as does awareness of one's own relative privilege (Curtin et al., 2016).

Looking beyond holding a singular disadvantaged identity, recognizing the role of intersecting identities can be used as a tool "to expose the...nature of interlocking forms of oppression" (Chun, Lipsitz, \& Shin, 2013). For example, the Asian Immigrant Women Advocates (AIWA) of Oakland and San Jose, California is an inclusive grassroots community organization that address the underpayment of Asian women in service jobs. Jihye Chun and colleagues (2013) recognize "core problems of women of color as both intersectional and radical," and by considering the needs of Asian women specifically, the efforts of AIWA address racism and sexism, along with class exploitation and 
language discrimination. As a collective, AIWA posits that the multiplicity of identities held by its members especially prepares them to combat social problems by equipping them with evidence, insights, and motivation, and works to develop leadership in its members. Addressing similar issues faced by working-class women of color, selfdeclared Black communist of the mid $20^{\text {th }}$ century, Claudia Jones was vocal about the need for an intersectional approach when attending to matters of race, gender, and class, which she attributed to the "superexploitation" of poor Black women (Jones, 1949). These examples from the literature and historical and current cases of social justice engagement call attention to the influence of intersecting identities on political participation and collective action in response to perceived racial injustices. The current study draws from what we know about social attitudes around modern forms of racism and examines this within the domain of social psychology, specifically. 


\section{Expressions and predictors of racism}

Contemporary research on intergroup relations focuses on newer forms of explicit and implicit attitudes as predictors of intergroup prejudice and discrimination. Various forms of racist beliefs have been identified through empirical research, such as modern racism, and the consequences, which may similarly or differently influence the outcomes of various racial minority groups. These varying forms of racism and their manifestations have been extensively studied as they relate to intergroup attitudes and relations (Awad, Cokley, \& Ravitch, 2005; Gaertner \& Dovidio, 2005; Nosek et al., 2007). Though examining differences between racial groups may reveal various group level differences in outcomes, the inclusion of social attitudes as an additional predictor of behavior between racial groups adds to the accuracy of these predictions, and may help further explain group disparities and disparate outcomes. This study addresses this by incorporating racial attitudes (e.g., modern racism) in addition to racial group membership when predicting intraminority attitudes and behaviors. The literature on racism, with a focus on modern racism, is reviewed next.

\section{Forms of racism}

A large amount of the social psychological study of racism originally stemmed from anti-Semitism and prejudice against Jewish people after World War II, and gained further attention after the Civil Rights era of the 1960s and 1970s in the United States (Benjamin, 1993). Racism is defined as prejudiced feelings or discriminatory behaviors against a person or group based only on a racial group membership, and one's racial group lacks power (Dépret \& Fiske, 1993; Operario \& Fiske, 1998). Racism differs from 
prejudice and discrimination in that it takes into account social structures and hierarchies in relation to power and access to power, or one group's ability to control the outcomes of another group, with racism directed at groups with low relative power by those with more power (Dépret \& Fiske, 1993; Feagan, 2013; Wilson, 1978). This explicit inclusion of power in the definition leads to more accurate understandings and examinations of the processes that lead to racial oppression and marginalization. This framework makes explicit that victims of racism are not racial groups in positions of relative power, and that beneficiaries of racism possess relative power. This can be in forms of economic, political, or social power (Operario \& Fiske, 1998).

Racism can occur within a system at a societal level or more interpersonally at an individual level. Systemic, or institutional, forms of racism have historically been seen in the restriction of Indigenous, Asian, African Americans from obtaining citizenship in the Unites States until 1924, 1943, and 1868, respectively (Bruyneel, 2004; Collins, 2004; Volpp, 2010). More currently, systemic racism is seen in redlining, or the restriction of Black Americans from buying homes in "White" neighborhoods (Zenou \& Boccard, 2000), and in voting restriction laws, which prevent primarily racial minorities and lowincome people from voting in democratic elections (Issacharoff, 2013).

At the individual level, interpersonal forms of racism occur directly between individuals, and follow the model of victim and perpetrator (Maluso, 1995). These acts can be seen in racially-motivated verbal or physical violence, and other forms of targeted discrimination. Both systemic/institutional and interpersonal/individual forms of racism and racial discrimination have effects on the target's psychological and physical well- 
being (Contrada et al., 2001; Sellers, Cherepanav, Hammer, Fryback, \& Palta, 2013), along with long-term group outcomes and chronic disparities, such as various health outcomes (Pascoe \& Smart Richman, 2009) incarceration rates (Mauer \& King, 2007), and educational attainment (Troyna \& Williams, 2012).

Both systemic and interpersonal forms of racism can be macro- or microaggressive. Macroaggressions result from larger systems of oppression, and have influence on the larger societal environment (Osanloo, Boske, \& Newcomb, 2016). Differently, as described by Sue and colleagues (2007), racial microaggressions are " brief and commonplace daily verbal, behavioral, or environmental indignities, whether intentional or unintentional, that communicate hostile, derogatory, or negative racial slights and insults toward people of color." Though these forms of biased behaviors may seem insignificant, the additive effects of small, repeated instances of discrimination can lead to significant burdens for targets across racial minority groups, such as increased psychological morbidity (Ong et al., 2013), decreased sense of psychological well-being (Seaton, Neblett, Upton, Hammond, \& Sellers, 2011), binge drinking (Blume, Lovato, Thyken, \& Denny, 2012), traumatic stress symptoms (Torres \& Taknint, 2015), and suicide ideation (O’Keefe, Wingate, Cole, Hollingsworth, \& Tucker, 2014), among others.

National surveys show that the majority of White Americans explicitly support racial equality and integration, thus explicitly endorsing egalitarian and non-racist values (Schuman, Steeh, \& Bobo, 1985; Welch \& Sigelman, 2011). However, over time, racist expressions and actions have shifted, with fewer instances of "old fashioned" racism, and 
more prevalence of "modern" racism. Old fashioned forms of racism are often seen as prototypical racist behaviors or systems, such as the use of explicit racial slurs towards a group or person (McConahay, Hardee, Batts, 1981). Modern and contemporary forms of racism are expressed differently, and are subtler and more ambiguous than old-fashioned forms of racism (McConahay \& Hough, 1976). Microaggressions are one form of modern racist expression, as they are subtle and often ambiguous in their intent, yet still discriminatory and may produce adverse outcomes.

Contemporary studies of racism focus on these modern forms of racism, in which racial prejudice is more hidden and subtle. One example of these modern forms of racism is aversive racism. Aversive racism describes "well-intentioned White" people who still hold racist tendencies (Gaertner \& Dovidio, 2005; Gaertner \& Dovidio, 1986). Originally coined by Joel Kovel (1970), aversive racism, or the "American dilemma," describes when a person explicitly holds non-prejudiced racial attitudes, yet unconsciously holds prejudiced attitudes. This mismatch between internal and external feelings creates discomfort, and leads the person with aversively racist attitudes to avoid situations that prompt this discomfort and possible indication that they may be racist, such as White people disengaging from conversations with Black partners and other interracial interactions (Gaertner, 1973).

\section{Predictors and correlates of modern racism}

Drawing from what is known in the social psychological literature about modern racist beliefs and group outcomes, this study incorporates this social attitude as a predictor of intraminority intergroup relations and behaviors. In this body of literature, an 
individual's level of modern racist beliefs has been linked to a number of other social attitudes that influence racial minority group outcomes. Modern forms of racism and prejudice are correlated with various social psychological factors, such as social dominance orientation (Ekehammer Akarami, Gylje, \& Zakrisson, 2004; Pratto, Sidanius, Stallworth, \& Malle, 1994), right-winged authoritarianism (Reynolds, Turner, Haslam, \& Ryan, 2001), and non-egalitarian and individualistic beliefs (Katz \& Hass, 1988; Swim, Aikin, Hall, \& Hunter, 1995). People with a low need for cognition also hold higher levels of racial prejudices, compared to people with a high need for cognition (Waller, 1993). Higher levels of modern racism relate to obedience to authority and subsequent justification to racially discriminate hiring practices (Brief, Dietz, Cohen, Pugh, \& Vaslow, 2000), less support for affirmative action (Awad et al., 2005), and stronger oppositions towards race-based social justice programs (Blatz \& Ross, 2009).

Numerous studies from both classic and more modern literature reveal significant gender differences in prejudice levels, with men holding more racial and ethnic prejudices (Bakanic, 2008), more approval of discrimination (McConahay, 1983, 1986; Oxendine, 2016), and being more socially-dominant orientated than women (Pratto et al., 1994). Considering subtler forms of bias, a large overview of over 2.5 million Implicit Association Test (IAT) results from 2000 to 2006 revealed important information about who tends to have higher anti-Black implicit attitudes. This review explored correlates of various implicit attitudes, including race-related attitudes, and showed that men and White people tended to hold stronger anti-Black implicit biases than women and racial minorities, respectively (Nosek et al., 2007). These results compliment previous research 
in showing that within the identity domains of gender and race, groups who face oppression and marginalization (i.e., women and racial minorities) tend to have less strong anti-Black/pro-White implicit racial biases. The current study will further explore these differences in modern racism by race, gender, and the intersection of these identities.

When considering the criminal justice domain, which is the focus of the current study, White people's beliefs about race predict attitudes towards police, such that White racial resentment towards Black people predicts their support for police use of force (Carter \& Corra, 2016). These results have been constant since the 1980s, and are not influenced by recent high-profile shootings of racial minorities by police officers. That is, recent increased social visibility of racial bias in policing, such as the shooting death of Michael Brown in 2014, has had insignificant influence on White people's attitudes towards police use of force (Carter \& Corra, 2016). However, these studies have not tested intraminority attitudes and perceptions and do not consider an intersectional framework, which is the focus of the current study. 


\section{The current study}

From the aforementioned literature, racial attitudes (Blatz \& Ross, 2009; Ellmers \& Barreto, 2009), social identity (Kawakami \& Dion, 1995, Simon \& Klanderman, 2001; Van Zomeren et al., 2008), and racial identity centrality (Becker et al., 2015; Cronin et al., 2012; Kelly \& Breinlinger, 1995) have been connected, both relationally and causally, to collective action engagement and political participation. The role of intersecting identities and having multiple disadvantaged social identities has been less explored in the social psychological literature. Drawing from history and current social discourse and climate, holding multiple marginalized identities has been shown as a possible significant influence on support for collective action, and, subsequently, with engagement with social justice initiatives.

Taking these findings into account, this study takes an intersectional perspective to examining intraminority support for a current race-based social movement combating anti-Black racial bias, Black Lives Matter. Using survey data, this study examines predictors of support for and participation in protests and BLM by considering the independent and interactive influences of social identities (e.g., race and gender), racial identity centrality (e.g., how important ones' race is to their identity), and racial attitudes (e.g., modern racist beliefs). Beyond their simple inclusion as predictors, this study also explores the question of if these factors account for differing amounts of variance between groups when predicting support for and participation in collective action. The implications from this study provide additional information and help fill the gaps in the social psychological literature regarding the role of intersecting identities, feelings of 
closeness with one's racial identity, and racial attitudes on intraminority intergroup relations in the specific social justice context. Additionally, findings from this study can be used in an applied context by community organizers, social justice activists, and policy makers to develop interventions or campaigns that change or increase support for racial justice causes. 


\section{Hypotheses}

The goal of this study is to explore the role of intersecting race and gender identities on intraminority support for and participation in collective action efforts in response to cases of police deadly use of force against Black people. Based on previous research, two sets of hypotheses are addressed.

\section{Hypothesis 1: Race and gender differences in support for and participation in BLM}

Past research has consistently shown group differences on support for social justice movements and equity-based political policy, with people who hold more politicized identities (i.e. marginalized group members) as generally holding more equitable attitudes towards racial justice (Blatz \& Ross, 2009; Oxendine, 2016) and more supportive and active in these social change efforts (Simon \& Klandermans, 2001; Stewart \& McDermott, 2004; Stürmer \& Simon, 2004a). Consistent with past findings, examining race and gender separately, the first hypothesis predicts that there will be race and gender group differences in both 1) support for protests and collective action movements in response to police deadly use of force against Black people (i.e., Black Lives Matter), and 2) in personal participation in protests and BLM (H1a). From these previous findings, it is predicted that, within gender, women will report 1) more support for and 2) higher participation in protests than men. Within race, it is predicted that Black people will have reported more 1) support and 2) participation than other racial groups, followed by Latinx and Asian respondents, with White people as reporting the least support and participation. Going beyond examining race and gender group membership separately (in Hypothesis 1a) to explore the role of intersecting race and gender identities, 
it is also hypothesized that there are intersecting group differences in levels of 1) support for and 2) participation in protests/BLM (H1b). That is, it is predicted that, within each racial group, women will report more 1) support and 2) participation than men. Overall, it is predicted that Black women will report the highest levels of support and participations and that White men will have reported the lowest.

\section{Hypothesis 2: Social identity and racial attitudes as predictors of support for and participation in BLM}

Perceived injustice and discrimination against a particular group is an important predictor of engagement with collective action (van Zomeren et al., 2008). Additionally, group consciousness is an important predictor of intergroup attitudes (Masuoka, 2006; Sanchez, 2008) and collective action (Dawson, 1994; Tate, 1994) above and beyond being a member of an oppressed group. Incorporating evidence of the role of social group membership, it is predicted that modern racism mediates the effects of intersecting identities on 1) support for protests and collective action movements, along with 2) participation in these movements (H2a). It is also predicted that, overall, Black people will score lowest in modern racism, followed by Latinx and Asian people, and lastly by White people. It is predicted that individuals with lower modern racist beliefs are more supportive of and participate at higher reported rates in BLM and racial protests.

Additionally, across domains, identity centrality is an important predictor of whether an individual is supportive or participates in collective action for social change (Becker et al., 2015; Cronin et al., 2012), above and beyond group membership itself (Kelly \& Breinlinger, 1995; Klandermans, 2014; Thomas et al., 2012). Incorporating the 
evidence of identity centrality on political engagement and on attitudes towards prejudice, discrimination, and modern racism, it is also hypothesized that racial centrality moderates the mediating effects of modern racism on intersecting identities and levels of 1) support and 2) participation in these movements (H2b). That is, for racial minorities in general, those who more strongly identify with their racial group will hold lower modern racist beliefs and will be more 1) supportive of and 2) report more participation with protests and BLM. A visual representation of the conceptual and statistical models can be viewed in Appendix C.

There are known group differences in social attitudes between racial and gender groups historically and currently (Nosek et al., 2007; Masuoka, 2006; Sanchez, 2008). The predicted influences of racial centrality and modern racist attitudes may not be as equally influential between race and gender groups. From this, it is also hypothesized that the conceptual moderated mediation will differently account for levels of 1) support and 2) participation between intersecting race and gender identities $(\mathrm{H} 2 \mathrm{c})$. In particular, because the outcomes of interest are in reference to a race-specific social justice initiative directed at combating pervasive discrimination against Black people in the US, it is predicted that modern racism and identity centrality will account for less variance for Black respondents than for other groups, as members of this group will be more supportive of BLM and protests, with less influence from their gender identity or social attitudes. Drawing from the evidence that shows the influence of holding a disadvantaged identity on increased support for social change efforts (Simon \& Klandermans, 2001; Stewart \& McDermott, 2004), it is predicted that modern racism and identity centrality 
will account for more variance for Latinx and Asian respondents than Black respondents. Modern racism and identity centrality is predicted to account for the most variance for White respondents, as, in the domain of race, White people have less shared historical and social experiences with race-based oppression, making attitudes a more significant predictor of 1) support and 2) participation than group membership. 


\section{Method}

\section{Overview}

To test these hypotheses, I used data collected from an online survey distributed to students at a large urban university. Data collection started in mid-2015 and was completed in mid-2016. I was centrally involved in all stages of the survey design and data collection, including the development of new measures and items, participant recruitment, and data management. The data was cleaned prior to analyses. This survey was designed to address attitudes on various current social issues related to public perceptions of policing, including the death of Michael Brown in Ferguson, Missouri, and the recent passing of a plan to arm campus security officers with guns on the campus that the data originates. The full survey and its items can be viewed in Appendix A, with specific items used in this study indicated.

\section{Participants}

For analysis in the current study, eighty-three cases $(14.3 \%)$ were deleted from the original dataset of 582 participants. Sixty-three (10.8\%) cases were deleted as participants did not identify as either the racial (Asian, Black, Latinx, White) or gender (women, men) groups included in this study. Twenty (3.4\%) cases were deleted due to missing item responses. A total sample size of 499 respondents was included in the current study.

Participants' racial demographics consisted of $63.3 \%$ White $(\mathrm{N}=316), 6.6 \%$ Black or African American ( $\mathrm{N}=33), 16.8 \%$ Latinx $(\mathrm{N}=84)$, and 13.2\% South, East, or Southeast Asian $(\mathrm{N}=66)$. Due to a limited sample size for other racial groups, this study will use 
responses from White, Black, Latinx, and Asian participants only. Participants' gender demographics consisted of $68.1 \%$ Women $(\mathrm{N}=340)$ and $31.9 \%$ Men $(\mathrm{N}=159)$. For this study, responses from participants who identify as either cisgender women or men. In future studies, it would be important to include other racial and gender groups in these analysis, however, low responses from these groups would lead to a severely underpowered test at this time, such as for transgender and non-gender conforming people ( $\mathrm{N}=27)$, Middle Eastern and North African people $(\mathrm{N}=24)$, or Native American people $(\mathrm{N}=8)$.

Survey respondents had an average age of 25.96 years $(\mathrm{SD}=8.49$, range $=18$ 64). Of the respondents, $15.0 \%$ identified themselves as first-year undergraduate students $(\mathrm{N}=75), 11.8 \%$ as second year $(\mathrm{N}=59), 24.6 \%$ as third year $(\mathrm{N}=123), 31.9 \%$ as fourth

year or higher $(\mathrm{N}=159), 6.0 \%$ as post-bac $(\mathrm{N}=30), 9.2 \%$ as graduate students $(\mathrm{N}=46)$, and $1.4 \%$ as not currently a student or no response $(\mathrm{N}=7)$. Participants' demographic information can be viewed in Tables 1 and 2 .

\section{Power analyses}

A priori power analyses using $\mathrm{G}^{*}$ Power were conducted for both sets of hypotheses. A medium effect size of .25 was hypothesized, as effect sizes around this value have been observed when examining group differences in political participation and solidarity between racial groups (e.g., Glasford \& Calcagno, 2012). For the first set of hypotheses, which will be tested using $2 \mathrm{X} 4$ factorial ANOVAs, to obtain a power level of .8 with a medium effect size (.25), a total of sample size of 179 (22 per intersecting race and gender group) participants are needed. Though the overall sample size for the 
existing data is sufficient $(\mathrm{N}=499)$, along with overall sample sizes per race and gender groups to examine main effects, adequate power might not be achieved for Black men $(\mathrm{N}=13)$ or for Black women $(\mathrm{N}=20)$ and Latinx men $(\mathrm{N}=19)$, though the latter two are approaching the desired sample size.

For the second set of hypotheses, which will be tested using a moderated multiple regression, to obtain a power level of .8 with a medium effect size (.25), a total sample size of 384 (48 per intersecting race and gender group) participants is needed. Similar to the first set of hypotheses, the overall sample size is sufficient. However, adequate power might not be achieved for Black men $(\mathrm{N}=13)$, Black women $(\mathrm{N}=20)$, Latinx men $(\mathrm{N}=19)$, Asian men $(\mathrm{N}=29)$, and Asian women $(\mathrm{N}=37)$. Implications of power are discussed in the limitations section of this paper.

\section{Procedure}

An online survey was distributed to students and consisted of a number of measures and items on various social attitudes and experiences, which took approximately 20 minutes to complete. Participants were recruited by classroom announcements, flyers, posters, student listservs, and digital announcements on screens around campus. Respondents completed the survey either for extra credit in a course, which had been pre-approved by the instructor, or to be entered into a drawing to win one of four $\$ 100$ Amazon.com gift cards. IRB approval was obtained prior to data collection, and the data collection process was determined to lead to minimal risk to participants. 


\section{Measures}

A full list of measures to be used to analyze the hypotheses can be seen in Appendix A, with items used in these analyses bolded.

Racial centrality. Two of the four items from the Identity factor of the Collective Self-Esteem Scale (Luthanen \& Crocker, 1992) were used to measure racial identity centrality, "The racial/ethnic group I belong to is an important reflection of who I am," and "In general, belonging to my racial/ethnic group is an important part of my selfimage." Participants rated their level of agreement with the two positively worded statements on a 1 (strongly disagree) to 7 (strongly agree) Likert scale. Higher scores indicate higher levels of racial identity centrality.

Modern racism. Six items from the Modern Racism Scale (McConahay, 1986) were used to measure individuals' levels of modern racism, for example, "Discrimination against Black people is no longer a problem in the United States." Participants rated their level of agreement with the statements on a 1 (strongly disagree) to 5 (strongly agree) Likert scale. Negatively worded statements were reverse coded. Higher scores indicate higher levels of modern racist beliefs in participant responses.

Support for protests and Black Lives Matter. Seven items were developed to measure support for race-related protests in response to the shooting of unarmed Black people by police officers and the subsequent Black Lives Matter movement. Items include, "The Black Lives Matter movement is necessary," and "I support the protests in Ferguson, Missouri in response to the shooting of Michael Brown.” Participants rated their level of agreement with the statements on a 1 (strongly disagree) to 7 (strongly 
agree) Likert scale. Negatively worded statements were reverse coded. Higher scores indicate higher levels of support. A previously conducted exploratory factor analysis and confirmatory factor analysis were run on this new scale from the sample used in this study. Results from the EFA and CFA showed that all seven items fit onto one factor with excellent reliability (Cronbach's $\alpha=.94)$. Tests for model fit from these analyses can be seen in Appendix C.

Participation in protests and Black Lives Matter. After giving a brief introduction that gave context and a brief description of the BLM movement (see Appendix A), participants responded to one item, which was developed for the survey to measure self-reported involvement with protests, "How much were you, personally, involved in any of the protest efforts for Michael Brown or similar cases?" This item was measured on a 1 (not at all) to 5 (extremely) Likert scale. Higher scores indicate greater participation in protests.

Participant race and gender identities. Participant self-identified race and gender identities were collected. Demographic measure items can be viewed in Appendix $\mathrm{B}$, and participant demographics can be viewed in Table 1 and Table 2. Participants who identified as biracial racial minority-White were re-coded into their racial minority group membership. Multiracial people who indicated belonging to multiple racial minority groups were excluded from these analyses (see Participant demographics above). Research shows that, for adults who come from a multiracial background, only about $39 \%$ of them identify as multiracial, and that White-minority multiracial people tend to identify with their racial minority identity more strongly (Pew Research Center, 2015). 
Additionally, White-minority biracial individuals are more categorized into their disadvantaged group (Black, Asian) by perceivers, than their majority (White) group membership (Ho et al., 2011). These findings support this recategorization of minorityWhite individuals into their respective minority groups. 


\section{Analysis and results}

\section{Preliminary analyses}

Missing and incomplete data. From examination of the measures that do include missing data, data seems to be missing at random, with very few cases missing overall. Data was estimated to be missing at random as the demographics of participants excluded in the analyses due to missing data roughly reflected the overall demographic structure of the dataset as a whole, and did not seem to reflect a patter in this way. Within measures, responses were missing in $.00-.02 \%$ of the 582 total cases. Because of this, it was determined that multiple imputation, as originally proposed, was not needed for these analyses, and mean substitution was used to estimate missing values instead. Mean substitution is useful in that it keeps the mean of the composite variables the same, but reduces variance within each participant (Raaijmakers, 1999). Because this study is not examining variance within person and few cases of missing data are present, this limitation is not a concern for these purposes.

Composite variables. Composite variables that represented the mean scores of scale item responses were created for the multi-item continuous measures: modern racism, racial identity centrality, and support for protests and BLM.

Reliability analyses. All measures showed good or excellent standards of reliability, with a Cronbach's $\alpha$ of .89 for modern racism, and .94 for support for protests and BLM. Inter-item correlations were run for both of these scales, revealing significant correlations between all items within each measure at the .01 level. For modern racism, 
Pearson's $r$ ranged from .40 to .72. For support for protests and BLM, Pearson's $r$ ranged from .55 to .85 .

For racial identity centrality, though only two of the four items from the Collective Self-Esteem Scale were utilized in the creation of the survey from which I am using data, correlation between the two items was strong with a Pearson's $r$ of .85. Single item measures have been used in past studies to measure similar constructs (e.g. Sherman, Kinias, Major, Kim, \& Prenovost, 2007), and the two items used from this scale have also been used in combination with other items to measure similar constructs, such as racial identification (e.g. Apfelbaum, Grunberg, Halevy, \& Kang, 2016). Testretest reliability was not tested for the single-item measuring participation in protests and BLM. The reliability of single-item measures is very difficult to determine (Postumes, Haslam, \& Jans, 2012).

\section{Descriptive statistics and bivariate correlations}

Overall, self-reports of modern racist beliefs were low $(M=1.66, S D=.72,1-5$ scale), as was participation in protests and $\operatorname{BLM}(M=1.43, S D=.82,1-5$ scale $)$. Racial identity centrality was reported as slightly higher than the scale's midpoint $(M=4.19$, $S D=1.73,1-7$ scale). Reported support for protests and BLM was moderately high overall $(M=5.12, S D=1.46,1-7$ scale $)$.

Pearson's correlations were computed to confirm the expected relationships between variables at the overall sample level. Modern racism was strongly and negatively related to support for protests and BLM $(r=-.67, p<.01)$, and was less strongly and negatively related to participation in protests and BLM $(r=-.20, p<.01)$. Support for and 
participation in protests and BLM were moderately and positively related $(r=.39, p<.01)$.

No other relationships between variables were found to be significant. See Table 28 for means and bivariate correlations between measures.

\section{Hypothesis 1a\&b: Intersecting race and gender differences in support for and participation in BLM.}

The first set of hypotheses aim to explore the main and interaction effects of race and gender group membership for two outcomes: 1) support for and 2) participation in protests and BLM. To evaluate these hypotheses, a series of 2 (Gender: women vs men) $\mathrm{x}$ 4 (Race: Asian vs Black vs Latinx vs White) factorial analysis of variance (ANOVA) with Tukey's HSD post-hoc tests were run using SPSS to examine main and interaction effects of race and gender on 1) support for and 2) participation in racial protests and the Black Lives Matter movement.

For the first outcome, support for protests and BLM, both race and gender main effects were significant, $F(1,3)=5.18, p=.00$, partial $\eta^{2}=.03$ and $F(1,1)=6.97, p=$ .01 , partial $\eta^{2}=.01$, respectively; see Table 3 , Figures 1 and 3 . For race, Black people $(M$ $=6.39, S D=.89$ ) reported higher levels of support for BLM than all other racial groups (Latinx: $M=5.48, S D=1.45$; Asian: $M=5.08, S D=1.50$; White: $M=5.55, S D=1.63$ ). Marginal significance was found between Asian and White participants; see Table 4. For gender, women reported higher levels of support for BLM than men, $M=5.70, S D=1.47$ and $M=5.18, S D=1.71$, respectively. The interaction between race and gender was not significant $F(1,3)=.10, p=.96$, partial $\eta^{2}=.00$. However, post-hoc simple effects $t$ tests revealed gender difference within race for White $(t(314)=-2.50, p=.01$; men: $M=$ 
5.22, $S D=1.76$; women: $M=5.70, S D=1.55)$ and Latinx $(t(82)=-2.88, p=.01$; men: $M$ $=5.16, S D=1.80$; women: $M=5.57, S D=1.33)$ participants, but not for Asian $(t(64)=$ $1.60, p=.12$; men: $M=4.69, S D=1.58$; women: $M=5.39, S D=1.38)$ or Black $(t(31)=$ $-1.38, p=.18$; men: $M=6.08, S D=1.12$; women: $M=6.60, S D=.68)$ participants, see Table 5, Figure 5.

For the second outcome, participation in protests and BLM, both race and gender main effects were significant, $F(1,3)=5.80, p=.00$, partial $\eta^{2}=.05$ and $F(1,1)=3.10, p$ $=.03$, partial $\eta^{2}=.01$, respectively, see Table 6 , Figures 2 and 4 . For race, Black people $(M=2.21, S D=1.27)$ reported higher levels of participation in BLM than all other racial groups (Latinx: $M=1.33, S D=.68$; Asian: $M=1.36, S D=.80$; White: $M=1.39, S D=$ .76), see Table 7. No other differences between racial groups was found. For gender, women reported higher levels of participation in BLM than men, $M=1.47, S D=.84$ and $M=1.34, S D=.76$, respectively. The interaction between race and gender was also found to be significant $F(1,3)=2.06, p=.02$, partial $\eta^{2}=.02$. Post-hoc simple effects $t$ tests revealed gender difference within race for White participants $(t(313)=-1.97, p=$ .05 ; men: $M=1.27, S D=.63$; women: $M=1.45, S D=.81$ ), and marginally significant for Black participants $(t(31)=-1.98, p=.06$; men: $M=1.69, S D=1.18$; women: $M=$ 2.55, $S D=1.23)$, but not for Latinx $(t(82)=-.51, p=.61$; men: $M=1.26, S D=.65$; women: $M=1.35, S D=.69)$ or Asian $(t(64)=-1.60, p=.12$; men: $M=1.48, S D=.95$; women: $M=1.27, S D=.65)$ participants; see Table 8 , Figure 6 .

H1 Discussion. From these analyses, I can partially confirm Hypothesis 1a, which predicted race and gender differences for both outcomes, 1) support for and 2) 
participation in protests and BLM. It was also predicted that there would be significant differences in support for and participation in protests and BLM between Black people, Asian and Latinx people, and White people. Significant differences were found between Black respondents and all other groups, though Asian, Latinx, and White respondents did not differ from each other, with the exception of marginal significant differences found in support between White and Asian respondents.

For Hypothesis 1b, which anticipated differences in both outcomes the interaction of gender and racial group membership, I can partially confirm my predictions. Gender group differences were significant for White and Latinx participants only in support for protests and BLM, and were significant for White and Black participants only in participation in protests and BLM. Where significant differences were found, results fell in line with the predicted results in that within racial groups, women reported more support for and participation in protests and BLM than men.

\section{Hypothesis 2a\&b: Social identity and racial attitudes as predictors of support for and participation in BLM.}

The second set of hypotheses explores the influence of modern racist attitudes and identity centrality on 1) support for and 2) participation in protests and BLM. To test the moderated mediation model (see Appendix B for a visualization of the conceptual model, but not the exact model statistically tested for the above reasons), a three-stage moderated multiple regression analysis, which examines the moderator of the indirect effects on the outcomes of interest, was conducted using SPSS (Edwards \& Lambert, 2007; Muller, 
Judd, \& Yzerbyt, 2005) $)^{2}$. Each intersecting race and gender group was dummy coded as 1 $=$ group, $0=$ all other groups (i.e. $1=$ Black men, $0=$ all other intersecting groups). Interaction terms were created with the intersecting race and gender group-specific dummy codes and the moderator (racial centrality), which was centered at its mean. Modern racism was also centered at its mean before being entered into the regressions. Both racial centrality (RC) and modern racism (MRS) were grand mean centered.

A series of three regressions was run to examine the specific components of the model, which predicts that modern racism mediates the effects of race and gender group membership on 1) support for and 2) participation in protests and BLM, and that racial identity centrality moderates the effects of race and gender group membership on modern racist beliefs. Analyses were run for each intersecting race and gender group to determine the significance of the model within each specific group.

Equation 1. To explore the influence of the interaction between race and gender group membership and racial centrality on modern racism, the following regression was computed for each of the eight intersecting race and gender groups.

$$
\begin{gathered}
M_{M R}=b_{0}+b_{1} X_{1, R G}+b_{2} X_{2, R C}+b_{3} X_{3, R G R C}+e \quad \text { Where } X_{3, R G R C}= \\
X_{1, R G} \times X_{2, R C}
\end{gathered}
$$

\footnotetext{
${ }^{2}$ Much of the literature on mediational models focuses on models with continuous or dichotomous independent variables (Hayes \& Preacher, 2014). This study is interested in a multicategorical independent variable, intersecting race and gender identities across different groups (totaling 8 groups). A common method of testing for moderated mediation is through the use of the PROCESS macro in SPSS (Hayes \& Preacher, 2014). The PROCESS macro can only test for mediation with multicategorical independent variables, and cannot test for moderated mediation with multicategorical independent variables, as this hypothesis proposes. Another method to test for multicategorical differences uses structural equation modeling (SEM) with AMOS software. However, with AMOS multicategorical predictors, such as race and gender in this study, cannot be included in the model. This again makes this method insufficient at testing the model proposed in the current study.
} 
$\mathrm{MR}=$ modern racism (centered); $\mathrm{RG}=$ intersecting race and gender group (dummy coded); $\mathrm{RC}=$ racial centrality (centered); $\mathrm{RGRC}=\mathrm{RGxRC}$ interaction

This regression analysis was found to be significant for Black women $\left(p=.00, R^{2}\right.$ $=.03)$, Asian men $\left(p=.00, R^{2}=.07\right)$ and Asian women $\left(p=.00, R^{2}=.03\right)$, and White men $\left(p=.01, R^{2}=.02\right)$ and White women $\left(p=.00, R^{2}=.06\right)$. The regression was marginally significant for Latino men $\left(p=.08, R^{2}=.01\right)$, and was not significant for Black men $\left(p=.32, R^{2}=.01\right)$ or Latina women $\left(p=.13, R^{2}=.01\right)$; see Table 9 for complete regression results. No single group showed significance across all three predictor variables for these analyses and none of the three predictors in this regression were significant for Black men.

Race and gender group membership (RG) was found to be significant in explaining modern racism for Black women $(\beta=-.14, p=.03)$, Latino men $(\beta=.11, p=$ $.03)$, Asian men $(\beta=.27, p=.00)$ and women $(\beta=.18, p=.00)$, and White men $(\beta=.16$, $p=.00)$ and women $(\beta=-.22, p=.00)$, but was not significant for Black men $(\beta=-.08, p$ $=.17)$ or Latina women $(\beta=.05, p=.36)$. Racial identity centrality $(\mathrm{RC})$ was significant in explaining modern racism for Black women $(\beta=.09, p=.04)$ and was marginally significant for Latina women $(\beta=.09, p=.06)$, but was not significant for any other group.

The interaction $\mathrm{RGxRC}$ was significant for Latina women $(\beta=-.12, p=.05)$, Asian women $(\beta=-.10, p=.06)$, and White women $(\beta=.12, p=.03)$, was marginally significant for White men $(\beta=.11, p=.06)$, but was not significant for Black women or 
Black, Latino, or Asian men. The interaction of RGxRC as a predictor of modern racism is significant for non-Black racial minority women, but not for racial minority men. Breaking down the significant interaction, for White men, being a White man and having a high level of racial centrality was related to higher levels of modern racist beliefs $(+1$ SD above the mean; $B=.46, t(489)=2.96, p=.003)$, while having a lower racial centrality demonstrated no relationship ( -1 SD below the mean; $B=.11, t(489)=1.14$, $p=.26$ ). For White women, having a higher or lower racial centrality both decreased levels of modern racism, but did so marginally for White women higher in racial centrality, and was found to be stronger for White women lower in racial centrality $(+1$ SD above the mean; $B=-.16 t(489)=-1.60, p=.10 ;-1$ SD below the mean; $B=-.46$, $t(489)=-5.14, p<.001)$. For Latina women, being a Latina woman and having lower racial centrality was approaching marginal significance in increased modern racist beliefs $(-1 \mathrm{SD}$ above the mean; $B=.35, t(489)=1.58, p=.11)$, while having a higher racial centrality showed no influence ( $+1 \mathrm{SD}$ below the mean; $B=-.11, t(489)=-1.06, p=.29)$. For Asian women, being an Asian woman and having lower racial centrality was related to higher modern racist beliefs more strongly than having higher racial centrality, though both showed a significant and positive relationship with modern racist beliefs $(+1 \mathrm{SD}$ above the mean; $B=.25, t(489)=1.81, p=.07 ;-1$ SD below the mean; $B=.74, t(489)=$ $3.09, p=.002)$. Results from each regression analysis by group for Equation 1 can be viewed in Table 10. 
Equation 2. To explore the effect of modern racism (MR) on 1) support for (SUP) and 2) participation in (PAR) protests and BLM, the following bivariate regressions were tested for each group.

$$
Y_{S U P}=b_{0}+b_{1} M_{M R}+e \quad \text { and } \quad Y_{P A R}=b_{0}+b_{1} M_{M R}+e
$$

$\mathrm{SUP}=$ support for protests and BLM; PAR = participation in protests and BLM

Outcome: Support for protests and BLM. MR was found to be a significant in explaining support for protests and BLM for all groups at the $p<.001$ level, except Black men $\left(\beta=.07, p=.83, R^{2}=.00\right)$. For all other groups, MR explained between $25-59 \%$ of the variance in predicting support; see Table 11.

Outcome: Participation in protests and BLM. MR was found to be significant in explaining participation in protests and BLM for Asian men $\left(\beta=.42, p=.02, R^{2}=.18\right)$ and Asian women $\left(\beta=-.42, p=.01, R^{2}=.18\right)$, and White men $\left(\beta=-.23, p=.03, R^{2}=05\right)$ and White women $\left(\beta=-.30, p<.001, R^{2}=.09\right)$. MR was not found to be significant for Black men $\left(\beta=.03, p=.92, R^{2}=.00\right)$ and Black women $\left(\beta=-.17, p=.48, R^{2}=.03\right)$, or for Latinx men $\left(\beta=-.06, p=.81, R^{2}=.00\right)$ and Latinx women $\left(\beta=.07, p=.56, R^{2}=.00\right)$. Results from each regression analysis by group for Equation 2 can be viewed in Table 12 .

Equation 3. To explore the combined influences of RG, RC, RGxRC, and MR, on both 1) support for (SUP) and 2) participation in (PAR) protests and BLM, the following regressions were tested for each group.

$$
\begin{aligned}
& Y_{S U P}=b_{0}+b_{1} X_{1, R G}+b_{2} X_{2, R C}+b_{3} X_{3, R G R C}+b_{4} M_{M R}+e \\
& Y_{P A R}=b_{0}+b_{1} X_{1, R G}+b_{2} X_{2, R C}+b_{3} X_{3, R G R C}+b_{4} M_{M R}+e
\end{aligned}
$$


Outcome: Support for protests and BLM. This regression analysis explaining support for protests and BLM was found to be significant for all groups at the $p<.001$ level, and explained between $46-48 \%$ of the variance; see Table 13 . For these analyses, Latino men and White women showed significance across all four predictor variables. Within this regression analysis, RG was a significant predictor of support for BLM for Latino men $(\beta=-.08, p=.02)$, Asian men $(\beta=.09, p=.01)$, and White women $(\beta=-.10$, $p=.01$ ), and was not found to be significant for any other group. RC was significant for all groups at the $p<.01$ level or lower. The interaction of RGxRC was significant for Black men $(\beta=.09, p=.05)$, Latino men $(\beta=.11, p<.001)$, and White women $(\beta=-.14$, $p<.001)$, and was not significant for any other group. Breaking down the significant interaction, for Black men, both being a Black man and having a higher racial centrality demonstrated no relationship ( $+1 \mathrm{SD}$ above the mean; $B=.64, t(488)=1.51, p=.13)$, though having a lower racial centrality was found to be more strongly related to lower support for protests and BLM (-1 SD below the mean; $B=-.81, t(488)=-1.99, p=.05)$. Following the same pattern as Black men, for Latino men, having a higher level of racial centrality did not influence support for protests and BLM $(+1 \mathrm{SD}$ above the mean; $B=$ $.06, t(488)=.24, p=.81)$, but having a lower racial centrality had a negative relationship with support (-1 SD below the mean; $B=-1.28, t(488)=-4.23, p<.001)$. Oppositely, for White women, having a higher racial centrality was found to be related to lower levels of support for protests and BLM (+1 SD above the mean; $B=-.65, t(488)=-3.77, p<.001)$, while having lower racial centrality showed no influence ( $-1 \mathrm{SD}$ below the mean; $B=.08$, 
$t(488)=.60, p=.55)$. MR was significant for all groups at the $p<.001$ level, and accounted for much of the variance that was explained.

Outcome: Participation in protests and BLM. This regression analysis explaining participation in protests and BLM was found to be significant for all groups at the $p<.001$ level, and explained between $5-10 \%$ of the variance. No single group showed significance across all four predictor variables for these analyses. Within this regression analysis, RG was a significant predictor of participation in BLM for Black women $(\beta=$ $.18, p<.001)$, was marginally significant for White men $(\beta=-.09, p=.08)$, and was not found to be significant for any other group. $\mathrm{RC}$ was significant for Latinx men $(\beta=.10, p$ $=.03)$ and Latinx women $(\beta=.13, p=.01)$, Asian men $(\beta=.10, p=.02)$ and Asian women $(\beta=.10, p=.04)$, and White men $(\beta=.11, p=.03)$ and White women $(\beta=.14, p$ $=.01)$, was marginally significant for Black men $(\beta=.08, p=.06)$, and was not significant for Black women $(\beta=.04, p=.32)$. The interaction of $\mathrm{RGxRC}$ was significant for Black men $(\beta=.12, p=.03)$ only, and was not significant for any other group. Breaking down the significant interaction, as similar pattern emerged as was found in support, in that both being a Black man and having a higher racial centrality were found to have no influence ( $+1 \mathrm{SD}$ above the mean; $B=.33, t(487)=1.07, p=.29)$, while having a lower racial centrality had a negative relationship with participation in protests and BLM (-1 SD below the mean; $B=-.81, t(487)=-2.67, p=.007)$. Similar to the results for this regression analysis examining support for protests and BLM, MR was significant for all groups at the $p<.001$ level, and accounted for much of the variance that was explained. Results from each regression analysis by group for Equation 3 can be viewed in Table 14. 
H2a\&b Discussion. Results from each tested regression infer significance of the total conceptual moderated mediation model, which predicted that modern racism mediates the effects of race and gender group membership on 1) support for and 2) participation in protests and BLM, and that racial identity centrality moderates the effects of race and gender group membership on modern racist beliefs.

Explaining support for protests and BLM, all three regression analyses were significant for Black women, Latino men, Asian men and women, and White men and women. Only Equation 3 was significant for Black men, indicating that the combined influence of all predictors are important to consider together. For Latina women explaining both support for and participation in protests and BLM, only Equations 2 and 3 were significant, suggesting that factors other than intersecting race and gender group and racial centrality are important influences on modern racism, but that all predictors are associated with both support for and participation in protests and BLM.

In explaining participation in protests and BLM, all three regression analyses were significant for Black women, Asian men and women, and White men and women. Only Equation 3 was significant for Black men. Only Equations 1 and 3 were significant for Latino men.

Beyond the significance of the regression analyses run, varying predictors were found to be significant for each group. In predicting support for protests and BLM, within racial groups, intersecting race and gender group was not found to be significant for racial minority women or for Black men, but was a significant negative factor for Latino men and a significant positive factor for Asian men. In predicting participation in protests 
and BLM, racial identity centrality and modern racism were found to be significant for all intersecting groups, except Black women where racial centrality was not significant. For all groups, higher levels of MR predicted less participation. Racial centrality yielded similar results across groups, with higher $\mathrm{RC}$ predicting higher participation across groups. These results highlight the overarching importance of these two factors (RC and MR) in explaining participation in protests and BLM.

However, overall, from these analyses I can mostly confirm the moderated mediational model predicted in Hypotheses $2 \mathrm{a} \& \mathrm{~b}$ across groups in predicting support for protests and BLM, except for Black men and Latina women. I can also mostly confirm the moderated mediational model predicted across groups predicting participation in protests for all groups except Black men, Latina women, and Latino men.

\section{Hypothesis 2c: Test of strength of model by group.}

Results from the moderated multiple regression analyses in SPSS used to test $\mathrm{H} 2 \mathrm{a} \& \mathrm{~b}$ were also utilized to test the hypothesis that the predictive factors differently accounted for outcomes for each intersecting race and gender group. That is, analyses were run to determine if racial centrality and modern racism account for similar amounts of variance between each of the eight intersecting race and gender groups. The equality of coefficients for the various regression lines were tested by comparing each group's regression $\beta$ outcomes with each other, for a total of 28 comparisons per $\beta$ value in each regression, using z-scores (Clogg, Petkova, \& Haritou, 1995; Paternoster, Brame, Mzaerolle, \& Piquero, 1998). These comparisons were tested for each of the three sets of 
regressions using the following formula, provided by Clogg et al. (1995) and Paternoster et al. (1998).

$$
Z=\frac{b_{1}-b_{2}}{\sqrt{S E b_{1}^{2}+S E b_{2}^{2}}}
$$

Calculated z-scores greater than \pm 1.96 were found to be significant at the $p<.05$ level, scores greater than \pm 2.58 were found to be significant at the $p<.01$ level, and scores greater than \pm 3.30 were found to be significant at the $p<.001$ level.

Equation 1. Equation 1 aimed to test the influence of intersecting race and gender group, racial centrality, and the interaction of the two on modern racist beliefs.

Race and gender group (RG). When considering $\mathrm{RC}$ and the interaction of $\mathrm{RGxRC}$, race and gender group membership accounted for similar amounts of variance between most groups ( $\beta=-.22$ to $.27, S E=.02$ to .27 ). Overall, RG differed between White women $(\beta=-.22, S E=.07)$ and White men $(\beta=.16, S E=.09)$, Latina women $(\beta=$ $.05, S E=.13)$, and Asian men $(\beta=.27, S E=.14)$ and Asian women $(\beta=.18, S E=.15)$, with $\mathrm{RG}$ as being a more significant predictor in this equation for White women than the other groups. See Table 15 for full z-score results.

Racial centrality $(\boldsymbol{R} \boldsymbol{C})$. Similar to results for $\mathrm{RG}$, when considering $\mathrm{RG}$ and RGxRC, racial centrality accounted for similar amounts of variance between most groups $(\beta=-.14$ to $.09, S E=.02$ to .24$)$. White women $(\beta=-.07, S E=.02)$ differed from all groups except Black women $(\beta=-.14, S E=.24, z=-.29)$, with $\mathrm{RG}$ being a more significant predictor for White women in this equation $(z=4.24$ to 6.36). However, Black 
women did not differ from any group and no differences were found between any of the intersecting racial minority groups $(z=.29$ to .96$)$. See Table 16 for full z-score results.

Interaction of race and gender group and racial centrality (RGxRC). When considering $\mathrm{RG}$ and $\mathrm{RC}$, the interaction of $\mathrm{RGxRC}$ accounted for similar amounts of variance between two overarching groups: 1) Latino men and women, and Asian men and women, and Black men ( $\beta=-.12$ to $.12, S E=.07$ to .14$)$, and 2) Black women, and White men and women $(\beta=.09$ to $.12, S E=.02$ to .05$)$. RGxRC differed for both White men and women between each other, between Latino men and women, Asian men and women, and Black men, but not from Black women. RGxRC differed for Black women between Latina women, and Asian men and women, but not from Black men, Latino men, or White men and women. See Table 17 for full z-score results.

Equation 2. Equation 2 aimed to test the influence of modern racism in both 1) support for and 2) participation in protests and BLM.

Modern racism (MR). When explaining support for protests and BLM, MR similarly accounted for variance between all eight intersecting groups and no differences were found when MR was found to be significant (all groups except Black men; $\beta=-.88$ to $-.50, S E=.14$ to 1.2 ). Though not significant, Black men had a large range in responses of $\mathrm{MR}$, leading to no differences being found overall between any other group; see Table 18. However, when explaining participation in protests and BLM, differences were found for Asian men between Latino men $(z=1.65)$, and White men $(z=2.73)$ and White women $(z=2.48)$, and Latina women marginally differed from White men $(z=$ 1.90). See Table 19 for full z-score results. From the analyses run for Hypotheses $2 \mathrm{a} \& b$, 
modern racism was a strong and negative predictor of both support for and participation in protests and BLM. Because of the large amount of variance MR explained in these analyses, it was expected that MR would account for similar amounts of variance between groups.

Equation 3. Equation 3 aimed to test the influence of intersecting race and gender group, racial centrality, the interaction of the two, and modern racist beliefs on both 1) support for and 2) participation in protests and BLM.

When predicting support for protests and BLM, all four predictors, $\mathrm{RG}(\beta=-.10$ to $.09, S E=.10$ to .40$), \mathrm{RC}(\beta=.06$ to $.17, S E=.03$ to .04$), \operatorname{RGxRC}(\beta=-.14$ to $.09, S E$ $=.06$ to .21$)$, and $\operatorname{MR}(\beta=-.70$ to $-.66, S E=.07$ for all groups $)$, accounted for similar amounts of variance between groups. Overall, most of the variance explained by Equation 3 was accounted for by MR. The only difference was found between Latino men and White women in the amount of variance accounted by RGxRC, but the difference was marginal.

When predicting participation in protests and BLM, similar amounts of variance were found between all groups for $\mathrm{RG}(\beta=-.09$ to $.18, S E=.08$ to .30$), \operatorname{RGxRC}(\beta=-.08$ to $.12, S E=.05$ to .16$)$, and $\mathrm{MR}(\beta=-.22$ to $-.16, S E=.05$ for all groups). However, differences were found in $\mathrm{RC}$ between Black women and all other groups except Black men $(z=-1.41)$, showing that, in this equation, racial centrality accounted for more variance for Black woman comparted to other groups $(z=1.66$ to 3.18 for all other groups). Black men were found to differ between Latina women and White women only, 
with racial centrality accounting for more variance for Black men comparted to these groups. See Table 20-27 for full z-score results.

H2c Discussion. Hypothesis $2 \mathrm{c}$ predicted that the proposed moderated mediation would carry a different strength for each of the groups. Because of the relevance of the outcomes to the ingroup, it was hypothesized that MR and RC would account for less variance in predicting support for and participation in protests and BLM for Black participants than for other racial groups overall. This prediction was found to be true for RC for Black women in Equation 3 only, though this pattern was also seen in the interaction of RGxRC in Equation 1. Overall, MR was found to be a strong predictor across groups for support (except Black men in Equation 2), and significant for some groups in predicting participation (Asian men and women and White men and women in Equation 2, significant for all in Equation 3), accounting for similar amounts of variance in both Equation 2 (SUP: $\beta=-.88$ to $-.50, S E=.14$ to 1.20 ; PAR: $\beta=-.30$ to $.42, S E=$ .09 to 1.23 ), for groups where MR was found to be significant, and Equation 3 (SUP: $\beta=$ -.70 to $-.66, S E=.07$ for all groups; PAR: $\beta=-.22$ to $-.16, S E=.05$ for all groups).

Racial centrality did reveal differing levels of importance between some groups in predicting MR and participation in protests and BLM, but not for support. In predicting support, no difference in variance explained was found between groups, though racial centrality was found to be a more significant and positive influence on participation in protests for Black women $(\beta=.04, S E=.02)$ between all groups other than Black men $(\beta$ $=.08, S E=.02, z=-1.41)$. Black men, however, were only significantly different from Latina and White women in that RC explained significantly more variance for White $(\beta=$ 
$.14, S E=.03, z=1.66)$ and Latina women $(\beta=.13, S E=.02, z=1.77)$ than Black men. Though Hypothesis 2c was somewhat exploratory, I can only partially confirm the predicted results for these analyses. 


\section{General Discussion}

This study incorporated the influences of racial identity centrality and social attitudes towards racism as predictors of both support for and participation in protests and the Black Lives Matter movement in response to racial bias in policing, while considering intersecting race and gender identities. Overall, results generally followed the predicted patterns drawn from past theory and research. For Hypothesis 1, significant race and gender differences were found for both 1) support for and 2) participation in protests and BLM. Women reported higher levels of both support for and participation in protests and BLM than men. For race, Black participants reported more support and participation than all other groups, while no differences were observed between the three other racial groups (Latinx, Asian, White). As predicted, within some racial groups, women reported more 1) support for (Latinx, White) and 2) participation in (Black, White) protests and BLM, but this pattern was not universally found to be significant. For support, gender group differences were not found within Black and Asian participants. For participation, gender group differences were not found within Latinx and Asian participants. A recent preliminary study revealed difference in participation with BLM between Latinx men college students and Latinx women college students, with women reporting more participation than men in the specific social movement (Hope, Keels, \& Durkee, 2016). Though not replicated for participation in this study, these results align with the results found in differences in support between Latinx men and women.

Results from the regression equations tended to confirm the significance of the predicted relationship between social identity and attitudinal factors on collective action 
support and participation, which predicted a negative influence of racial centrality on modern racist beliefs for racial minority groups, and a negative influence of modern racist beliefs on both support for and participation in protests and BLM. For Equation 1, which included intersecting race and gender group membership, racial centrality, and the intersection of the two variables predicting reported modern racism, little overall variance was explained by these factors $\left(R^{2}=.01-.07\right)$. This equation was significant for each group except Black men and was approaching marginal significance for Latinx women. Within Equation 1, racial centrality was found to be significant when predicting modern racist beliefs for Black and Latina women within race, and the interaction of intersecting identify and racial centrality was significant for all racial minority women, but not racial minority men. This aligns with past literature that revealed that, generally, Latina women tend to think of their lives and identities to be more political than Latino men (Pardo, 1997; Rios, 2011). Additionally, when considering social identity theory, it is suggested that holding a feminist identity predicts engagement in collective action for womancentered causes (Liss, Crawford, \& Popp, 2004). However, when predicting support for and participation in protests and BLM in Equation 3, with the inclusion of modern racism, racial centrality was observed to be significant for both men and women for all races.

Looking at modern racism in predicting support for protests and BLM, the predictor was negatively and significantly related across all groups and accounted for a large amount of variance across groups, except for Black men, where significance was not observed. This suggests that, for Black men only, beliefs about anti-Black racism do 
not contribute to levels of support for BLM, which was overall reported to be very high for this group, potentially indicating a ceiling effect. That is, though Black men are highly supportive of protests in response to deadly use of force by police officers on racial minorities and the subsequent Black Lives Matter movement, these particular social attitudes have very little additional influence on support beyond their racial group membership. Though the Black Lives Matter movement addresses a number of systemic issues rooted in anti-Blackness (Black Lives Matter, 2016), because the context from which this data was collected and the references to Michael Brown (Ferguson, MO in 2014), the particular issue of Black men being disproportionately targeted by racial bias in policing may have been perceived as particularly more relevant to the survival of their own group, inciting support regardless of social attitudes.

Looking at modern racism predicting participation in protests and BLM, the predictor was only significant for White and Asian men and women, but not for Black and Latinx men and women. Black and Latinx people are more represented in racial disparities in policing (Brandt \& Markus, 2000; Kahn \& Martin, 2016) than White and Asian people, which may incite more feelings of social responsibility and survival to participate in protests and social movements addressing these issues among these groups.

Including all factors (RG, RC, RGxRC, MR) predicting both 1) support for and 2) participation in protests and BLM, the combination of factors was significant across all groups, with modern racism accounting for much of the variance explained. In predicting support for protests and BLM, modern racism and racial centrality were significant across all groups, though intersecting race and gender identity and the interaction of these 
identities with racial centrality varied across groups. In predicting participation in protests, modern racism was significant across groups and accounted for much of the variance, and racial centrality was significant for all groups except for Black women, who reported the highest levels of participation in protests and BLM across groups. For Black women only, their intersecting race and gender identity was found to be a significant predictor.

Though predicted differences in variance explained by each of the factors in the regressions run were generally similar, the significant difference between the importance of modern racist beliefs between Black women and other groups aligns with the predictions from the previous hypothesis in that modern racist beliefs were found to be a less important factor, though still significant, for Black people than other groups. The BLM movement directly addresses inequalities face by Black people. Since the goals of this movement are so close to the everyday lives and long-term outcomes for Black people, modern racist beliefs may not have much of an influence on support as Black people may support the movement regardless of these social attitudes.

\section{Summary general discussion by intersecting group}

As predicted in Hypothesis 2, the proposed model did not equally apply across groups. Group differences were found in the strengths of some of the factors included in this study, while other patterns were found more universally, as discussed above. Below are breakdowns by each intersecting race and gender group of the results from this study to further highlight both the found difference and the similarities. 
Black women. Confirming Hypothesis 1c, mean levels for support for and participation in protests and BLM were highest for Black women. For support for protests and BLM, all of the three regressions run were significant, confirming the proposed model for this group on this outcome. Though generally significant across groups, racial identity centrality was generally more strongly related to participation than for other groups, with higher Black racial identity centrality related to higher reported participation in protests and BLM. Modern racism was a strong and negative predictor in support for protests and BLM, but not for participation, suggesting that, for Black women, other factors not included in the model may influence participation other than social attitudes.

Black men. Similar to Black women, Black men reported high levels of support for protests and BLM. However, Black women reported more participation than Black men, which aligned with the predictions of this study and follow the pattern of examples from recent Black-centered racial equity social movements mentioned in the introduction. For Black men, the proposed model in this study is not supported for either outcome. Intersecting race and gender identity, racial identity centrality, and their interaction had little to no influence on modern racist beliefs, and modern racist beliefs had no relationship with either outcome. However, the combination of all predictors did predict both support for and participation in protests and BLM, though intersecting race and gender identity was not significant, but the interaction of intersecting identity and racial identity centrality was significant. That is, though each of the predictors (except intersecting race and gender identity) was significant, the paths hypothesized in the 
moderated mediation were not. This may be due to a possible ceiling effect, as reported support was very high for this group with little variation within the group.

Latinx women. Latinx women reported significantly more support for protests and BLM than Latinx men, though both groups reported similar levels of participation. For Latinx women, modern racism was strongly and negatively related to support for protest and BLM, but was only related to participation when all other predictors were included. For both outcomes, racial identity centrality was significantly and positively related to both outcomes, highlighting this as an important factor and a possible point of intervention for this group specifically.

Latinx men. For Latinx men, the proposed moderated mediation can be confirmed when predicting support for protests and BLM, but not when predicting participation. Overall, reported levels of participation were among the lowest for Latinx men. All predictors were significantly related to support, while only racial identity centrality and modern racism were significantly related to participation. Similar to Latinx women, with all predictors included, both racial identity centrality and modern racism were strongly and positively related to both outcomes.

Asian women. No differences were found for either support for or participation in protests and BLM between Asian women and men. For Asian women, all tested paths were significant for each outcome, confirming the predicted moderated mediation. For both outcomes, when including all predictors, modern racism and racial identity centrality revealed to be significantly related to both outcomes, with modern racism negatively related and racial centrality positively related, while intersecting race and 
gender identity and the interaction of intersecting identity and racial identity centrality were not significant. This pattern shows the similar relationship between these factors and both outcomes, which is not necessarily reflected in other groups.

Asian men. Though not significantly different from other non-Black groups, Asian men reported the lowest mean levels of support for protests and BLM, but the highest mean levels of participation within non-Black groups. Similar to Asian women, all tested paths were significant for each outcome, confirming the predicted moderated mediation. Similar patterns were found between Asian women and men except that Asian men's intersecting race and gender group was positively and strongly related to support for protests and BLM.

White women. White women reported both more support for and participation in protests and BLM than White men, aligning with Hypothesis 1c. All tested paths were significant for each outcome, confirming the predicted moderated mediation. When including all predictors, White women's responses revealed a similar pattern to that of Latinx men. All factors were significantly related to support for protests and BLM, with racial centrality positively related and modern racism negatively related. This same pattern is reflected when predicting participation in protests and BLM, though intersecting race and gender identity and the interaction of intersecting identity and racial identity centrality were not significant.

White men. For White men, all tested paths were significant for each outcome, confirming the predicted moderated mediation. Reflecting the patterns of most other groups, for both outcomes, racial identity centrality was positively and significantly 
related to both outcomes, while modern racism was negatively and positively related to both. Intersecting race and gender identity was marginally significantly related to participation in protests and BLM, though this factor was not related to support, and the interaction of intersecting race and gender identity and racial identity centrality was not related to either outcome when all factors were included. It was predicted that White men would report the lowest levels of both support for and participation in protests and BLM, and though no differences were significantly found, mean levels for this group when reporting support fell more central in the range of group responses, while mean levels of participation were within some of the lowest reported along with Latinx men and Asian women.

Summary. Overall, Black participants reported higher levels of both support for and participation in protests and BLM than all other racial groups, while Latinx, Asian, and White participants reported similar level in both support and participation. These results align with past research that identifies higher levels of engagement with collective action for own-group efforts, as opposed to cross-group efforts. However, this study predicted that Latinx and Asian people would report more support and participation in protests and BLM than White people, but these results were not found.

Reports of support for protests and BLM were much higher than reports of participation for each of the eight intersecting race and gender groups. For Black people and support, a possible ceiling effect may have occurred as reported levels of support were very high with little variance. For participation, reports were overall low, and were very low for all non-Black groups, revealing a possible floor effect, though there was 
variance within each group in reported participation with each group having some respondents indicating high levels of participation in protests and BLM.

Overall, racial identity centrality and modern racism were important factors in predicting both support for and participation in protests and BLM. These similarities across groups identify common factors that may be more universally examined when predicting or promoting collective action engagement, either for one's own group or across groups. However, some differences were found in the strength of these factors, suggesting that these factors may be more important points of investigation for some groups over others.

\section{Implications}

Results from this study provide new information and insights on intraminority intergroup relations as they pertain to support for and participation in a current and critical collective action movement in a rapidly changing social context. First, by examining racial and gender group differences of support for and participation in racial protests that address police excessive use of force on racial minorities and the Black Lives Matter movement, important information on current and socially relevant intraminority attitudes and relations are explored within the domain of race. The results helps provide a deeper understanding of the under-explored area of intraminority intergroup attitudes and relations, and more specifically as they apply to collective behaviors beyond intent.

Though significant, the predictive factors accounted for much less variance in predicting participation (Equation 2: .00-18\%; Equation 3: 5-10\%) than they did in 
predicting support (Equation 2: .00-59\%; Equation 3: 46-48\%). These results are consistent with the literature on attitude-behavior inconsistency, which highlights the significant but low predictive value that attitudes have for behaviors (see Ajzen \& Fishbein, 2005 for a review). In this study, though relatively high levels of support for protests and BLM are found across groups, participation is low. There are a number of barriers to engagement with social movements and political participation, including socioeconomic status (Paulson, 1991), access to internet (Xenos \& Moy, 2001), and access to social capital such as child care, transportation, and time (Rydin \& Pennington, 2000), which may account for more variance when predicting participation. That is, if a person does not have access or resources that allow them to participate in these actions and movements, identity and social attitudinal factors may not matter as much, even if the person is highly supportive. For Black and other men of color in particular, who are disproportionally stopped by police (Fagan, Geller, \& Davies, 2010), participating in protests such as rallies and marches may be a safety concern and barrier to participation, as they may be, intentionally or unintentionally, targeted by law enforcement during these actions.

Though much of the more visible actions of the BLM movement include street protests, the movement also includes off-the-streets organizing, such as political education events and free food programs (Black Lives Matter, 2016), where Black men and other people of color may feel safer participating in collective action. For those who may identify as an ally or accomplice to a targeted group who are also unable or uncomfortable with participating in politicized protests and direct actions, participation 
may look like volunteering, charitable giving to grassroots organizations, or signing online petitions that align with the social movement's goals. Though "participation" is undefined in this study, bringing light to the many ways that people may participate in social movements, such as having interpersonal discussion about particular topics or posting information online, may reveal higher levels of participation and engagement with this movement across groups. Additionally, sharing skills that could be used to promote social movements towards more equitable social change, such as teaching how to lead letter-writing campaigns, may be useful in increasing participation with movements without requiring participants who may be at higher risk to enter potentially harmful actions.

Beyond basic racial group differences, by examining the role of intersecting race and gender identities, a better understanding of attitudes and behaviors of people with multiple marginalized identities, as opposed to people with singular or no marginalized race or gender identity, is explored. As mentioned in the introduction, one can draw from history and past collective action movements and see that, though leadership or perceived leadership in these movements that combat oppression is generally attributed to prototypical persons who hold only a singular marginalized identity, there has been a trend of persons with multiple marginalized identities as active organizers in many collective action movements (i.e. Black Lives Matter, Asian Immigrant Women Advocates). Though this pattern is observed, this is limited to persons who are actually actively involved with collective action movements. Because of the lack of intersectional research, especially as it relates to collective action, it is difficult to say that this same 
pattern translates to general public attitudes. That is, though people who are involved in collective action movements tend to hold multiple marginalized identities, it is not said that persons with multiple marginalized identities in general tend to be more involved in or have more positive attitudes towards collective action movements. This study shows that, within some intersecting groups, this pattern of women being more supportive and engaged than men of the same racial group, somewhat holds for both support for and participation in protests and BLM.

Research on behaviors that are difficult to collect data on, such as participation in collective action movements, and much of the social psychological research on collective action measures the behavior indirectly, such as by assessing attitudes or intentions, with very little literature on actual behaviors as outcomes (van Zomeren et al., 2008). This study directly asks for self-reported past or current behaviors as they relate to participation in collective action, along with attitudes. Though the data collected is crosssectional, by using data about self-report participation, rather than only attitudes or intentions, this study gets closer to understanding true collective behaviors and engagement with current movements. This is a strength in the outcome measures where there have previously been weaknesses. The differences observed in the results for the two outcomes of interest, 1) support for and 2) participation on protests and BLM, show that attitudes towards these movements, though related, may not be enough to accurately predict participation.

This study focuses on attitudes towards a specific social issue, which continues to be relevant and continues to be a source of tension between racial minority communities 
and police. Developing a better understanding of opinions towards public reactions to cases of police excessive use of force can aid in evaluating the current social climate and offer information that may lead to improved community-police relations. Additionally, because of social and other media outlets, many misconceptions of both Black Lives Matter and policing exist. By evaluating public perceptions of these collective action responses to police, steps are being taking towards understanding public attitudes and interpretations of these current issues and the movements that stem from them.

In line with past research, results from this study show that support and participation are related to social identities and social attitudes, suggesting that support and engagement may be malleable. Factors such as modern racism and racial identity centrality may be targeted as important points of intervention to increase both support and participation, though these factors more strongly influence support (attitudes) than participation (behaviors). For racially prejudiced attitudes, past interventions have found success in methods such as engagement with conversations about race (Aboud \& Fenwick, 1999), mere exposure to other-race faces (Zebrowitz, White, \& Wieneke, 2008), learning about racial discrimination (Case, 2007; Craig \& Richeson, 2011), and practicing empathy (Finlay \& Stephan, 2000). Past social attitudes, as discussed there may be structural barriers to participation in collective action. Removing these barriers, such as providing childcare, bus passes for transportation, or compensation for participants' time, may increase in-person participation with community organizations combating racial inequality. Additionally, providing education and workshops on the many ways in which people can be involved in collective action outside of street protests 
and direct actions may increase participation by developing individual and community skills and knowledge.

This study and the analyses include data collected from White participants, though the focus of the study is intraminority attitudes and solidarity. Much of the research on race-based ally work examines the engagement of White people with social justice efforts for racial minorities (Curtin et al., 2016; DeTurk, 2011), though a few recent studies have moved towards also examining intraminority allyship (Brown \& Ostrove, 2013; Droogendyk, Wright, Lubensky, \& Louis, 2016). By including White participants in the analyses, this study adds to the growing literature on White allyship and the predictive factors of White engagement with movements towards racial justice. However, the model and relations between predictors (racial centrality and modern racism) may not be an accurate prediction of support for and participation in these movements for White individuals. For example, for White people, scoring high in racial centrality may mean that they hold more White supremacist beliefs (Leonardo, 2013), but it could also mean that they recognize the importance of their White identity as it relates to oppression and privilege (Case, 2012). In the current study for White women only, higher White racial identity centrality was related to more support for protests and BLM, while White racial identity centrality was not significantly related to support for White men, and was not significantly related to participation in protests and BLM for either White men or women. The insignificance of this measure variable may be due to the additional nuance this predictor may have for White people, who are in a position of power as comparted to other racial groups. That is, an interaction between racial 
centrality and racial attitudinal predictors may be a more accurate predictor of support and participation, rather than the model tested in this study. Further studies examining responses from only White participants are needed to further explore the relationship between these and other predictive factors for this group.

Alliance and accomplice by White people in racial justice efforts are different from intraminority alliance in that White participants in these movements are combating the forces that produce their relative power, often by the use of this power itself (Nakayama \& Martin, 1999). This tension adds nuance to their position and use of privilege in racial justice organizing, at times hindering full commitment to these efforts (DeTurk, 2011). This may be a result of a conceptualization of social power as a zerosum resource that needs to be competed for (Norton \& Sommers, 2011), and a resistance towards the idea of truly forgoing one's own relative power in order to support efforts by groups who have been continuously oppressed. Perceptions of zero-sum competition for social resources are related to belief systems such as social dominance orientation and ethnic prejudices related to those measured in this study (Esses et al., 2001), helping further explain the nuances of the influence of social attitudes on support for and engagement with racial equity social movements.

Perceptions of zero-sum resources may also influence intraminority support for social change targeted at specific groups. The idea that helping one marginalized group distracts from or contributes to the further marginalization of another group may be tied to perceptions of intergroup distance. Perceptions of common fate or a common ingroup identity may contribute to increased intraminority solidarity through an understanding of 
"when you help your neighbor, you help yourself." The dataset used in this study did not include measures of feelings of intergroup closeness, but would be an important factor to both measure and manipulate in future studies, as they may have a strong influence on cross-group support for and participation in social change efforts.

Internalized oppression (Hall, 1986) is another potential factor that may be inhibiting support for and participation in protests and BLM by racial minorities. Internalized oppression may lead marginalized group members to blame other group members and themselves for their low social power and status, rather than acknowledging the oppressive systems and group hierarchies that influence marginalized group members' conditions. Self-subtyping oneself as an exception to the group may also be a product of internalized oppression for a group member who does not see their fate tied to their whole group, while considering group members with worse outcomes as more deserving of their condition (Pyke, 2010).

By further exploring the influence of the predictive factor on support for and participation in collective action engagement, community organizers and social justice activists can use the information gained to develop interventions, programs, or campaigns that increase engagement with and mobilization of social movements towards more equitable racial justice outcomes. Past research on a program implemented with counseling psychologists-in-training showed the importance of social consciousnessraising and self-examination as critical in developing more social justice-oriented practice (Goodman et al., 2004). Additionally, a qualitative study examining self-identified social justice workers, all participants reported that the role of "changes in cognition," or 
understanding systems of oppression, self-awareness, and self-questioning as important factors in their development as more productive social justice workers (Dollarhide, Clevenger, Dogan, \& Edwards, 2016). For members of oppressed groups specifically, critical consciousness can be used as a tool towards collective liberation (Freire, 1990). Though definitions vary, critical consciousness involves critical social evaluations that ultimately lead to social action engagement (Watts, Griffith, \& Abdul-Adil, 1999), and the development of critical consciousness has been implemented in a number of programs that aim to increase and promote collective action engagement (Watts \& HipolitoDelgado, 2015). The results from these and other studies show the influence that these factors may have on engagement with social justice efforts. The results from this study show the strength of these related factors, and may provide information to further these efforts by promoting intergroup collaboration and coalition building.

\section{Limitations}

Though this study serves as an important stepping-off point with many implications for future studies, there are a number of limitations present. As discussed earlier, when considering collective behaviors and actions, and the way identities play a role, it is important to understand the relevant context and history of both the social roles and the social issue that is being examined. Similarly, though the sample is from a university with representation of non-traditional students, which adds to generalizability in variability in age, veteran status, and other demographics, the specific geographic location and local politics may compromise the generalizability of results. Even with this limitation, the results from this study provides important initial information about the role 
of intersecting race and gender identities and the role they play in race-based collective action movements. From this, important next steps would be to repeat the analysis with a more representative and diverse community sample, adding further variability in age, educational attainment, socioeconomic status, and other potentially important factors. Currently, data are being collected from a community sample for a different study using items similar to those for these analyses. After the data collection for that study is completed, similar tests will be re-run for the new community sample and results will be compare with those from this study's university student sample. However, both tests will still be geographically specific, and neither will reveal wider regional or national representativeness. Though this will not be achieved, valuable information can be gained about the specific context from which the data was collected.

Recruitment for this study was conducted through classroom announcements, flyers, and digital ads at a large urban public university. Recruitment advertised the survey as one that wanted to gather opinions on the recent arming of campus security and other social issues, and students were offered either extra credit in a course or a chance to win a $\$ 100$ gift card for their participation. Though the overall demographics are included in data collection are fairly representative of the university as a whole at the time of data collection, self-selection into the survey may have skewed results. Students with more strong feelings (either for or against) about social issues, policing, and the arming of campus police may have been more drawn to sharing these thoughts through the survey than students who felt more neutral. For students who were offered extra credit for participation, strength of these attitudes may have been less of an influence on 
participation than students who expressed an interest or investment in these topics.

Additionally, when conducting initial cleaning of data shortly after recruitment and data collection ended, the researchers noticed a pattern of participants dropping out of the survey after items that asked opinions about the recent approval to arm of campus security officers with firearms. Aside from demographics and racial identity centrality, all items used in this study occurred after these items on campus security, and this possible common point of participant drop out may have further biased the representativeness of the cases included in the final dataset.

Accessibility of social movements must be kept in mind when evaluating participation in these movements. Though the data was collected from students from a university in a large city that has a number of community organizations and groups that address the issue of police use of force on racial minorities, it is unknown how easily these movements and organizations may be accessed by people who may be interested in becoming involved. This may have a real influence in responses regarding personal participation in these movements, with a possible floor effect for this outcome measure, which is reflected in the low responses across groups of participation in protests and BLM and the positive skew in responses.

This study also focuses on a very context-specific case of attitudes towards and participation in collective action as a result of specific and visible cases of police killings of unarmed Black people. Though there have been past movements towards addressing racial bias in policing and disparate outcomes in police interactions by race, it is critically 
important to consider the specific cultural, political, and social climates when evaluating public attitudes of this social issue.

Some scales used for these analyses (i.e. racial identification, modern racism) have been previously tested for reliability (e.g. McConahay, 1986; Vandiver, Cross, Worrell, \& Fhegen-Smith, 2002). However, because of the recency of the specific events that this study aims to evaluate, scales and items were created for this specific purpose, and have not yet been validated (i.e., support for protests and BLM). A team of researchers were involved in the creation of these measures and a previously conducted confirmatory factor analysis revealed a single factor for all seven items. Additionally, reliability testing partially alleviated this concern by revealing a very strong Cronbach's Alpha.

There are a number of limitations for the single item that aims to measure participation in racial protest and BLM, specifically. First, it is a single item meant to measure a self-reported behavioral outcome. It is very difficult, if not impossible to evaluate the reliability and validity of single-item behavioral measures (Gardner, Cummings, Dunham, \& Pierce, 1998; Postmes, Haslam, \& Jans, 2012; Wanous \& Reichers, 1996). Second, the single item intended to measure participation is broad, with "participation" not defined. This item, relies on the respondent's interpretation of what it means to be a participant in these movements, followed by a subjective evaluation of one's own behaviors in reference to these movements. This unknown variability in subjective participation makes it difficult to accurately compare responses, and may potentially have an influence when using this item as an outcome variable. Recent social 
discourse and academic literature address what it means to be a participant in collective action movements (Mountz et al., 2015; Postmes \& Brunsting, 2002; Sampson, McAdam, MacIndoe, \& Weffer-Elizondo, 2005). Though some may attribute participation to actively marching in street protests or rallies, many have embraced alternative definitions of participation in these movements, which may include behaviors such as creating art that brings attentions to the issue being addressed, starting interpersonal conversations to discuss these issues, and through the act of self- and community-care as a liberation technique (Collins, 2002). So, by leaving this item up to interpretation, alternative and evolved operationalizations of "participation" may have informed the responses that were collected, though this range of interpretations is not reflected in the data.

All data used in this study came from a cross-sectional survey. Because of this, causal interpretations cannot be made, but can only be inferred by the observed relationships. This study further shows the relationship between social attitudes and collective action engagement. Models of collective action, such as the Social Identity Model of Collective Action (van Zomeren, Postmes, \& Spears, 2008) posit the causal influence of social beliefs on engagement, but the relationship may be bi-directional. The Volunteer Process Model (VPM) highlights the impact that volunteerism and social service have on attitudes, knowledge, and subsequent behavior of those who do volunteer (Omoto \& Snyder, 1995). That is, participation in social movements may aid in the process of developing critical consciousness and changing social attitudes. Further research and experimental methods (see Future Directions) should be utilized to examine 
the potential causal nature of social attitudes, such as modern racist beliefs, on collective action support and engagement.

\section{Future Directions}

From the results of this study, a number of directions can be taken to further this line of research. Qualitative analyses, such as identity-specific focus groups that ask those with intersecting identities about attitudes towards and participation in collective action movements, would contribute to a more whole understanding of these identity factors as they relate to the outcomes of interest. Bowleg (2008), Stewart and McDermott (2004), and others argue that qualitative methods, compared to quantitative methods, are better methods when examining intersectionality, as they allow for more complex data to emerge that better describe experiences of people at their specific intersections, especially for those who hold intersecting identities that are not prototypical and thus underrepresented both in research and in social dialogue (Marecek, Fine, \& Kidder, 2001).

Experimental methods could be utilized in order to further understand intraminority support for collective action. Past research has manipulated participant's perceptions of the ingroup in order to measure changes in intergroup interdependence (Gaertner \& Dovidio, 2000), but has not yet been utilized to evaluate behavioral outcomes as they relate to intraminority intergroup support for collective action and social movements. For example, by involving of the Common Ingroup Identity Model (CIIM; Gaertner et al., 1993), and inclusion of the ingroup in the self (Tropp \& Wright, 2001) as an intragroup approach to the inclusion of the other in the self (Aron, Aron, \& 
Smollan, 1992), feelings of closeness of one's self or one's racial ingroup to other racial minorities may be manipulated to evaluate the influence of the shift of intergroup boundaries on cross-group collective action engagement. Past cross-sectional research has shown the positive relationship between recognition of own-group discrimination on intraminority attitudes (Masuoka, 2006; Sanchez, 2008). Experimental methods may expand on these findings by exposing racial minority participants to examples of information on either own-group or other minority group pervasive discrimination to induce feelings of common fate, commonality, and closeness (e.g. Craig \& Richeson, 2011) and potentially increase support for or participation intraminority collective action efforts.

Applied or intervention methods could also be used with the information gained in this study. For example, because this study finds that modern racism is an important predictor across groups, implementing a program or intervention that focuses on developing critical consciousness through political education that addresses the history, structures, and current manifestations of racial bias and how they influence inequalities may be a way to change modern racist beliefs and highlight the importance of collective action (e.g. Ginwright \& Cammarota, 2007; Goodman et al., 2007). This type of program may improve both one's own group status if they are a member of a marginalized group and are led to engage more in social movements, or enhance cross-group engagement by acting as an ally or accomplice. However, previous research has also shown that the positive influence of more equitable attitudes from learning about racial diversity in a university setting may plateau over time (Kernahan \& Davis, 2010). Incorporating these 
findings, future research could test the influence of a one-time political education session or long-term intervention that continuously requires learning and engagement with topics around social issues, and measure the influence on short-term and long-term support for and participation in collective action and movements towards social change.

Though BLM and similar collective action movements have gained media, political, and general social recognition, there are still many public misconceptions of the purpose and goals of this and similar movements. The Black Lives Matter movement, like other social movements, has been portrayed in the media in various ways, from being called the hate group (Mettler, 2016) to a necessary revolutionary movement (Garber, 2015). This study does not directly address reports of individual understanding of these movements, which is an avenue for future research. However, media consumption influences attitudes around political topics and various social issues such as protests (Arpan, Baker, Lee, Jung, Lorusso, \& Smith, 2006; McLeod, 1994) and may influence direct political participation (Tufekci \& Wilson, 2012). The media that one chooses to seek out and consume may inform perceptions of these movements. Further studies examining a possible discrepancy in individual understanding of the causes and the purposes of these movements and how this perceived understanding relates to support for and participation in these movements should also be explored.

Looking at social media use specifically, engagement with political information on websites such as Facebook have directly influenced the mobilization of collective action movements (Gil de Zúñiga, Molyneux, \& Zheng 2014; Harlow, 2001). Future studies should incorporate the influence of media consumption as it relates to perceptions 
of BLM and other social movements in this context. Paired with media consumption, social group membership has also been found to relate to how strongly media may influence a person's attitudes (Gunther, 1992). Similar to this, pairing media consumption with factors similar to those included in this study, such as measures of social and racial attitudes, may provide a better understanding of support and participation that aid in the mobilization of social movements. Currently, a new study explores the combined influence of social networking ( $\mathrm{SN}$ ) site use and awareness of privilege and oppression (APO) on both support for and participation in protests and BLM, finding that for people with higher awareness of APO, the use of $\mathrm{SN}$ websites to obtain and share policingrelated news helped explain increases in both outcomes (Lake, Alston, \& Kahn, under review).

This study addresses a social issue that, though it affects a number of racial minority groups, is more representative of disparate outcomes of Black people in police interactions. It would be important to examine the role of intersecting identities on other social issues that affect disadvantaged groups, such as attitudes towards and participation in collective action movements that address immigration, the entrance of refugees into the Unites States, and other race-related issues. Additionally, it would be vital to use these tests to examine issues that are gender-specific, such as reproductive and transgender rights. By looking at other issues in this way, information about who supports these issues could be evaluated, along with a comparison between studies that may help understand which factors (i.e., identity, psychological, environmental) are more influential predictors of support for collective action movements towards productive 
social change more generally. Expanding the literature around collective action and engagement would both aid in understanding factors that are more influential for specific social issues, and in understanding more universal factors that may be influential across issues. For example, one could hypothesize that when predicting support for and participation in transgender rights movements, identity factors such as gender would serve as a strong influence, but when predicting support for and participation in immigration reform, attitudinal factors such beliefs about racial, ethnic, or economic structures would be a strong influence.

This study explores understudied areas in social psychology, such as intersectionality and collective action, while considering the current and changing social context. Results from this study highlight similarities across groups, such as the negative influence of modern racist beliefs on both support for and participation in protests and BLM, and differences, such as the influence of intersecting race and gender group membership, racial centrality, and the interaction of the two on support and participation. This study focuses on a relevant and visible social movement that highlights historical and current racial disparities within policing and beyond. The information gained from this study can hopefully be used by researchers to further explore these topics, along with community organizers, activists, and policy makers in promoting intergroup support and coalition building between groups with common group memberships, experiences, and social change goals. 
Tables

Table 1. Participant demographics.

\begin{tabular}{lcc}
\hline Demographic Variable & Frequency & Percent \\
\hline Gender & $\frac{\mathrm{N}=499}{159}$ & \\
Men & 340 & 31.9 \\
Women & & 68.1 \\
Race/Ethnicity & 316 & 63.3 \\
White & 33 & 6.6 \\
Black or African American & 84 & 16.8 \\
Latinx & 66 & 13.2 \\
Asia, South, or Southeast Asian & & \\
Year in School & 75 & 15.0 \\
First Year Undergraduate & 59 & 11.8 \\
Second Year Undergraduate & 123 & 24.6 \\
Third Year Undergraduate & 159 & 31.9 \\
Fourth Year Undergraduate or Higher & 30 & 6.0 \\
Post-Bac & 46 & 9.2 \\
Graduate Student & 7 & 1.4 \\
Not a current student or missing & &
\end{tabular}

Table 2. Participant gender demographics by race.

\begin{tabular}{llcc}
\hline Race & \multicolumn{1}{c}{ Gender } & Frequency & Percent \\
\hline White & Men & $\frac{\mathrm{N}=316}{98}$ & \\
& Women & 218 & 31.0 \\
& & $\frac{\mathrm{N}=33}{13}$ & 69.0 \\
Black or & & 20 & \\
African & Men & $\frac{\mathrm{N}=84}{19}$ & 37.5 \\
American & Women & 65 & \\
Latinx & & $\mathrm{N}=66$ & 22.9 \\
& Men & 29 & 77.1 \\
& Women & 37 & \\
Asia, South, & & & 43.9 \\
$\begin{array}{c}\text { or Southeast } \\
\text { Asian }\end{array}$ & Men & Women & 56.1 \\
\hline
\end{tabular}


Table 3.2 (Gender) x 4 (Race) Factorial ANOVA results for support for protests and the Black Lives Matter Movement.

\begin{tabular}{lrrrrrrr}
\hline & SS & df & $\begin{array}{c}\text { Mean } \\
\text { square }\end{array}$ & F & Sig. & $\begin{array}{r}\text { Partial } \\
\eta^{2}\end{array}$ & $\begin{array}{c}\text { Observed } \\
\text { Power }\end{array}$ \\
\hline Intercept & 7261.47 & 1 & 7261.47 & 3085.18 & .00 & .86 & 1.00 \\
Race & 36.59 & 3 & 12.20 & 5.18 & .00 & .03 & .93 \\
Gender & 16.41 & 1 & 16.41 & 6.97 & .01 & .01 & .75 \\
Race*Gender & .70 & 3 & .23 & .10 & .96 & .00 & .07 \\
\hline
\end{tabular}

Table 4. Means and mean differences in support for protests and the Black Lives Matter movement by racial group from Tukey's HSD post-hocs.

\begin{tabular}{lllll}
\hline Race & Mean & White & Black & Latinx \\
\hline White & 5.55 & & & \\
Black & 6.39 & $.84^{*}$ & & \\
Latinx & 5.48 & -.09 & $-.92^{*}$ & \\
Asian & 5.08 & $-.48^{+}$ & $-1.32^{* * *}$ & -.40 \\
$* * * p<.001,{ }^{* *} p<.01,{ }^{*} p<.05,{ }^{+} p<.1$ & &
\end{tabular}

Table 5. Means and differences in support for protests and the Black Lives Matter movement by gender group within race from post-hoc t-tests.

\begin{tabular}{llcrcl}
\hline Race & Gender & Mean & SD & t & Sig. \\
\hline White & Total & 5.55 & 1.63 & -2.50 & $.01^{* *}$ \\
& Men & 5.22 & 1.76 & & \\
& Women & 5.70 & 1.55 & & \\
Black or & Total & 6.39 & .89 & -1.38 & .18 \\
African & Men & 6.08 & 1.12 & & \\
American & Women & 6.60 & .68 & & \\
Latinx & Total & 5.48 & 1.45 & -2.88 & $.01^{* *}$ \\
& Men & 5.16 & 1.80 & & \\
& Women & 5.57 & 1.33 & & \\
Asia, & Total & 5.08 & 1.50 & -1.60 & .12 \\
South, or & Men & 4.69 & 1.58 & & \\
Southeast & Women & 5.38 & 1.38 & & \\
Asian & & & & & \\
All & Total & 5.53 & 1.57 & -3.70 & $.00^{* * *}$ \\
& Men & 5.18 & 1.71 & & \\
& Women & 5.70 & 1.47 & & \\
*** $p<.001, * * p<.01, * p<.05$ & & & &
\end{tabular}

Table 6. Means and mean differences in participation in protests and the Black Lives Matter movement by racial group.

\begin{tabular}{lrrrrrrc}
\hline & SS & df & $\begin{array}{l}\text { Mean } \\
\text { square }\end{array}$ & F & Sig. & Partial $\eta^{2}$ & $\begin{array}{c}\text { Observed } \\
\text { Power }\end{array}$ \\
\hline Intercept & 559.97 & 1 & 559.97 & 898.01 & .00 & .65 & 1.00 \\
Race & 17.40 & 3 & 5.80 & 9.30 & .00 & .05 & .99 \\
Gender & 3.10 & 1 & 3.10 & 4.98 & .03 & .01 & .61 \\
Race*Gender & 6.19 & 3 & 2.06 & 3.31 & .02 & .02 & .75 \\
\hline
\end{tabular}


Table 7. Means and mean differences in participation in protests and the Black Lives Matter movement by racial group from Tukey's HSD post-hocs.

\begin{tabular}{lllll}
\hline Race & Mean & White & Black & Latinx \\
\hline White & 1.39 & & & \\
Black & 2.21 & $.82^{* * *}$ & & \\
Latinx & 1.33 & -.06 & $-.88^{* * *}$ & \\
Asian & 1.36 & -.03 & $-.85^{* * *}$ & .03 \\
\hline
\end{tabular}

*** $p<.001,{ }^{* *} p<.01,{ }^{*} p<.05$

Table 8. Means and differences for participation in protests and the Black Lives Matter movement by gender group within race from posthoc t-tests.

\begin{tabular}{llcccc}
\hline Race & Gender & Mean & SD & t & Sig. \\
\hline White & Total & 1.39 & .76 & -1.97 & $.05^{*}$ \\
& Men & 1.27 & .63 & & \\
& Women & 1.45 & .81 & & \\
Black or & Total & 2.21 & 1.27 & -1.98 & $.06^{+}$ \\
African & Men & 1.69 & 1.18 & & \\
American & Women & 2.55 & 1.23 & & \\
Latinx & Total & 1.33 & .68 & -.51 & .61 \\
& Men & 1.26 & .65 & & \\
& Women & 1.35 & .69 & & \\
Asia, & Total & 1.36 & .80 & -1.60 & .12 \\
South, or & Men & 1.48 & .95 & & \\
Southeast & Women & 1.27 & .65 & & \\
Asian & & & & & \\
All & Total & 1.43 & .82 & -1.72 & $.09^{+}$ \\
& Men & 1.34 & .76 & & \\
& Women & 1.47 & .84 & & \\
$* * * p<.001, * * p<.01,{ }^{*} p<.05,{ }^{+} p<.1$ & & &
\end{tabular}

Table 9. Model summaries for Equation 1 for each intersecting race and gender group.

\begin{tabular}{|c|c|c|c|c|c|}
\hline \multicolumn{2}{|c|}{ Group } & \multicolumn{4}{|c|}{ Modern Racism } \\
\hline Race & Gender & $\mathrm{R}$ & $\mathrm{R}^{2}$ & F & $p$ \\
\hline \multirow[t]{2}{*}{ White } & Men & .15 & .02 & 3.81 & $.01 * *$ \\
\hline & Women & .25 & .06 & 10.55 & $.00 * * *$ \\
\hline \multirow[t]{2}{*}{ Black } & Men & .09 & .01 & 1.18 & .32 \\
\hline & Women & .18 & .03 & 5.15 & $.00 * *$ \\
\hline \multirow[t]{2}{*}{ Latinx } & Men & .12 & .01 & 2.29 & $.08^{+}$ \\
\hline & Women & .11 & .01 & 1.87 & .13 \\
\hline \multirow[t]{2}{*}{ Asian } & Men & .27 & .07 & 12.71 & $.00 * * *$ \\
\hline & Women & .16 & .03 & 4.44 & $.00 * *$ \\
\hline
\end{tabular}

*** $p<.001,{ }^{* *} p<.01,{ }^{*} p<.05,{ }^{+} p<.1$ 
Table 10. Results from Equation 1 for each intersecting race and gender group.

\begin{tabular}{|c|c|c|c|c|c|c|c|}
\hline \multirow[t]{2}{*}{ Race } & \multirow[t]{2}{*}{ Gender } & \multirow[t]{2}{*}{ Variable } & \multicolumn{5}{|c|}{ Modern Racism } \\
\hline & & & $B$ & $S E B$ & $\beta$ & $t$ & $p$ \\
\hline \multirow[t]{8}{*}{ White } & Men & $\mathrm{RG}$ & .29 & .09 & .16 & 3.06 & $.00 * *$ \\
\hline & & $\mathrm{RC}$ & .02 & .02 & .05 & .97 & .33 \\
\hline & & RGxRC & .10 & .05 & .11 & 1.93 & $.06^{+}$ \\
\hline & & $R^{2}$ & .02 & & & & \\
\hline & Women & RG & -.31 & .07 & -.22 & -4.73 & $.00 * * *$ \\
\hline & & $\mathrm{RC}$ & -.03 & .02 & -.07 & -1.20 & .23 \\
\hline & & RGxRC & .09 & .04 & .12 & 2.15 & $.03 *$ \\
\hline & & $R^{2}$ & .06 & & & & \\
\hline \multirow[t]{8}{*}{ Black } & Men & RG & -.36 & .27 & -.08 & -1.38 & .17 \\
\hline & & $\mathrm{RC}$ & .03 & .02 & .06 & 1.29 & .20 \\
\hline & & RGxRC & .10 & .14 & .04 & .74 & .46 \\
\hline & & $R^{2}$ & .01 & & & & \\
\hline & Women & RG & -.54 & .24 & -.14 & -2.25 & $.03 *$ \\
\hline & & $\mathrm{RC}$ & .04 & .02 & .09 & 2.02 & $.04 *$ \\
\hline & & RGxRC & -.06 & .11 & -.03 & -.53 & .60 \\
\hline & & $R^{2}$ & .03 & & & & \\
\hline \multirow[t]{8}{*}{ Latinx } & Men & $\mathrm{RG}$ & .34 & .18 & .11 & 2.20 & $.03 *$ \\
\hline & & $\mathrm{RC}$ & .03 & .02 & .06 & 1.37 & .17 \\
\hline & & RGxRC & -.12 & .09 & -.06 & -1.31 & .19 \\
\hline & & $R^{2}$ & .01 & & & & \\
\hline & Women & $\mathrm{RG}$ & .12 & .13 & .05 & .92 & .36 \\
\hline & & $\mathrm{RC}$ & .04 & .02 & .09 & 1.86 & $.06^{+}$ \\
\hline & & RGxRC & -.13 & .07 & -.12 & -1.97 & $.05 *$ \\
\hline & & $R^{2}$ & .01 & & & & \\
\hline \multirow[t]{8}{*}{ Asian } & Men & RG & .82 & .14 & .27 & 6.03 & $.00 * * *$ \\
\hline & & $\mathrm{RC}$ & .02 & .02 & .05 & 1.18 & .24 \\
\hline & & RGxRC & -.12 & .08 & -.06 & -1.37 & .17 \\
\hline & & $R^{2}$ & .07 & & & & \\
\hline & Women & $\mathrm{RG}$ & .50 & .15 & .18 & 3.41 & $.00 * * *$ \\
\hline & & $\mathrm{RC}$ & .02 & .02 & .06 & 1.23 & .22 \\
\hline & & RGxRC & -.14 & .08 & -.10 & -1.88 & $.06^{+}$ \\
\hline & & $R^{2}$ & .03 & & & & \\
\hline
\end{tabular}

Note. $\mathrm{RG}=$ intersecting race and gender group (dummy coded); $\mathrm{RC}=$ racial centrality (centered); $\mathrm{RGRC}=\mathrm{RG} x \mathrm{RC}$ interaction 
Table 11. Model summaries for Equation 2 for each intersecting race and gender group.

\begin{tabular}{|c|c|c|c|c|c|c|c|c|c|}
\hline \multicolumn{2}{|c|}{ Group } & \multicolumn{4}{|c|}{ Support for BLM } & \multicolumn{4}{|c|}{ Participation in BLM } \\
\hline Race & Gender & $R$ & $R^{2}$ & $F$ & $p$ & $R$ & $R^{2}$ & $F$ & $p$ \\
\hline \multirow[t]{2}{*}{ White } & Men & .77 & .59 & 139.93 & $.00 * * *$ & .23 & .05 & 5.13 & $.03 *$ \\
\hline & Women & .70 & .49 & 207.99 & $.00 * *$ & .30 & .09 & 20.98 & $.00 * * *$ \\
\hline \multirow[t]{2}{*}{ Black } & Men & .07 & .00 & .05 & .83 & .03 & .00 & .01 & .92 \\
\hline & Women & .60 & .36 & 10.21 & $.01 * *$ & .17 & .03 & .52 & .48 \\
\hline \multirow[t]{2}{*}{ Latinx } & Men & .60 & .36 & 9.52 & $.01 * *$ & .06 & .00 & .06 & .81 \\
\hline & Women & .55 & .30 & 27.19 & $.00 * * *$ & .07 & .01 & .34 & .56 \\
\hline \multirow[t]{2}{*}{ Asian } & Men & .50 & .25 & 21.01 & $.00 * *$ & .43 & .18 & 5.90 & $.02 *$ \\
\hline & Women & .74 & .55 & 33.18 & $.00 * *$ & .42 & .18 & 7.40 & $.01 * *$ \\
\hline
\end{tabular}

Table 12. Results from Equation 2 for each intersecting race and gender group.

\begin{tabular}{|c|c|c|c|c|c|c|c|c|c|c|c|c|}
\hline \multirow[b]{2}{*}{$\mathrm{R}$} & \multirow[b]{2}{*}{ Gen } & \multirow[b]{2}{*}{ Var } & \multicolumn{5}{|c|}{$\underline{\text { Support for BLM }}$} & \multicolumn{5}{|c|}{ Participation in Protests } \\
\hline & & & $B$ & $\begin{array}{c}S E \\
B\end{array}$ & $\beta$ & $t$ & $p$ & $B$ & $S E B$ & $\beta$ & $t$ & $p$ \\
\hline \multirow[t]{4}{*}{$\mathrm{W}$} & $\mathrm{M}$ & MR & -1.61 & .14 & -.88 & -11.83 & .00 & -.19 & .09 & -.23 & -2.26 & .03 \\
\hline & & $R^{2}$ & .59 & & & & & .05 & & & & \\
\hline & W & MR & -1.76 & 1.2 & -.70 & -14.42 & .00 & -.39 & .09 & -.30 & -4.58 & .00 \\
\hline & & $R^{2}$ & .49 & & & & & .09 & & & & \\
\hline \multirow[t]{4}{*}{ B } & $\mathrm{M}$ & MR & .19 & .88 & .07 & .22 & .83 & .09 & .87 & .03 & .10 & .92 \\
\hline & & $R^{2}$ & .00 & & & & & .00 & & & & \\
\hline & $\mathrm{W}$ & MR & -2.55 & .80 & -.60 & -3.20 & .00 & -1.17 & 1.61 & -.17 & -.73 & .48 \\
\hline & & $R^{2}$ & .36 & & & & & .03 & & & & \\
\hline \multirow[t]{4}{*}{$\mathrm{L}$} & $\mathrm{M}$ & MR & -1.23 & .40 & -.60 & -3.09 & .01 & -.05 & .19 & -.06 & -.24 & .81 \\
\hline & & $R^{2}$ & .36 & & & & & .00 & & & & \\
\hline & W & MR & -.79 & .15 & -.55 & -5.21 & .00 & .08 & .13 & .07 & .59 & .56 \\
\hline & & $R^{2}$ & .30 & & & & & .00 & & & & \\
\hline \multirow[t]{4}{*}{ A } & $\mathrm{M}$ & MR & -.69 & .23 & -.50 & -3.03 & .00 & .53 & .22 & .42 & 2.43 & .02 \\
\hline & & $R^{2}$ & .25 & & & & & .18 & & & & \\
\hline & W & MR & -1.23 & .19 & -.74 & -6.56 & .00 & -.33 & 1.23 & -.42 & -2.72 & .01 \\
\hline & & $R^{2}$ & .55 & & & & & .18 & & & & \\
\hline
\end{tabular}

Note. $\mathrm{R}=$ Race, $\mathrm{W}=$ White, $\mathrm{B}=$ Black, $\mathrm{L}=$ Latinx, $\mathrm{A}=$ Asian, $\mathrm{Gen}=$ Gender, $\mathrm{M}=\mathrm{Men}, \mathrm{W}=$ Women, $\mathrm{MR}=$ Modern racism 
Table 13. Model summaries for Equation 3 for each intersecting race and gender group.

\begin{tabular}{|c|c|c|c|c|c|c|c|c|c|}
\hline \multicolumn{2}{|c|}{ Group } & \multicolumn{4}{|c|}{ Support for BLM } & \multicolumn{4}{|c|}{ Participation in BLM } \\
\hline Race & Gender & $\mathrm{R}^{-}$ & $\mathrm{R}^{2}$ & $\mathrm{~F}$ & $p$ & $\mathrm{R}$ & $\mathrm{R}^{2}$ & $\mathrm{~F}$ & $p$ \\
\hline White & Men & .68 & .46 & 103.11 & $.00 * * *$ & .23 & .05 & 6.95 & $.00 * * *$ \\
\hline & Women & .69 & .48 & 110.45 & $.00 * * *$ & .23 & .05 & 6.52 & $.00 * * *$ \\
\hline Black & Men & .68 & .46 & 104.97 & $.00 * * *$ & .24 & .06 & 7.35 & $.00 * * *$ \\
\hline & Women & .68 & .46 & 103.29 & $.00 * * *$ & .32 & .10 & 13.59 & $.00 * * *$ \\
\hline Latinx & Men & .68 & .47 & 107.08 & $.00 * * *$ & .22 & .05 & 6.17 & $.00 * * *$ \\
\hline & Women & .68 & .46 & 103.33 & $.00 * * *$ & .23 & .05 & 6.76 & $.00 * * *$ \\
\hline Asian & Men & .68 & .46 & 105.19 & $.00 * * *$ & .23 & .05 & 6.70 & $.00 * * *$ \\
\hline & Women & .68 & .46 & 105.34 & $.00 * * *$ & .22 & .05 & 6.42 & $.00 * * *$ \\
\hline
\end{tabular}

*** $p<.001,{ }^{* *} p<.01,{ }^{*} p<.05$

Table 14. Results from Equation 3 for each intersecting race and gender group.

\begin{tabular}{|c|c|c|c|c|c|c|c|c|c|c|c|c|}
\hline \multirow[b]{2}{*}{$\mathrm{R}$} & \multirow[b]{2}{*}{ Gen } & \multirow[b]{2}{*}{ Var. } & \multicolumn{5}{|c|}{ Support for BLM } & \multicolumn{5}{|c|}{ Participation in Protests } \\
\hline & & & $B$ & $\begin{array}{c}S E \\
B\end{array}$ & $\beta$ & $t$ & $p$ & $B$ & $\begin{array}{c}S E \\
B\end{array}$ & $\beta$ & $t$ & $p$ \\
\hline \multirow[t]{10}{*}{ W } & $\mathrm{M}$ & RG & -.19 & .14 & -.05 & -1.35 & .18 & -.19 & .11 & -.09 & -1.76 & .08 \\
\hline & & $\mathrm{RC}$ & .09 & .03 & .11 & 2.88 & .00 & .05 & .02 & .11 & 2.19 & .03 \\
\hline & & RGxRC & -.05 & .08 & -.03 & -.64 & .53 & -.08 & .06 & -.08 & -1.34 & .19 \\
\hline & & MR & -1.35 & .07 & -.66 & -19.76 & .00 & -.21 & .05 & -.19 & -4.21 & .00 \\
\hline & & $R^{2}$ & .46 & & & & & .05 & & & & \\
\hline & $\mathrm{W}$ & $\mathrm{RG}$ & -.28 & .10 & -.10 & -2.75 & .01 & -.01 & .08 & -.01 & -.16 & .88 \\
\hline & & $\mathrm{RC}$ & .15 & .04 & .17 & 4.19 & .00 & .07 & .03 & .14 & 2.56 & .01 \\
\hline & & RGxRC & -.21 & .06 & -.14 & -3.45 & .00 & -.06 & .05 & -.08 & -1.35 & .18 \\
\hline & & MR & -1.38 & .07 & -.68 & -20.07 & .00 & -.22 & .05 & -.19 & -4.24 & .00 \\
\hline & & $R^{2}$ & .48 & & & & & .05 & & & & \\
\hline \multirow[t]{10}{*}{ B } & M & $\mathrm{RG}$ & -.09 & .40 & -.01 & -.23 & .82 & -.24 & .30 & -.05 & -.80 & .42 \\
\hline & & $\mathrm{RC}$ & .08 & .03 & .10 & 2.85 & .01 & .04 & .02 & .08 & 1.85 & .06 \\
\hline & & RGxRC & .42 & .21 & .09 & 2.00 & .05 & .33 & .16 & .12 & 2.12 & .03 \\
\hline & & MR & -1.37 & .07 & -.67 & -20.19 & .00 & -.23 & .05 & -.20 & -4.54 & .00 \\
\hline & & $R^{2}$ & .46 & & & & & .06 & & & & \\
\hline & $\mathrm{W}$ & $\mathrm{RG}$ & .46 & .36 & .06 & 1.27 & .20 & .78 & .26 & .18 & 2.98 & .00 \\
\hline & & $\mathrm{RC}$ & .09 & .03 & .10 & 2.98 & .00 & .02 & .02 & .04 & .99 & .32 \\
\hline & & RGxRC & -.05 & .16 & -.02 & -.33 & .75 & .13 & .12 & .07 & 1.14 & .25 \\
\hline & & MR & -1.35 & .07 & -.67 & -19.65 & .00 & -.18 & .05 & -.16 & -3.67 & .00 \\
\hline & & $R^{2}$ & .46 & & & & & .10 & & & & \\
\hline
\end{tabular}

$\mathrm{R}=$ Race, $\mathrm{W}=$ White, $\mathrm{B}=$ Black, $\mathrm{L}=$ Latinx, $\mathrm{A}=$ Asian, Gen $=$ Gender, $\mathrm{M}=$ Men, $\mathrm{W}=$ Women, Note . $\mathrm{MR}=$ modern racism (centered); $\mathrm{RG}=$ intersecting race and gender group (dummy coded); $\mathrm{RC}=$ racial centrality (centered); $\mathrm{RGRC}=\mathrm{RGxRC}$ interaction 
Table 14. (continued)

\begin{tabular}{|c|c|c|c|c|c|c|c|c|c|c|c|c|}
\hline \multirow[b]{2}{*}{$\mathrm{R}$} & \multirow[b]{2}{*}{ Gen } & \multirow[b]{2}{*}{ Var. } & \multicolumn{5}{|c|}{$\underline{\text { Support for BLM }}$} & \multicolumn{5}{|c|}{ Participation in Protests } \\
\hline & & & $B$ & $\begin{array}{c}S E \\
B\end{array}$ & $\beta$ & $t$ & $p$ & $B$ & $\begin{array}{c}S E \\
B\end{array}$ & $\beta$ & $t$ & $p$ \\
\hline \multirow[t]{10}{*}{$\mathrm{L}$} & \multirow[t]{5}{*}{$\mathrm{M}$} & RG & -.61 & .27 & -.08 & -2.27 & .02 & -.15 & .20 & -.03 & -.72 & .47 \\
\hline & & $\mathrm{RC}$ & .08 & .03 & .09 & 2.72 & .01 & .05 & .02 & .10 & 2.22 & .03 \\
\hline & & RGxRC & .39 & .13 & .11 & 2.94 & .00 & .01 & .10 & .01 & .13 & .90 \\
\hline & & MR & -1.35 & .07 & -.66 & -19.93 & .00 & -.22 & .05 & -.20 & -4.40 & .00 \\
\hline & & $R^{2}$ & .47 & & & & & .05 & & & & \\
\hline & \multirow[t]{5}{*}{$\mathrm{W}$} & RG & .26 & .19 & .06 & 1.35 & .18 & -.12 & .14 & -.05 & -.86 & .39 \\
\hline & & $\mathrm{RC}$ & .10 & .03 & .12 & 3.27 & .00 & .06 & .02 & .13 & 2.67 & .01 \\
\hline & & RGxRC & -.14 & .10 & -.06 & -1.37 & .17 & -.05 & .08 & -.04 & -.60 & .55 \\
\hline & & MR & -1.37 & .07 & -.68 & -20.19 & .00 & -.23 & .05 & -.20 & -4.57 & .00 \\
\hline & & $R^{2}$ & .46 & & & & & .05 & & & & \\
\hline \multirow[t]{10}{*}{ A } & \multirow[t]{5}{*}{$\mathrm{M}$} & RG & .56 & .22 & .09 & 2.52 & .01 & .26 & .17 & .08 & 1.57 & .12 \\
\hline & & $\mathrm{RC}$ & .10 & .03 & .11 & 3.31 & .00 & .05 & .02 & .10 & 2.28 & .02 \\
\hline & & $\mathrm{RGxRC}$ & -.11 & .12 & -.03 & -.85 & .40 & -.07 & .10 & -.04 & -.73 & .47 \\
\hline & & MR & -1.41 & .07 & -.70 & -20.19 & .00 & -.25 & .05 & -.22 & -4.75 & .00 \\
\hline & & $R^{2}$ & .46 & & & & & .05 & & & & \\
\hline & \multirow[t]{5}{*}{ W } & RG & .33 & .22 & .06 & 1.47 & .14 & -.20 & .17 & -.06 & -1.21 & .23 \\
\hline & & $\mathrm{RC}$ & .08 & .03 & .09 & 2.53 & .01 & .05 & .02 & .10 & 2.11 & .04 \\
\hline & & RGxRC & .12 & .12 & .04 & 1.07 & .29 & .06 & .09 & .04 & .72 & .47 \\
\hline & & MR & -1.38 & .07 & -.68 & -20.22 & .00 & -.22 & .05 & -.19 & -4.26 & .00 \\
\hline & & $R^{2}$ & .46 & & & & & .05 & & & & \\
\hline
\end{tabular}

Table 15. $z$-scores comparing the equality of coefficients for race and gender identity predicting modern racism in Equation 1 between intersecting race and gender groups.

\begin{tabular}{lrrrrrrr}
\hline Group & WM & WW & BM & BW & LM & LW & AM \\
\hline WW & $-3.33^{* * *}$ & & & & & & \\
BM & .28 & .50 & & & & & \\
BW & -1.34 & 1.56 & .17 & & & & \\
LM & -.19 & 1.71 & .59 & .66 & & & \\
LW & -.70 & $1.83^{+}$ & .43 & .47 & -.27 & & \\
AM & .66 & $3.13^{* *}$ & 1.15 & $1.68^{+}$ & .70 & 1.15 & \\
AW & .11 & $2.42^{*}$ & .84 & 1.23 & .30 & .65 & -.44 \\
\hline$* * *<<.001,{ }^{* *} p<.01,{ }^{*} p<.05,{ }^{+} p<.1$
\end{tabular}

Note. $\mathrm{WM}=$ White men, $\mathrm{WW}=$ White women, $\mathrm{BM}=$ Black men, $\mathrm{BW}$ = Black women, $\mathrm{LM}=$ Latino men, $\mathrm{LW}=$ Latina women, $\mathrm{AM}=$ Asian man, $\mathrm{AW}=$ Asian women 
Table 16. z-scores comparing the equality of coefficients for racial centrality predicting modern racism in Equation 1 between intersecting race and gender groups.

\begin{tabular}{lcllllll}
\hline Group & WM & WW & BM & BW & LM & LW & AM \\
\hline WW & $-4.24 * * *$ & & & & & & \\
BM & .35 & $4.60^{* * *}$ & & & & & \\
BW & -.79 & -.29 & -.83 & & & & \\
LM & .35 & $4.60^{* * *}$ & .00 & .83 & & & \\
LW & 1.41 & $6.36^{* * *}$ & 1.06 & .96 & 1.06 & & \\
AM & .00 & $4.24 * * *$ & -.35 & .79 & -.35 & -1.41 & \\
AW & .35 & $4.60^{* * *}$ & .00 & .83 & .00 & -1.06 & -.35 \\
\hline$p<.001, * * p<.01, * p<.05$ & & & & &
\end{tabular}

Note. $\mathrm{WM}=$ White men, $\mathrm{WW}=$ White women, $\mathrm{BM}=$ Black men, $\mathrm{BW}=$ Black women, $\mathrm{LM}=$ Latino men, $\mathrm{LW}=$ Latina women, $\mathrm{AM}=\mathrm{Asian}$ man, $\mathrm{AW}=$ Asian women

Table 17. z-scores comparing the equality of coefficients for the interaction of race and gender identity and racial centrality predicting modern racism in Equation 1 between intersecting race and gender groups.

\begin{tabular}{llllllll}
\hline Group & WM & WW & BM & BW & LM & LW & AM \\
\hline WW & .16 & & & & & & \\
BM & -.47 & -.55 & & & & & \\
BW & -.37 & -.67 & .35 & & & & \\
LM & $-1.65^{+}$ & $-1.83^{+}$ & -.60 & -1.63 & & & \\
LW & $-2.67^{* *}$ & $-2.98^{* *}$ & -1.02 & $-2.88^{* *}$ & -.53 & & \\
AM & $-1.80^{+}$ & $-2.01^{*}$ & -.62 & $-1.82^{+}$ & .00 & .56 & \\
AW & $-2.23^{*}$ & $-2.46^{*}$ & -.87 & $-2.30^{+}$ & .50 & .10 & -.36 \\
\hline$* * * p<.001,{ }^{* *} p<.01, * p<.05,^{+} p<.1$ & & & &
\end{tabular}

Note. $\mathrm{WM}=$ White men, $\mathrm{WW}=$ White women, $\mathrm{BM}=$ Black men, $\mathrm{BW}=$ Black women, $\mathrm{LM}=$ Latino men, $\mathrm{LW}=$ Latina women, $\mathrm{AM}=$ Asian man, $\mathrm{AW}=$ Asian women

Table 18. z-scores comparing the equality of coefficients for modern racism predicting support for protests and the Black Lives Matter movement in Equation 2 between intersecting race and gender groups.

\begin{tabular}{lrrrrrrr}
\hline Group & WM & WW & BM & BW & LM & LW & AM \\
\hline WW & .15 & & & & & & \\
BM & 1.07 & -.42 & & & & & \\
BW & .35 & .07 & -.56 & & & & \\
LM & .66 & .08 & -.69 & .00 & & & \\
LW & .07 & .18 & -.54 & .06 & .12 & & \\
AM & 1.33 & .16 & -.63 & .12 & .22 & .18 & \\
AW & .59 & -.03 & -.90 & -.17 & -.32 & -.78 & -.80 \\
\hline
\end{tabular}

No differences were found to be significant.

Note. $\mathrm{WM}=$ White men, $\mathrm{WW}=$ White women, $\mathrm{BM}=$ Black men, $\mathrm{BW}=$ Black women, $\mathrm{LM}=$ Latino men, $\mathrm{LW}=$ Latina women, $\mathrm{AM}=$ Asian man, $\mathrm{AW}=$ Asian women 
Table 19. z-scores comparing the equality of coefficients for modern racism predicting participation in protests and the Black Lives Matter movement in Equation 2 between intersecting race and gender groups.

\begin{tabular}{lccccccc}
\hline Group & WM & WW & BM & BW & LM & LW & AM \\
\hline WW & -.55 & & & & & & \\
BM & .30 & .37 & & & & & \\
BW & .04 & .08 & -.11 & & & & \\
LM & .81 & 1.14 & -.03 & .07 & & & \\
LW & $1.90^{+}$ & 1.61 & .05 & .15 & .56 & & \\
AM & $2.73^{* *}$ & $2.48^{*}$ & .43 & .36 & $1.65^{+}$ & 1.37 & \\
AW & -.15 & -.10 & -.30 & -.12 & -.29 & -.40 & .00 \\
\hline
\end{tabular}

$* * * p<.001, * * p<.01, * p<.05,{ }^{+} p<.1$

Note. $\mathrm{WM}=$ White men, $\mathrm{WW}=$ White women, $\mathrm{BM}=$ Black men, $\mathrm{BW}=$ Black women, $\mathrm{LM}=$ Latino men, $\mathrm{LW}=$ Latina women, $\mathrm{AM}=$ Asian man, $\mathrm{AW}=\mathrm{Asian}$ women

Table 20. z-scores comparing the equality of coefficients for race and gender identity predicting support for protests and the Black Lives Matter movement in Equation 3 between intersecting race and gender groups.

\begin{tabular}{lccccccc}
\hline Group & WM & WW & BM & BW & LM & LW & AM \\
\hline WW & -.29 & & & & & & \\
BM & .09 & .22 & & & & & \\
BW & .28 & .43 & .13 & & & & \\
LM & -.10 & .07 & -.15 & -.31 & & & \\
LW & .47 & .75 & .16 & .00 & .42 & & \\
AM & .54 & .79 & .22 & .07 & .49 & -.10 & \\
AW & .42 & .66 & .15 & .00 & .40 & .00 & -.10 \\
\hline
\end{tabular}

No differences were found to be significant.

Note. $\mathrm{WM}=$ White men, $\mathrm{WW}=$ White women, $\mathrm{BM}=$ Black men, $\mathrm{BW}=$ Black women, $\mathrm{LM}=$ Latino men, $\mathrm{LW}=$ Latina women, $\mathrm{AM}=$ Asian man, $\mathrm{AW}=$ Asian women

Table 21. z-scores comparing the equality of coefficients for racial centrality predicting support for protests and the Black Lives Matter movement in Equation 3 between intersecting race and gender groups.

\begin{tabular}{lrrrrrrr}
\hline Group & WM & WW & BM & BW & LM & LW & AM \\
\hline WW & 1.20 & & & & & & \\
BM & -.24 & -1.40 & & & & & \\
BW & -.24 & -1.40 & .00 & & & & \\
LM & -.47 & -1.60 & .24 & .24 & & & \\
LW & .24 & -1.00 & -.82 & -.82 & 1.24 & & \\
AM & .00 & 1.20 & -.41 & -.41 & .82 & .71 & \\
AW & -.47 & -1.60 & .24 & .24 & .00 & 1.24 & .82 \\
\hline
\end{tabular}

No differences were found to be significant.

Note. $\mathrm{WM}=$ White men, $\mathrm{WW}=$ White women, $\mathrm{BM}=$ Black men, $\mathrm{BW}=$ Black women, $\mathrm{LM}=$ Latino men, $\mathrm{LW}=$ Latina women, $\mathrm{AM}=$ Asian man, $\mathrm{AW}=$ Asian women 
Table 22. z-scores comparing the equality of coefficients for the interaction of race and gender identity and racial centrality predicting support for protests and the Black Lives Matter movement in Equation 3 between intersecting race and gender groups.

\begin{tabular}{lrrrrrrr}
\hline Grou & WM & WW & BM & BW & LM & LW & AM \\
\hline WW & -.90 & & & & & & \\
BM & .22 & 1.05 & & & & & \\
BW & .06 & .12 & -.42 & & & & \\
LM & .92 & $1.75^{+}$ & .08 & .63 & & & \\
LW & -.24 & .69 & -.64 & -.21 & -1.04 & & \\
AM & .00 & .82 & -.50 & -.05 & -.79 & .19 & \\
AW & .49 & 1.34 & -.21 & .30 & -.40 & .64 & .41 \\
\hline$* * *<.001,{ }^{* *} p<.01,{ }^{*} p<.05,^{+} p<.1$ & & &
\end{tabular}

Note. $\mathrm{WM}=$ White men, $\mathrm{WW}=$ White women, $\mathrm{BM}=$ Black men, $\mathrm{BW}=$ Black women, $\mathrm{LM}=$ Latino men, $\mathrm{LW}=$ Latina women, $\mathrm{AM}$

$=$ Asian man, $\mathrm{AW}=$ Asian women

Table 23. z-scores comparing the equality of coefficients for modern racism predicting support for protests and the Black Lives Matter movement in Equation 3 between intersecting race and gender groups.

\begin{tabular}{lrrrrrrr}
\hline Group & WM & WW & BM & BW & LM & LW & AM \\
\hline WW & -.20 & & & & & & \\
BM & -.10 & .10 & & & & & \\
BW & -.10 & .10 & .00 & & & & \\
LM & .00 & .20 & .10 & .10 & & & \\
LW & -.20 & .00 & -.10 & -.10 & -.20 & & \\
AM & -.40 & -.20 & -.30 & -.30 & -.40 & -.20 & \\
AW & -.20 & .00 & -.10 & -.10 & -.20 & .00 & .20 \\
\hline
\end{tabular}

No differences were found to be significant.

Note. $\mathrm{WM}=$ White men, $\mathrm{WW}=$ White women, $\mathrm{BM}=$ Black men, $\mathrm{BW}=$ Black women, $\mathrm{LM}=$ Latino men, $\mathrm{LW}=$ Latina women, $\mathrm{AM}=\mathrm{Asian}$ man, $\mathrm{AW}=$ Asian women

Table 24. z-scores comparing the equality of coefficients for race and gender identity predicting participation in protests and the Black Lives Matter movement in Equation 3 between intersecting race and gender

\begin{tabular}{|c|c|c|c|c|c|c|c|}
\hline Group & WM & WW & BM & BW & LM & LW & $\mathrm{AM}$ \\
\hline WW & .59 & & & & & & \\
\hline BM & .13 & -.13 & & & & & \\
\hline BW & .96 & .70 & .58 & & & & \\
\hline LM & .26 & -.09 & .06 & -.64 & & & \\
\hline LW & .22 & -.25 & .00 & -.78 & -.08 & & \\
\hline AM & .84 & .48 & .38 & -.32 & .42 & .59 & \\
\hline AW & .15 & -.27 & -.15 & -.77 & -.11 & -.05 & -.58 \\
\hline
\end{tabular}

No differences were found to be significant.

Note. $\mathrm{WM}=$ White men, $\mathrm{WW}=$ White women, $\mathrm{BM}=$ Black men, $\mathrm{BW}=$ Black women, $\mathrm{LM}=$ Latino men, $\mathrm{LW}=$ Latina women, $\mathrm{AM}=$ Asian man, $\mathrm{AW}=$ Asian women 
Table 25. z-scores comparing the equality of coefficients for racial centrality predicting participation in protests and the Black Lives Matter movement in Equation 3 between intersecting race and gender groups.

\begin{tabular}{lccccccc}
\hline Group & WM & WW & BM & BW & LM & LW & AM \\
\hline WW & .83 & & & & & & \\
BM & -1.06 & $-1.66^{+}$ & & & & & \\
BW & $-2.47^{*}$ & $-2.77^{* *}$ & -1.41 & & & & \\
LM & -.35 & -1.11 & .71 & $2.12^{*}$ & & & \\
LW & .71 & -.28 & $1.77 *$ & $3.18^{* *}$ & 1.06 & & \\
AM & -.35 & -1.11 & .71 & $2.12^{*}$ & .00 & -1.06 & \\
AW & -.35 & -1.11 & .71 & $2.12^{*}$ & .00 & -1.06 & .00 \\
\hline$* * *<001, * * p<01 *^{*} p<05^{+} p<1$ & & & &
\end{tabular}

$* * * p<.001, * * p<.01, * p<.05,{ }^{+} p<.1$

Note. $\mathrm{WM}=$ White men, $\mathrm{WW}=$ White women, $\mathrm{BM}=$ Black men, $\mathrm{BW}=$ Black women, $\mathrm{LM}=$ Latino men, $\mathrm{LW}=$ Latina women, $\mathrm{AM}=$ Asian man, $\mathrm{AW}=$ Asian women

Table 26. z-scores comparing the equality of coefficients for the interaction of race and gender identity and racial centrality predicting participation in protests and the Black Lives Matter movement in Equation 3 between intersecting race and gender groups.

\begin{tabular}{lrrrrrrr}
\hline Group & WM & WW & BM & BW & LM & LW & AM \\
\hline WW & .00 & & & & & & \\
BM & 1.17 & 1.19 & & & & & \\
BW & 1.12 & 1.15 & -.25 & & & & \\
LM & .77 & 1.34 & -.58 & -.38 & & & \\
LW & .35 & .42 & -.89 & -.76 & -.39 & & \\
AM & .34 & .36 & -.85 & -.51 & -.35 & .00 & \\
AW & 1.11 & 1.17 & -.32 & -.20 & .22 & -.66 & -.59 \\
\hline
\end{tabular}

No differences were found to be significant.

Note. $\mathrm{WM}=$ White men, $\mathrm{WW}=$ White women, $\mathrm{BM}=$ Black men, $\mathrm{BW}=$ Black women, $\mathrm{LM}=$ Latino men, $\mathrm{LW}=$ Latina women, $\mathrm{AM}=$ Asian man, $\mathrm{AW}=$ Asian women

Table 27. z-scores comparing the equality of coefficients for modern racism predicting participation in protests and the Black Lives Matter movement in Equation 3 between intersecting race and gender groups.

\begin{tabular}{lrrrrrrr}
\hline Group & WM & WW & BM & BW & LM & LW & AM \\
\hline WW & .00 & & & & & & \\
BM & -.14 & -.14 & & & & & \\
BW & .42 & .42 & .57 & & & & \\
LM & -.14 & -.14 & .00 & -.57 & & & \\
LW & -.14 & -.14 & .00 & -.57 & .00 & & \\
AM & -.42 & -.42 & -.28 & -.85 & .28 & .28 & \\
AW & .00 & .00 & .14 & -.42 & -.14 & -.14 & .42 \\
\hline
\end{tabular}

No differences were found to be significant.

Note. $\mathrm{WM}=$ White men, $\mathrm{WW}=$ White women, $\mathrm{BM}=$ Black men, $\mathrm{BW}=$ Black women, $\mathrm{LM}=$ Latino men, $\mathrm{LW}=$ Latina women, $\mathrm{AM}=$ Asian man, $\mathrm{AW}=$ Asian women 
Table 28. Means and bivariate correlations between variables

\begin{tabular}{llrlrl}
\hline & Mean & SD & MR & RC & SUP \\
\hline MR & 1.66 & .72 & 1.00 & & \\
RC & 4.19 & 1.73 & .06 & 1.00 & \\
SUP & 5.12 & 1.46 & $-.67 * * *$ & .07 & 1.00 \\
PAR & 1.43 & .82 & $-.20 * * *$ & .09 & $.39 * * *$ \\
\hline$* * p<.001, * * p<.01, * p<.05$ & & &
\end{tabular}

Note $. \mathrm{MR}=$ Modern racism, $\mathrm{RC}=$ Racial centrality, $\mathrm{SUP}=$ Support for protests \& BLM, PAR $=$ Participation in protests \& BLM 
Figures

Figure 1. Racial group differences in support for protests and the Black Lives Matter Movement (Hypothesis 1a).

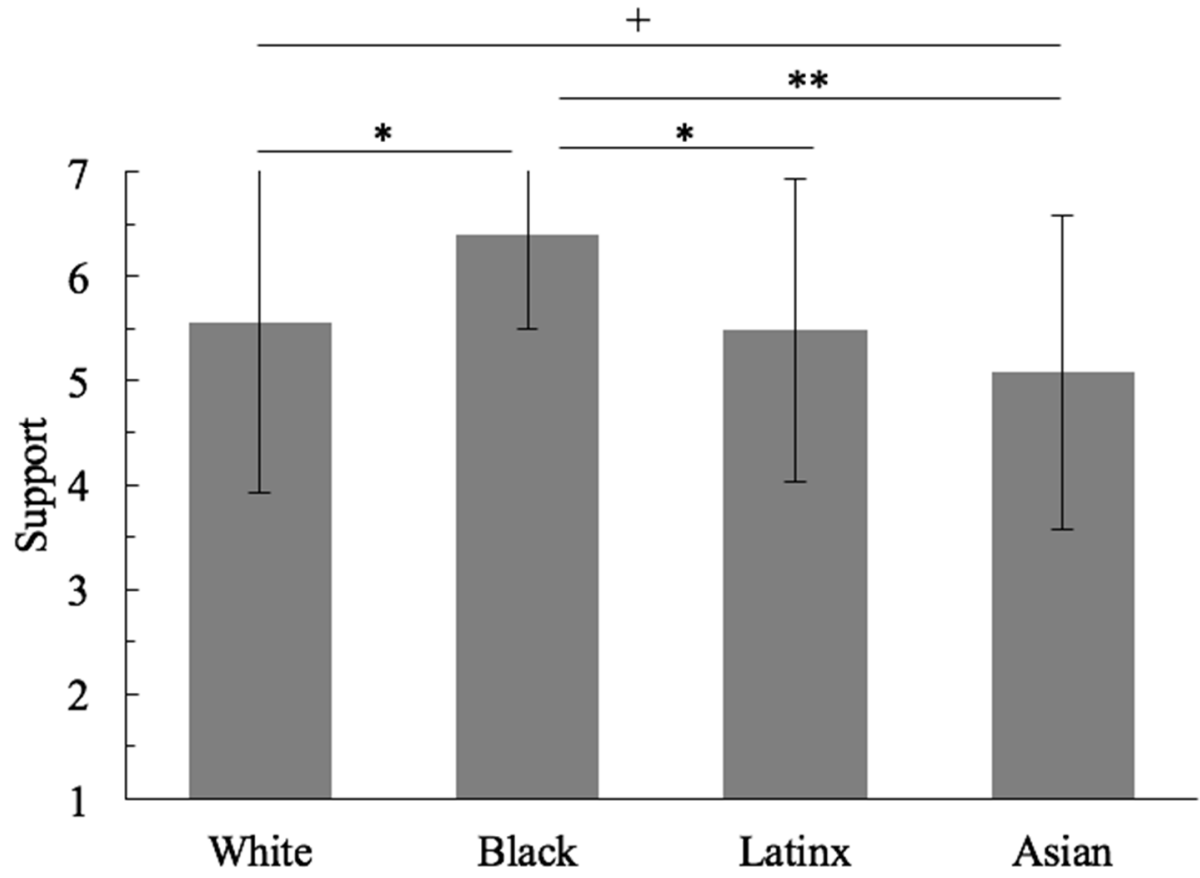

$* * *$ Significant at the $p=.001$ level, **Significant at the $p=.01$ level, ${ }^{*}$ Significant at the $p=.05$ level, ${ }^{+}$Marginally significant 
Figure 2. Racial group differences in participation in protests and the Black Lives Matter movement (Hypothesis 1a).

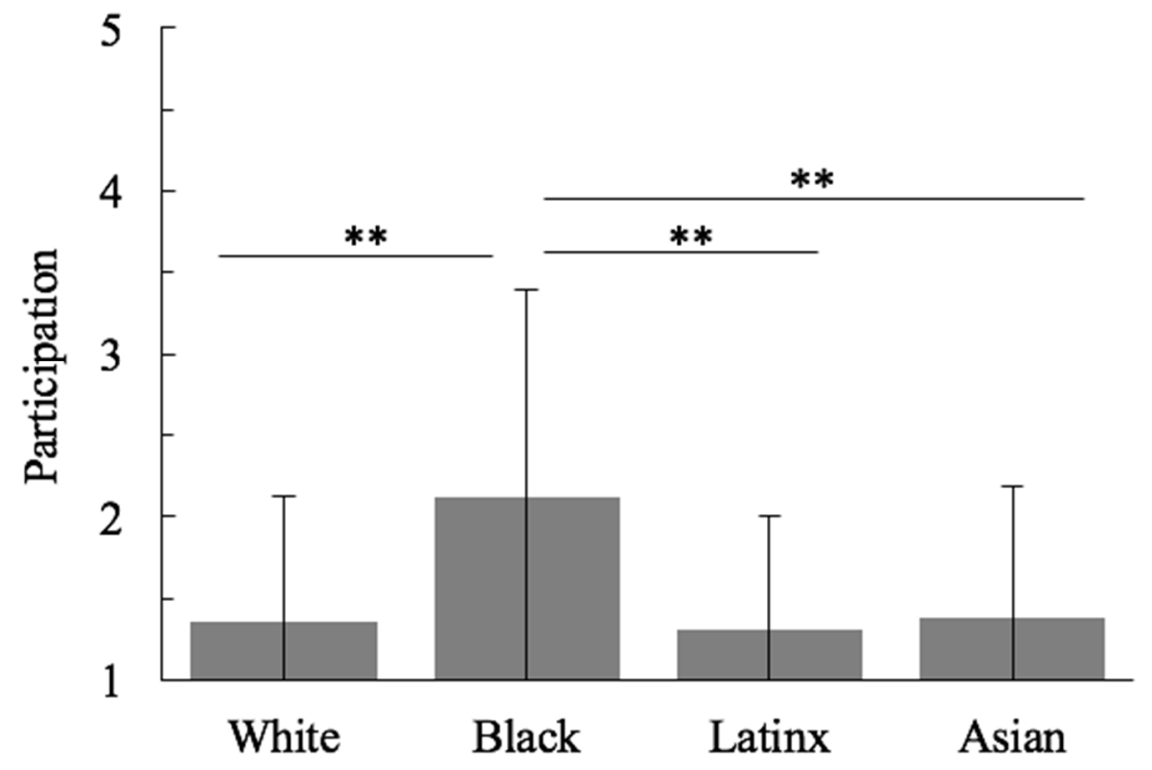

*** Significant at the $p=.001$ level, **Significant at the $p=.01$ level, $*$ Significant at the $p=.05$ level 
Figure 3. Racial group differences in support for protests and the Black Lives Matter movement (Hypothesis 1a).

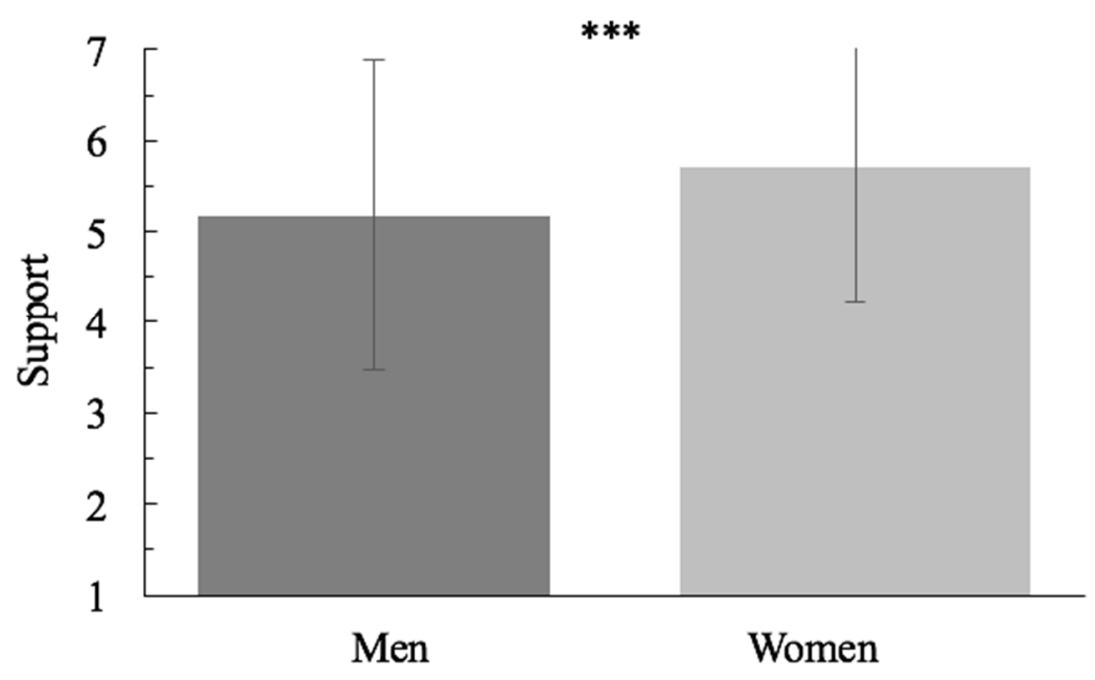

$* * *$ Significant at the $p=.001$ level, **Significant at the $p=.01$ level, *Significant at the $p=.05$ level, ${ }^{+}$Marginally significant 
Figure 4. Gender group differences in participation in protests and the Black Lives Matter movement (Hypothesis 1a).

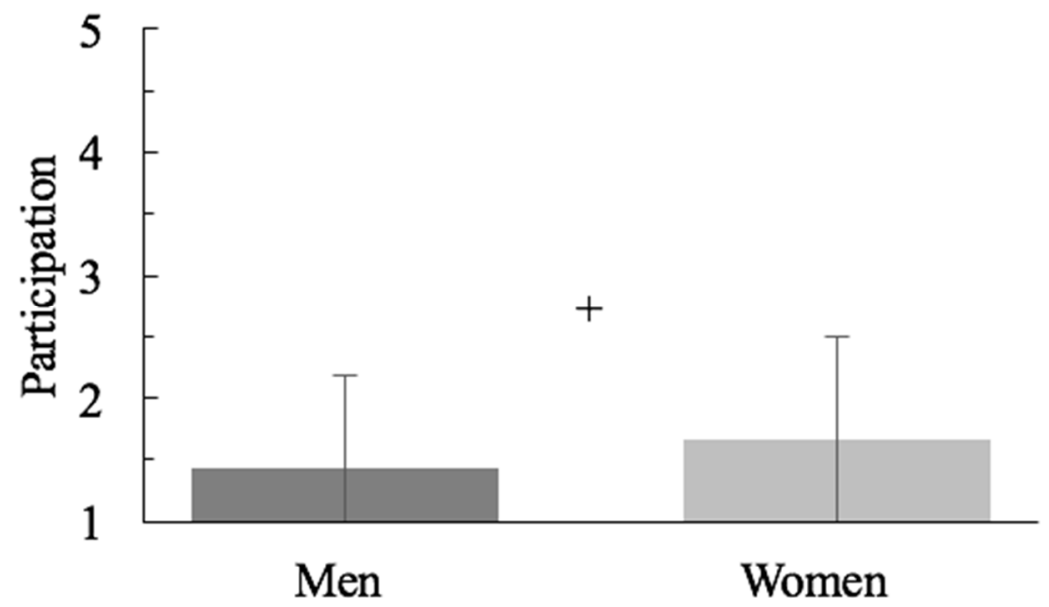

$* * *$ Significant at the $p=.001$ level, $* *$ Significant at the $p=.01$ level, ${ }^{*}$ Significant at the $p=.05$ level, ${ }^{+}$Marginally significant 
Figure 5. Intersecting racial and gender differences in support for protests and the Black Lives Matter movement (Hypothesis 1b).

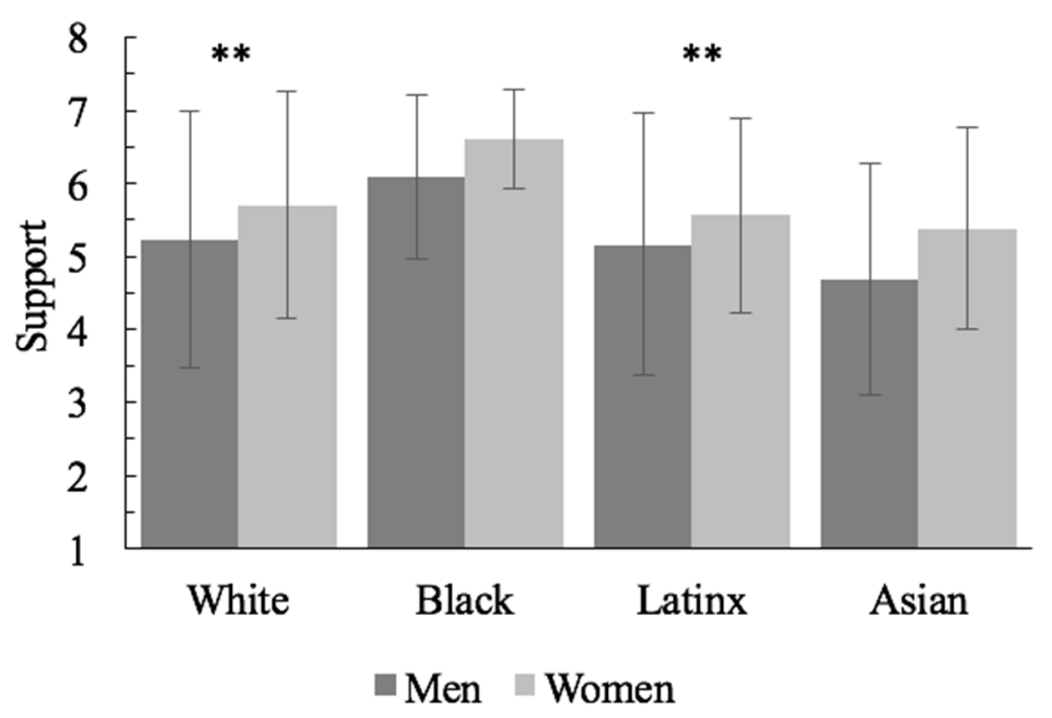

*** Significant at the $p=.001$ level, **Significant at the $p=.01$ level, *Significant at the $p=.05$ level 
Figure 6. Intersecting racial and gender differences in participation in protests and the Black Lives Matter movement (Hypothesis 1b).

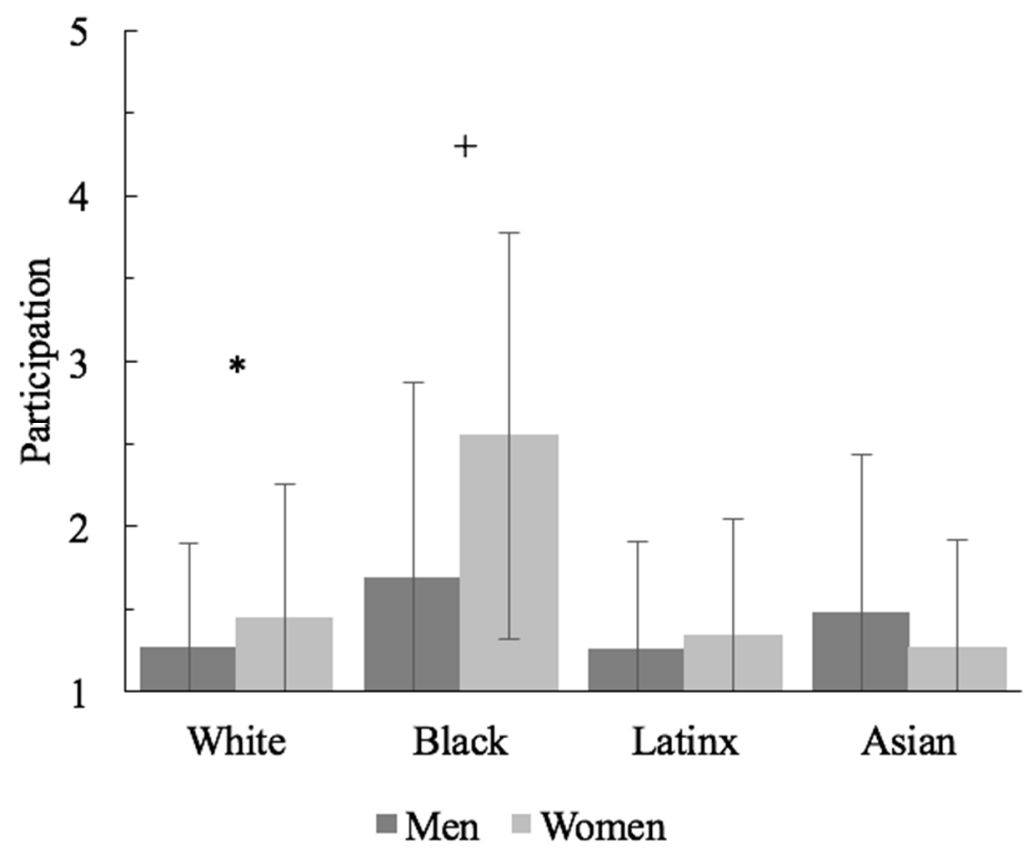

Significant at the $p=.001$ level, ${ }^{* *}$ Significant at the $p=.01$ level, *Significant at the $p=.05$ level, ${ }^{+}$Marginally significant 
References

Aboud, F. E., \& Fenwick, V. (1999). Exploring and Evaluating School-Based Interventions to Reduce Prejudice. Journal of Social Issues, 55(4), 767-785. http://doi.org/10.1111/0022-4537.00146

Ajzen, I., \& Fishbein, M. (2005). The influence of attitudes on behavior. In The Handbook of Attitudes (pp. 173-221).

Akfirat, S., Polat, F. Ç., \& Yetim, U. (2016). How the poor deal with their own poverty: A social psychological analysis from the Social Identity perspective. Social Indicators Research, 127(1), 413-433. doi: 10.1007/s11205-015-0953-2

Alexander, M. (2010). The new Jim Crow: Mass incarceration in the age of colorblindness. New York, NY: The New Press

Allport, G. W. (1954). The nature of prejudice. Cambridge/Reading, MA: Addison Wesley.

Apfelbaum, E. P., Grunberg, R., Halevy, N., \& Kang, S. (2016). From ignorance to intolerance: Perceived intentionality of racial discrimination shapes preferences for colorblindness versus multiculturalism. Journal of Experimental Social Psychology. doi: 10.1016/j.jesp.2016.08.002

Aron, A., Aron E. N., \& Smollan, D. (1992). Inclusion of other in the self scale and the structure of interpersonal closeness. Journal of Personality and Social Psychology, 63, 596-612. 
Arpan, L. M., Baker, K., Lee, Y., Jung, T., Lorusso, L., \& Smith, J. (2006). News coverage of social protests and the effects of photographs and prior attitudes. Mass Communication \& Society, 9(1), 1-20. doi: 10.1207/s15327825mcs0901_1

Asian Pacific American Labor Alliance (APALA). (2016). Over 100 organizations sign on to joint statement for AAPI solidarity with \#BlackLivesMatter and the Movement for Black Lives [Press release]. Retrieved from http://www.apalanet.org/press-releases/over-100-organizations-sign-on-to-jointstatement-for-aapi-solidarity-with-blacklivesmatter-and-the-movement-for-blacklives

Awad, G. H., Cokley, K., \& Ravitch, J. (2005). Attitudes toward affirmative action: A comparison of color-blind versus modern racist attitudes. Journal of Applied Social Psychology, 35(7), 1384-1399. doi: 10.1111/j.1559-1816.2005.tb02175.x

Bakanic, V. (2008). Prejudice: Attitudes about race, class, and gender. Pearson/Prentice Hall.

Barnett, B. M. (1993). Invisible southern black women leaders in the civil rights movement: The triple constraints of gender, race, and class. Gender \& Society, 7(2), 162-182. doi: 10.1177/089124393007002002

Beale, F. (1970). Double jeopardy: To be Black and female. The Black Woman: An Anthology. doi: 10.2979/MER.2008.8.2.166

Becker, H. S. (1974). Art as collective action. American Sociological Review, 39(6), 767776. doi: $10.2307 / 2094151$ 
Becker, J. C., Barreto, M., Kahn, K. B., \& de Oliveira Laux, S. H. (2015). The collective value of "me" (and it's limitations): Towards a more nuanced understanding of individual and collective coping with prejudice. Journal of Social Issues, 71(3), 497-516. doi: 10.1111/josi.12125

Becker, J. C., Wright, S. C., Lubensky, M. E., \& Zhou, S. (2013). Friend or ally: Whether cross-group contact undermines collective action depends on what advantaged group members say (or don’t say). Personality \& Social Psychology Bulletin, 39(4), 442-55. doi: 10.1177/0146167213477155

Benjamin, L. T. (1993). A history of psychology in letters. Dubuque, IA: Brown \& Benchmark.

Bhavnani, K. K., \& Davis, A. Y. (1989). Complexity, activism, optimism: An interview with Angela Y. Davis. Feminist Review, (31), 66-81.

Black Lives Matter. (2017). Black Lives Matter: Guiding Principles. Retrieved January, 2017, from http://blacklivesmatter.com/about/

Blatz, C. W., \& Ross, M. (2009). Principled ideology or racism: Why do modern racists oppose race-based social justice programs? Journal of Experimental Social Psychology, 45(1), 258-261. doi: 10.1016/j.jesp.2008.08.008

Blume, A. W., Lovato, L. V., Thyken, B. N., \& Denny, N. (2012). The relationship of microaggressions with alcohol use and anxiety among ethnic minority college students in a historically White institution. Cultural Diversity and Ethnic Minority Psychology, 18(1), 45-54. 
Bobo, L., \& Hutchings, V. L. (1996). Perceptions of racial group competition: Extending Blumer's Theory of Group Position to a multiracial social context. American Sociological Review, 61(6), 951. doi: 10.2307/2096302

Bowleg, L. (2008). When Black + Lesbian + Woman $\neq$ Black Lesbian Woman: The methodological challenges of qualitative and quantitative intersectionality research. Sex Roles, 59(5-6), 312-325. doi: 10.1007/s11199-008-9400-z

Brady, H. E., Verba, S., \& Schlozman, K. L. (1995). Beyond SES: A Resource model of political participation. The American Political Science Review, 89(2), 271-294. doi: $10.2307 / 2082425$

Branscombe, N. R., \& Ellemers, N. (1998). Coping with group-based discrimination: Individualistic versus group-level strategies. In J. K. Swim \& C. Stangor (Eds.), Prejudice: The target's perspective (pp. 243-266). San Diego, CA: Academic Press

Brandt, D. E., \& Markus, K. A. (2000). Adolescent attitudes towards the police: A new generation. Journal of Police and Criminal Psychology, 15, 10-16. doi: $10.1007 / \mathrm{BF} 02802653$

Breines, W. (2002). What's love got to do with it? White women, Black women, and feminism in the movement years. Signs, 27(4), 1095-1133.

Brief, A., Dietz, J., Cohen, R., Pugh, S., \& Vaslow, J. (2000). Just doing business: Modern racism and obedience to authority as explanations for employment discrimination. Organizational Behavior and Human Decision Processes, 81(1), 72-97. doi: 10.1006/obhd.1999.2867 
Brown, E. (1992). A taste of power: A Black woman's story. New York: Pantheon Books.

Brown, K. T., \& Ostrove, J. M. (2013). What does it mean to be an ally?: The perception of allies from the perspective of people of color. Journal of Applied Social Psychology, 43(11), 2211-2222.

Bruyneel, K. (2004). Challenging American boundaries: Indigenous people and the "gift" of U.S. citizenship. Studies in American Political Development, 18(1), 30-43. Retrieved from http://search.proquest.com/docview/205468786?accountid=49533 LA - English

Carter, J. S., \& Corra, M. (2016). Racial resentment and attitudes toward the use of force by police: An over-time trend analysis. Sociological Inquiry, 86(4), 492-511. doi: 10.1111/soin. 12136

Case, K. A. (2007). Raising White Privilege awareness and reducing racial prejudice: Assessing diversity course effectiveness. Teaching of Psychology, 34(4), 231235. doi: $10.1080 / 00986280701700250$

Case, K. A. (2012). Discovering the privilege of Whiteness: White women's reflections on anti-racist identity and ally behavior. Journal of Social Issues, 68(1), 78-96. doi: $10.1111 / \mathrm{j} .1540-4560.2011 .01737 . x$

Cheema, J. R. (2014). Some general guidelines for choosing missing data handling methods in educational research. Journal of Modern Applied Statistical Methods, $13(2), 53-75$. 
Cheng, A. W., Iwamoto, D. K., \& McMullen, D. (2016). Model minority stereotype and the diagnosis of alcohol use disorders: Implications for practitioners working with Asian Americans. Journal of Ethnicity in Substance Abuse, 1-18. doi:

$10.1080 / 15332640.2016 .1175990$

Chun, J. J., Lipsitz, G., \& Shin, Y. (2013). Intersectionality as a social movement strategy: Asian immigrant women advocates. Signs: Journal of Women in Culture and Society, 38(4), 917-940. doi: 10.1017/CBO9781107415324.004

Clogg, C. C., Petkova, E., \& Haritou, A. (1995). Statistical methods for comparing regression coefficients between models. American Journal of Sociology, 100(5), 1261-1293. doi: 10.1086/230638

Cole, E. R. (2009). Intersectionality and research in psychology. American Psychologist, 64(3), 170-180. doi: 10.1037/a0014564

Collins, P. H. (1989). The social construction of Black Feminist Thought. Signs: Journal of Women in Culture and Society, 14(4), 745-773. h doi: 10.1086/494543

Collins, P. H. (2002). Black feminist thought: Knowledge, consciousness, and the politics of empowerment. New York: Routledge.

Collins, C. W. (2004). The Fourteenth Amendment and the States: A study of the Operation of the Restraint Clauses of section one of the fourteenth amendment to the constitution of the United States. The Lawbook Exchange, Ltd.

Commons, J. R., \& Parsons, K. H. (1950). Economics of collective action. New York: Macmillan 
Condor, S. (1986). Sex role beliefs and "traditional" women: Feminist and intergroup perspectives. Feminist Social Psychology: Developing Theory and Practice, 97118.

Contrada, R., Ashmore, R., Gary, M. L., Coups, E., Egeth, J., Sewell, A., ... Chase, V. (2001). Measures of ethnicity-related stress: Psychometric properties, ethnic group differences, and associations with well-being. Journal of Applied Social Psychology, 31, 1775-1820. doi: 10.1111/j.1559-1816.2001.tb00205.x

Craig, M. A., \& Richeson, J. A. (2011). Coalition or derogation? How perceived discrimination influences intraminority intergroup relations. Journal of Personality and Social Psychology, 102(4), 759-777. doi: 10.1037/a0026481

Craig, M., \& Richeson, J. (2014). Discrimination divides across identity dimensions: Perceived racism reduces support for gay rights and increases anti-gay bias. Journal of Experimental Social Psychology, 55, 169-175.

Crenshaw, K. (1989). Demarginalizing the intersection of race and sex: A Black feminist critique of antidiscrimination doctrine, feminist theory and antiracist policies. The University of Chicago Legal Forum, 1989(1), 139-167. http://doi.org/10.1525/sp.2007.54.1.23.

Crosby, F. (1976). A model of egoistical relative deprivation. Psychological Review, 83(2), 85-113. doi: 10.1037/0033-295x.83.2.85

Curtin, N., Kende, A., \& Kende, J. (2016). Navigating multiple identities: The simultaneous influence of advantaged and disadvantaged identities on 
politicization and activism. Journal of Social Issues, 72(2), 264-285. doi: 10.1111/josi.12166

Czopp, A., \& Monteith, M. (2003). Confronting prejudice (literally): Reactions to confrontations of racial and gender bias. Personality and Social Psychology Bulletin,29(4), 532-544.

Dalbert, C., Montada, L., \& Schmitt, M. (1987). Glaube an eine gerechte Welt als Motiv: Validierungskorrelate zweier Skalen [The belief in a just world as a motive: Validity correlates of two scales]. Psychologische Beiträge, 29(4), 596-615. doi: 10.1007/BF01937162

Dawson, M. C. (1994). Behind the mule: Race and class in African American politics. Princeton, NJ: Princeton University Press.

DeNavas-Walt, C., \& Proctor, B. D. (2015). Income and poverty in the United States: 2014 (Rep.). Retrieved August 16, 2016, from U.S. Census Bureau website: http://www.census.gov/content/dam/Census/library/publications/2015/demo/p60252.pdf

Dépret, E., \& Fiske, S. T. (1993). Social cognition and power: Some cognitive consequences of social structure as a source of control deprivation. In G. Weary, F. Gleicher, \& K. L. Marsh (Eds.), Control Motivation and Social Cognition (pp. 176-202). Springer New York. doi: 10.1007/978-1-4613-8309-3_7

DeTurk, S. (2011). Allies in action: The communicative experiences of people who challenge social injustice on behalf of others. Communication Quarterly, 59(5), 569-590. doi: 10.1080/01463373.2011.614209 
Dixon, J., Durrheim, K., Thomae, M., Tredoux, C., Kerr, P., \& Quayle, M. (2015).

Divide and rule, unite and resist: Contact, collective action and policy attitudes among historically disadvantaged groups. Journal of Social Issues, 71(3), 576596. doi: $10.1111 /$ josi.12129

Dollarhide, C. T., Clevenger, A., Dogan, S., \& Edwards, K. (2016). Social justice identity: A phenomenological study. Journal of Humanistic Psychology, 56(6), 624-645. doi: 10.1177/0022167816653639

Doss, E. (1999). "Revolutionary art is a tool for liberation": Emory Douglas and protest aesthetics at the Black Panther. New Political Science, 21(2), 245-259.

Droogendyk, L., Wright, S. C., Lubensky, M., \& Louis, W. R. (2016). Acting in solidarity: Cross-group contact between disadvantaged group members and advantaged group allies. Journal of Social Issues, 72(2), 315-334. doi: 10.1111/josi.12168

Edwards, J. R., \& Lambert, L. S. (2007). Methods for integrating moderation and mediation: A general analytical framework using moderated path analysis. Psychological Methods, 12(1), 1-22. doi: 10.1037/1082-989X.12.1.1

Ekehammar Akrami, N., Gylje, M., Zakrisson, I., B. (2004). What matters most to prejudice: Big Five Personality, Social Dominance Orientation, or Right-Wing Authoritarianism? European Journal of Personality, 18(6), 463-482.

Elephrame. (2017). At least 1892 Black Lives Matter demonstrations have been held in the last 824 days. (Downloaded January, 2017 from https://elephrame.com/textbook/protests). 
Ellemers, N., \& Barreto, M. (2009). Collective action in modern times: How modern expressions of prejudice prevent collective action. Journal of Social Issues, 65, $749-768$.

Esses, V. M., Dovidio, J. F., Jackson, L. M., \& Armstrong, T. L. (2001). The Immigration Dilemma: The role of perceived group competition, ethnic prejudice, and national identity. Journal of Social Issues, 57(3), 389-412.

Fiske, S. T., Cuddy, A. J. C., Glick, P., \& Xu, J. (2002). A model of (often mixed) stereotype content: Competence and warmth respectively follow from perceived status and competition. Journal of Personality and Social Psychology, 82(6), 878-902. doi: 10.1037//0022-3514.82.6.878

Fagan, J., A. Geller, G. Davies, \& V. West (2010) “Street stops and broken windows revisited," in S. K. Rice \& M. D. White, eds., Race, Ethnicity and Policing. New York: NYU Press.

Finlay, K. A., \& Stephan, W. G. (2000). Improving intergroup relations: The effects of empathy on racial attitudes. Journal of Applied Social Psychology, 30(8), 17201737. doi: $10.1111 / j .1559-1816.2000 . t b 02464 . x$

Freire, P. (1970). Pedagogy of the oppressed. New York: Continuum.

Freire, P. (1990). Education for a critical consciousness. New York: Continuum

Garber, M. (2015). The revolutionary aims of Black Lives Matter. Retrieved May, 2017, from https://www.theatlantic.com/politics/archive/2015/09/black-lives-matterrevolution/408160/ 
Gardner, D. G., Cummings, L. L., Dunham, R. B., \& Pierce, J. L. (1998). Single-item versus multiple-item measurement scales: An empirical comparison. Educational and Psychological Measurement, 58(6), 898-915. doi:

$10.1177 / 0013164498058006003$

Gaertner, S. L. (1973). Helping behavior and racial discrimination among liberals and conservatives. Journal of Personality and Social Psychology, 25(3), 335-341. doi: $10.1037 / \mathrm{h} 0034221$

Gaertner, S. L., \& Dovidio, J. F. (1986). The aversive form of racism. In Prejudice, discrimination, and racism.

Gaertner, S. L., \& Dovidio, J. F. (2000). Reducing intergroup bias: The Common Ingroup Identity Model. Philadelphia, PA: The Psychology Press.

Gaertner, S. L., Dovidio, J. F., Anastasio, P. A., Bachman, B. A., \& Rust, M. C. (1993). The Common Ingroup Identity Model: Recategorization and the reduction of intergroup bias. In W. Stroebe \& M. Hewstone (Eds.), European review of social psychology (Vol. 4, pp. 1-26). New York: Wiley.

Gil de Zúñiga, H., Molyneux, L., \& Zheng, P. (2014). Social media, political expression, and political participation: Panel analysis of lagged and concurrent relationships. Journal of Communication, 64(4), 612-634. doi: 10.1111/jcom.12103

Ginwright, S., \& Cammarota, J. (2007). Youth activism in the urban community: Learning critical civic praxis within community organizations. International Journal of Qualitative Studies in Education, 20, 693-710.

doi:10.1080/09518390701630833 
Glasford, D. E., \& Calcagno, J. (2012). The conflict of harmony: Intergroup contact, commonality and political solidarity between minority groups. Journal of Experimental Social Psychology, 48(1), 323-328. doi: 10.1016/j.jesp.2011.10.001

Glasford, D. E., \& Caraballo, K. L. (2016). Collective action from a distance: Distance shapes how people view victims of injustice and decreases willingness to engage in collective action. Group Processes \& Intergroup Relations, 19(1), 27-42. doi: $10.1177 / 1368430215570505$

Glenn, E. N. (1992). From servitude to service work: Historical continuities in the racial division of paid reproductive labor. Signs: Journal of Women in Culture and Society, 18(1), 1. doi: 10.1086/494777

Grant, P. R., Abrams, D., Robertson, D. W., \& Garay, J. (2015). Predicting protests by disadvantaged skilled immigrants: A test of an integrated social identity, relative deprivation, collective efficacy (SIRDE) model. Social Justice Research, 28(1), 76-101. doi: 10.1007/s11211-014-0229-Z

Greenwald, A. G., \& Banaji, M. R. (1995). Implicit social cognition: Attitudes, selfesteem, and stereotypes. Psychological Review, 102(1), 4-27.

Greenwood, R. M. (2012) Standing at the crossroads: An intersectional approach to women's social identities and political consciousness. In S.Wiley, \& T. A. Revenson (Eds.), Social categories in everyday experience (pp. 103-129). Washington, DC: American Psychological Association. 
Good, J. J., Moss-Racusin, C. A., \& Sanchez, D. T. (2012). When do we confront? Perceptions of costs and benefits predict confronting discrimination on behalf of the self and others. Psychology of Women Quarterly, 36(2), 210-226.

Goodman, L. A., Bohligh, A., Litwin, A., Weintraub, S. R., Green, A., Walker, J., et al. (2007). Applying feminist theory to community practice: a multilevel empowerment intervention for low-income women with depression. In E. Aldarando (Ed.), Advancing social justice through clinical practice (pp. 267290). Florence, KY: Lawrence Erlbaum Associates

Goodman, L. A., Liang, B., Helms, J. E., Latta, R. E., Sparks, E., \& Weintraub, S. B. (2004). Training counseling psychologists as social justice agents: Feminist and multicultural principles in action. The Counseling Psychologist, 32(6), 793-836. doi: $10.1177 / 0011000004268802$

Goff, P. A., \& Kahn, K. B. (2013). How psychological science impedes intersectional thinking. Du Bois Review, 10(2), 365-384.

Goff, P. A., Thomas, M. A., \& Jackson, M. C. (2008). “Ain’t I a woman?”: Towards an intersectional approach to person perception and group-based harms. Sex Roles, 59(5-6), 392-403. doi: 10.1007/s11199-008-9505-4

Gunther, A. C. (1992). Biased press or biased public? Attitudes toward media coverage of social groups. American Association for Public Opinion Research, 56(2), 147167. doi: $10.1086 / 269308$

Gurin, P., Miller, A. H., \& Gurin, G. (1980). Stratum identification and consciousness. Social Psychology Quarterly, 43(1), 30-47. doi: 10.2307/3033746 
Hall, S. (1986). Gramsci's Relevance for the study of race and ethnicity. Journal of Communication Inquiry, 10, 5-27. doi: 10.1177/019685998601000202

Harlow, S. (2012). Social media and social movements: Facebook and an online Guatemalan justice movement that moved offline. New Media \& Society, 14(2), 225-243. doi: 10.1177/1461444811410408

Hayes, A. F., \& Preacher, K. J. (2014). Statistical mediation analysis with a multicategorical independent variable. British Journal of Mathematical and Statistical Psychology, 67(3), 451-470. doi: 10.1111/bmsp.12028

Heuchan, C. (2016). Self-care or speaking out? A Black feminist dilemma. Retrieved September 2, 2016, from https://sisteroutrider.wordpress.com/2016/08/08/selfcare-or-speaking-out-a-black-feminist-dilemma/

Ho, A. K., Sidanius, J., Levin, D. T., \& Banaji, M. R. (2011). Evidence for hypodescent and racial hierarchy in the categorization and perception of biracial individuals. Journal of Personality and Social Psychology, 100(3), 492-506.

Hope, E. C., Keels, M., \& Durkee, M. I. (2016). Participation in Black Lives Matter and deferred action for childhood arrivals: Modern activism among Black and Latino college students. Journal of Diversity in Higher Education, 9(3), 203-215. doi: $10.1037 /$ dhe 0000032

Hornsey, M. J., \& Hogg, M. A. (2000). Subgroup relations: A comparison of mutual intergroup differentiation and Common Ingroup Identity Models of prejudice reduction. Personality and Social Psychology Bulletin, 26(2), 242-256. doi: $10.1177 / 0146167200264010$ 
Horsham-Brathwaite, C. (2012). The Relationship Between Liberation and Black Women's Self-Care. Lecture presented at York College, York, Nebraska.

Islam, R., \& Hewstone, M. (1993). Dimensions of contact as predictors of intergroup anxiety, perceived out-group variability, and out-group attitude: An integrative model. Personality and Social Psychology Bulletin, 19(6), 700-710. doi: 0803973233

Issacharoff, S. (2013). Beyond the discrimination model of voting. Harvard Law Review, 127(1), 95-124.

Jones, C. (1949). An end to the neglect of the problems of the Negro woman!. Jefferson School of Social Science.

Kahn, K. B., \& Martin, K. D. (2016). Policing and race: Disparate treatment, perceptions, and policy responses. Social Issues and Policy Review, 10(1), 82-121.

Katz, I., \& Hass, R. (1988). Racial ambivalence and American value conflict: Correlational and priming studies of dual cognitive structures. Journal of Personality and Social Psychology. doi: 10.1037/0022-3514.55.6.893

Kaufmann, K. M. (2003). Cracks in the rainbow: Group commonality as a basis for Latino and African-American political coalitions. Political Research Quarterly, 56(2), 199-210. doi:10.1177/10659129030560020

Kawakami, K., \& Dion, K. L. (1995). Social identity and affect as determinants of collective action: Towards an integration of Relative Deprivation and Social Identity Theories. Theory \& Psychology, 5(4), 551-577. 
Kelly, C., \& Breinlinger, S. (1995). Identity and injustice: Exploring women's participation in collective action. Journal of Community \& Applied Social Psychology, 5(1), 41-57. doi: 10.1002/casp.2450050104

Kernahan, C., \& Davis, T. (2009). What are the long-term effects of learning about racism?. Teaching of Psychology, 37(1), 41-45.

King, D. K. (1988). Multiple jeopardy, multiple consciousness: The context of a Black feminist ideology. Source: Signs, 14(1), 42-72. doi: 10.1086/494491

Klandermans, P. G. (2014). Identity politics and politicized identities: Identity processes and the dynamics of protest. Political Psychology, 35(1), 1-22. doi: $10.1111 /$ pops. 12167

Kohatsu, E. L., Victoria, R., Lau, A., Flores, M., \& Salazar, A. (2011). Analyzing AntiAsian prejudice from a racial identity and color-blind perspective. Journal of Counseling \& Development, 89(1), 63-72. doi: 10.1002/j.15566678.2011.tb00061.x

Kovel, J. (1970). White racism: A psychohistory. New York, NY: Pantheon Books Lake, J., Alston, A. T., Kahn, K. B. (under review). The influence of social networking use and perceived discrimination on support for and participation in racial justice efforts.

Leonardo, Z. (2004). The color of supremacy: Beyond the discourse of "white privilege". Educational Philosophy \& Theory, 36(2), 137-152. doi: 10.1111/j.14695812.2004.00057.x 
Letters for Black Lives. (2016). Letters for Black Lives: An open letter project on antiBlackness. Retrieved August 20, 2016, from https://lettersforblacklives.com/

Liss, M., Crawford, M., \& Popp, D. (2004). Predictors and correlates of collective action. Sex Roles, 50(11/12), 771-779. doi: 10.1023/B:SERS.0000029096.90835.3f

Louie, M. C. Y. (2001). "It's never ever boring: Triple jeopardy from the Korean side.” In Asian Americans: The Movement and the Moment. Los Angeles, CA: UCLA American Studies.

Luhtanen, R., \& Crocker, J. (1992). A Collective Self-Esteem Scale: Self-evaluation of one's social identity. Personality and Social Psychology Bulletin, 18(3), 302-318. doi: $10.1177 / 0146167292183006$

Lorde, A. (1988). A burst of light. Ithaca, NY: Firebrand Books.

Maluso, D. (1995). Shaking hands with a clenched fist: Interpersonal racism. In The Social Psychology of Interpersonal Discrimination (pp. 50-79). New York, NY: Guilford Press.

Masuoka, N. (2006). Together they become one: Examining the predictors of panethnic group consciousness among Asian Americans and Latinos. Social Science Quarterly. doi: 10.1111/j.1540-6237.2006.00412.x

Marecek, J., Fine, M., \& Kidder, L. (2001). Working between two worlds: Qualitative methods and psychology. In D. L. Tolman \& M. Brydon Miller (Eds.), From subjects to subjectivities: A handbook of interpretive and participatory methods. (pp. 29-41). New York, NY: New York University Press. 
Mauer, M., \& King, R. S. (2007). Uneven justice: State rates of incarceration by race and ethnicity. The Sentencing Project, 1-23. Retrieved from http://sites.google.com/site/lkeber/SentencingProjRatesofIncarcerationby.pdf

McAdam, D., McCarthy, J. D., \& Zald, M. N. (1996). Comparative perspectives on social movements. Political opportunities, mobilizing structures, and cultural framings. Cambridge studies in comparative politics. doi: 10.1007/s13398-0140173-7.2

McCarthy, J. D., \& Zald, M. N. (1977). Resource mobilization and social movements: A partial theory. American Journal of Sociology, 82(6), 1212-1241. doi: $10.1086 / 226464$

McConahay, J. B. (1986). Modern racism, ambivalence, and the modern racism scale. In Prejudice, Discrimination, and Racism (pp. 91-125).

McConahay, J. B., Hardee, B. B., \& Batts, V. (1981). Has racism declined in America? It depends on who is asking and what is asked. The Journal of Conflict Resolution, 25(4), 563-579.

McConahay, J. B., \& Hough, J. C. (1976). Symbolic racism. Journal of Social Issues. doi: 10.1111/j.1540-4560.1976.tb02493.x

McLeod, D. M. (1994). Communicating deviance: The effects of television news coverage of social protest. Journal of Broadcasting \& Electronic Media, 39(1), 419. doi: $10.1080 / 08838159509364285$ 
McMahon, J. M., \& Kahn, K. B. (2015). Benevolent racism? The impact of target race on ambivalent sexism. Group Processes \& Intergroup Relations, 19(2), 169-183. doi: $10.1177 / 136843021558315$

Meraji, S. M., Chow, K., \& Xu, C. (n.d.). A letter from young Asian-Americans to their families about Black Lives Matter. Retrieved August 20, 2016, from http://www.npr.org/sections/codeswitch/2016/07/27/487375314/a-letter-fromyoung-asian-americans-to-their-families-about-black-lives-matter

Mettler, K. (2016). Why SPLC says White Lives Matter is a hate group but Black Lives Matter is not. Retrieved May, 2017, from https://www.washingtonpost.com/news/morning-mix/wp/2016/08/31/splc-themuch-cited-designator-of-hate-groups-explains-why-white-lives-matter-is-one/ Miller, A. H., Gurin, P., Gurin, G., \& Malanchuk, O. (1981). Group consciousness and political participation. American Journal of Political Science, 25(3), 494-511. doi: $10.2307 / 2110816$

Morris, A. D. (1992). Frontiers in social movement theory. Yale University Press. Mountz, A., Bonds, A., Mansfield, B., Loyd, J., Hyndman, J., Walton-Roberts, M., Basu, R., Whitson, R., Hawkins, R., Hamilton, T., \& Curran, W. (2015). For Slow Scholarship: A feminist politics of resistance through collective action in the neoliberal university. ACME: An International Journal for Critical Geographies, 14(4), 1235-1259.

Mueller, C., \& Tarrow, S. (1995). Power in movement: Social movements, collective action and politics. Contemporary Sociology, 24(4), 343. doi: 10.2307/2077646 
Muller, D., Judd, C. M., \& Yzerbyt, V. Y. (2005). When moderation is mediated and mediation is moderated. Journal of Personality and Social Psychology, 89(6), 852-863. doi: 10.1037/0022-3514.89.6.852

Muller, E. N., \& Opp, K.-D. (1986). Rational choice and rebellious collective action. The American Political Science Review, 80(2), 471-488. doi: 10.2307/1958269

Nakayama, T. K., \& Martin, J. N. (1999). Whiteness: The communication of social identity. Thousand Oaks, CA: Sage.

National Center for Education Statistics (NCES). (2015). Retrieved August 12, 2016, from http://nces.ed.gov/ccd/data_tables.asp

Norton, M. I., \& Sommers, S. R. (2011). Whites see racism as a zero-sum game that they are now losing. Perspectives on Psychological Science, 6(3), 215-218. doi: $10.1177 / 1745691611406922$

Nosek, B. A., Smyth, F. L., Hansen, J. J., Devos, T., Lindner, N. M., Ranganath, K. A., ... Banaji, M. R. (2007). Pervasiveness and correlates of implicit attitudes and stereotypes. European Review of Social Psychology, 18(1), 36-88. doi: $10.1080 / 10463280701489053$

O’Keefe, V. M., Wingate, L. R., Cole, A. B., Hollingsworth, D. W., \& Tucker, R. P. (2015). Seemingly harmless racial communications are not so harmless: Racial microaggressions lead to suicidal ideation by way of depression symptoms. Suicide and Life-Threatening Behavior, 45(5), 567-576. doi: 10.1111/sltb.12150 
Oliver, P., Marwell, G., \& Teixeira, R. (1985). A theory of the critical mass. I. Group heterogeneity, interdependence, and the production of collective action. American Journal of Sociology, 91(3), 522-556.

Omoto, A. M., \& Snyder, M. (1995). Sustained helping without obligation: Motivation, longevity of service, and perceived attitude change among AIDS volunteers. Journal of Personality and Social Psychology, 68(4), 671-686.

Ong, A. D., Burrow, A. L., Fuller-Rowell, T. E., Ja, N. M., \& Sue, D. W. (2013). Racial microaggressions and daily well-being among Asian Americans. Journal of Counseling Psychology, 60(2), 188-199. doi: 10.1037/a0031736

Osanloo, A. F., Boske, C., \& Newcomb, W. S. (2016) Deconstructing macroaggressions, microaggressions, and structural racism in education: Developing a conceptual model for the intersection of social justice practice and intercultural education. International Journal of Organizational Theory and Development, 4(1). 1-18.

Ostrom, E. (2000). Collective action and the evolution of social norms. Journal of Economic Perspectives. doi: 10.1257/jep.14.3.137

Oxendine, D. B. (2016). Gender, race, and college major: Do they predict modern racism?. Journal of Social Science Studies, 3(2), 90.

Pardo, M. (1997). Mexican American women grassroots community activists: Mothers of East Los Angeles. In F. Chris Garcia, ed., Pursuing power: Latinos in the political system. Notre Dame, IN: University of Notre Dame Press 
Pascoe, E. A., \& Smart Richman, L. (2009). Perceived discrimination and health: A meta-analytic review. Psychological Bulletin, 135(4), 531-554. doi: $10.1037 / \mathrm{a} 0016059$

Paternoster, R., Brame, R., Mazerolle, P., \& Piquero, A. (1998). Using the correct statistical test for the equality of regression coefficients. Criminology, 36(4), 859866. doi: $10.1111 / \mathrm{j} .1745-9125.1998 . t b 01268 . x$

Paulsen, R. (1991). Education, social class, and participation in collective action. Sociology of Education, 64, 96-110. doi: 10.2307/2112881

Pettigrew, T. F., \& Tropp, L. R. (2006). A meta-analytic test of intergroup contact theory. Journal of Personality and Social Psychology, 90(5), 751-783. doi: $10.1037 / 0022-3514.90 .5 .751$

Pettigrew, T. F., \& Tropp, L. M. (2011). When groups meet: The dynamics of intergroup contact. Philadelphia, PA: Psychology Press.

Pew Research Center. (2015). Chapter 3: The Multiracial Identity Gap. Retrieved April 23, 2017, from www.pewsocialtrends.org/2015/06/11/chapter-3-the-multiracialidentity-gap

Pinderhughes, D. M. (1987). Race and ethnicity in Chicago politics: A reexamination of pluralist theory. Urbana: University of Illinois Press.

Ponterotto, J. G. (1988). Racial/ethnic minority research in the Journal of Counseling Psychology: A content analysis and methodological critique. Journal of Counseling Psychology, 35(4), 410. doi: 10.1037/0022-0167.35.4.410 
Postmes, T., \& Brunsting, S. (2002). Collective action in the age of the internet: Mass communication and online mobilization. Social Science Computer Review, 20(3), 290-301. doi: 10.1177/089443930202000306

Postmes, T., Haslam, S. A., \& Jans, L. (2012). A single-item measure of social identification: Reliability, validity, and utility. The British Journal of Social Psychology, 52(2006), 597-617. doi: 10.1111/bjso.12006

Postmes, T., Spears, R., \& Lea, M. (1999). Social identity, group norms, and" deindividuation": Lessons from computer-mediated communication for social influence in the group. In Social Identity: Context, Commitment, Content. Oxford: Blackwell.

Purdie-Vaughns, V., \& Eibach, R. P. (2008). Intersectional Invisibility: The distinctive aadvantages and disadvantages of multiple subordinate-group identities. Sex Roles, 59(5-6), 377-391. doi: 10.1007/s11199-008-9424-4

Pratto, F., Sidanius, J., Stallworth, L., \& Malle, B. (1994) Social dominance orientation: A personality variable predicting social and political attitudes. Journal of Personality and Social Psychology, 67, 741-763.

Pyke, K. D. (2010). What is internalized racial oppression and why don't we study it? Acknowledging racism's hidden injuries. Sociological Perspectives, 53(4), 551572. doi: $10.1525 /$ sop.2010.53.4.551

Raaijmakers, Q. A. W. (1999). Effectiveness of different missing data treatments in surveys with Likert-type data: Introducing the relative mean substitution 
approach. Educational and Psychological Measurement, 59(5), 725-748. doi: $10.1177 / 00131649921970116$

Reicher, S. D., Spears, R., \& Postmes, T. (1995). A social identity model of deindividuation phenomena. European Review of Social Psychology, 6, 161-198.

Reid, P. T. (1984). Feminism versus minority group identity: Not for black woman only. Sex Roles, 10(3-4), 247-255. doi: 10.1007/BF00287778

Reynolds, K. J., Turner, J. C., Haslam, S. A., \& Ryan, M. K. (2001) The role of personality and group factors in explaining prejudice. Journal of Experimental Social Psychology, 37, 427-434.

Rattan, A., \& Dweck, C. S. (2010). Who confronts prejudice? The role of implicit theories in the motivation to confront prejudice. Psychological Science, 21(7), 952-959.

Richeson, J., \& Craig, M. (2011). Intra-minority intergroup relations in the twenty-first century. Daedalus, 140(2), 166-175.

Richeson, J. A., \& Sommers, S. R. (2016). Toward a social psychology of race and race relations for the twenty-first century. Annual Review of Psychology, 67, 439-63. doi: 10.1146/annurev-psych-010213-115115

Rotella, K. N., Richeson, J. A., Chiao, J. Y., \& Bean, M. G. (2012). Blinding trust: The effect of perceived group victimhood on intergroup trust. Personality and Social Psychology Bulletin, 39(1), 115-127. doi:10.1177/0146167212466114

Rydin, Y., \& Pennington, M. (2011). Public participation and local environmental planning : The collective action problem and the potential of social capital. Local 
Environment: The International Journal of Justice and Sustainability, 5(2), 153169. doi: $10.1080 / 13549830050009328$

Sabol, W. J., Coulton, C. J., \& Korbin, J. E. (2004). Building community capacity for violence prevention. Journal of Interpersonal Violence, 19(3), 322-340. doi: $10.1177 / 0886260503261155$

Safdar, A. (2016). Black Lives Matter: The social media behind a movement. Retrieved September 28, 2016, from http://www.aljazeera.com/news/2016/08/black-livesmatter-social-media-movement-160803042719539.html

Sampson, R. J., McAdam, D., MacIndoe, H., \& Weffer-Elizondo, S. (2005). Civil society reconsidered: The durable nature and community structure of collective civic action. American Journal of Sociology, 111(3), 673-714. doi: 10.1086/497351

Sampson, R. J., Raudenbush, S. W., \& Earls, F. (1997). Neighborhoods and violent crime: a multilevel study of collective efficacy. Science, 277(5328), 918-924. http://doi.org/10.1126/science.277.5328.918

Sanchez, G. R. (2008). Latino group consciousness and perceptions of commonality with African Americans. Social Science Quarterly, 89(2), 428-444. doi: 10.1111/j.1540-6237.2008.00540.x

Sandler, T., \& Hartley, K. (2001). Economics of alliances: The lessons for collective action. Journal of Economic Literature, 39(3), 869-896. doi: 10.1257/jel.39.3.869

Schafer, J. L. (1999). Multiple imputation: A primer. Statistical Methods in Medical Research, 8(1), 3-15. 
Schug, J., Alt, N. P., \& Klauer, K. C. (2015). Gendered race prototypes: Evidence for the non-prototypicality of Asian men and Black women. Journal of Experimental Social Psychology, 56, 121-125. doi: 10.1016/j.jesp.2014.09.012

Scroggins, W. A., Mackie, D. M., Allen, T. J., \& Sherman, J. W. (2016). Reducing prejudice with labels: Shared group memberships attenuate implicit bias and expand implicit group boundaries. Personality and Social Psychology Bulletin, 42(2), 219-229. doi: 10.1177/0146167215621048

Sellers, R. M., Caldwell, C. H., Schmeelk-Cone, K. H., \& Zimmerman, M. A. (2003). Racial identity, racial discrimination, perceived stress, and psychological distress among African American young adults. Journal of Health and Social Behavior, 44(3), 302-317. doi: 10.2307/1519781

Sellers, S., Cherepanav, D., Hanmer, J., Fryback, D. G., \& Palta, M. (2013). Interpersonal discrimination and health-related quality of life among black and white men and women in the United States. Quality of Life Research, 22(6), 1307-1312. doi: $10.1007 / \mathrm{s} 11136-012-0258-8$

Sesko, A. K., \& Biernat, M. (2010). Prototypes of race and gender: The invisibility of Black women. Journal of Experimental Social Psychology, 46(2), 356-360. doi: 10.1016/j.jesp.2009.10.016

Sherif, M. (1958). Superordinate goals in the reduction of intergroup conflict. American Journal of Sociology, 349-356.

Sherif, M. (1998). Experiments in group conflict. In J.M. Jenkins, K. Oatley, \& N. Stein (Eds.) Human emotions: A reader (pp. 245-252). Malden, MA: Blackwell. 
Sherif, M., Harvey, O. J., White, B. J., Hood, W. R., \& Sherif, C. W. (1961). Intergroup conflict and cooperation: The Robbers Cave experiment (Vol. 10). Norman, OK: University Book Exchange.

Sherman, D. K., Kinias, Z., Major, B., Kim, H. S., \& Prenovost, M. (2007). The group as a resource: Reducing biased attributions for group success and failure via group affirmation. Personality and Social Psychology Bulletin, 33, 1100-1112. doi: $10.1177 / 0146167207303027$

Simon, B., \& Klandermans, B. (2001). Politicized collective identity: A social psychological analysis. The American Psychologist, 56(4), 319-31. doi: 10.1037/0003-066X.56.4.319

Simon, B., Loewy, M., Stürmer, S., Weber, U., Freytag, P., Habig, C., Kampmeier, C., Spahlinger, P. (1998). Collective identification and social movement participation. Journal of Personality and Social Psychology, 74(3), 646-658. doi: $10.1037 / 0022-3514.74 .3 .646$

Smith, H. J., \& Tyler, T. R. (1996). Justice and power: When will justice concerns encourage the advantaged to support policies which redistribute economic resources and the disadvantaged to willingly obey the law? European Journal of Social Psychology, 26(2), 171-200. doi: 10.1002/(SICI)10990992(199603)26:2<171::AID-EJSP742>3.0.CO;2-8

Spencer, R. C. (2016). Engendering the Black freedom struggle: Revolutionary Black womanhood and the Black Panther Party in the Bay Area, California. Journal of Women's History, 20(1), 90-113. doi: jowh.2008.0006 
Stanton, E. C., Anthony, S. B., \& Gage, M. J. (Eds.) (1881). History of Woman Suffrage. New York: Fowler \& Wells.

Stewart, A., \& McDermott, C. (2004). Civic engagement, political identity, and generation in developmental context. Research in Human Development, 1(3), 189-203. doi: 10.1207/s15427617rhd0103_4

Stroebe, K. (2013). Motivated inaction: When collective disadvantage does not induce collective action. Journal of Applied Social Psychology, 43(10), 1997-2006. doi: $10.1111 /$ jasp. 12153

Stürmer, S., \& Simon, B. (2004a). Collective action: Towards a dual-pathway model. European Review of Social Psychology, 15, 59-99.

Stürmer, S. \& Simon, B. (2004b). The role of collective identification in social movement participation: A panel study in the context of the German gay movement. Personality and Social Psychology Bulletin, 30, 263-277.

Sue, D., Capodilupo, C., Torino, G., Bucceri, J., Holder, A., Nadal, K., \& Esquilin, M. (2007). Racial microaggressions in everyday life: Implications for clinical practice. American Psychologist, 62(4), 271-286.

Swarns, R. (2006). An immigration debate framed by family ties. The New York Times. (Down- loaded from http://www.nytimes.com/2006/04/04/washington/04immig.html, accessed August $1,2016)$ 
Swim, J. K., Aikin, K. J., Hall, W. S., \& Hunter, B. A. (1995). Sexism and racism: Oldfashioned and modern prejudices. Journal of Personality and Social Psychology, 68(2), 199-214. doi: 10.1037/0022-3514.68.2.199

Tate, K. (1994). From protest to politics: The new Black voters in American elections. Harvard University Press.

Tajfel, H. \& Turner, J. C. (1986). The social identity theory of intergroup behavior. In S. Worchol \& W. G. Austin (Eds.), Psychology of Intergroup Relations (2nd ed). Chicago: Nelson-Hall.

Thomae, M. \& Viki, G. T. (2008) Reducing ambivalent sexism through intergroup contact. In: 11th Jena Workshop on Intergroup Processes "Positive Behaviour between Social Groups: Processes, Problems and Promises, 19-23 June 2008, Oppurg, Germany.

Thomas, E. F., Mavor, K. I., \& McGarty, C. (2012). Social identities facilitate and encapsulate action-relevant constructs: A test of the social identity model of collective action. Group Processes \& Intergroup Relations, 15(1), 75-88. doi: $10.1177 / 1368430211413619$

Torres, L., \& Taknint, J. T. (2015). Ethnic microaggressions, traumatic stress symptoms, and Latino depression: A moderated mediational model. Journal of Counseling Psychology, 62(3), 393-401. doi: 10.1037/cou0000077

Triandis, H. C., \& Gelfand, M. J. (1998). Converging measurement of horizontal and vertical individualism and collectivism. Journal of Personality and Social Psychology, 74(1), 118-128. doi: 10.1037/0022-3514.74.1.118 
Tropp, L. R., \& Wright, S. C. (2001). Ingroup identification as the inclusion of ingroup in the self. Personality and Social Psychology Bulletin, 27(5), 585-600.

Troyna, B., \& Williams, J. (2012). Racism, education and the state. Taylor \& Francis.

Tufekci, Z., \& Wilson, C. (2012). Social media and the decision to participate in political protest: Observations from Tahrir Square. Journal of Communication, 62(2), 363379. doi: 10.1111/j.1460-2466.2012.01629.x

US Census Bureau. (2014). National Population Projections. Retrieved August 19, 2016, from http://www.census.gov/population/projections/data/national/2008/ summarytables.html

van Zomeren, M., Postmes, T., \& Spears, R. (2008). Toward an integrative social identity model of collective action: A quantitative research synthesis of three sociopsychological perspectives. American Psychological Association, 134(4), 504535. doi: 10.1037/0033-2909.134.4.504

Vandiver, B. J., Cross, W. E., Worrell, F. C., \& Fhagen-smith, P. E. (2002). Validating the Cross Racial Identity Scale. Journal of Counseling Psychology, 49(1), 71-85. doi: $10.1037 / / 0022-0167.49 .1 .71$

Verba, S., \& Nie, N. H. (1987). Participation in America: Political democracy and social equality. University of Chicago Press.

Verba, S., Schlozman, K. L., Brady, H. E., \& Brady, H. E. (1995). Voice and equality: Civic voluntarism in American politics (Vol. 4). Cambridge, MA: Harvard University Press. 
Vollhardt, J. R. (2012). Collective victimization. In The Oxford Handbook of Intergroup Conflict. doi: 10.1093/oxfordhb/9780199747672.013.0009

Vollhardt, J. R. (2015). Inclusive victim consciousness in advocacy, social movements, and intergroup relations: Promises and pitfalls. Social Issues and Policy Review, 9(1), 89-120. doi: 10.1111/sipr.12011

Volpp, L. (2001). Obnoxious to their very nature: Asian Americans and constitutional citizenship. Citizenship Studies, 5(1), 57-71. doi: 10.1080/13621020020025196

Walch, S. E., Sinkkanen, K. A., Swain, E. M., Francisco, J., Breaux, C. A., \& Sjoberg, M. D. (2012). Using intergroup contact theory to reduce stigma against transgender individuals: Impact of a transgender speaker panel presentation. Journal of Applied Social Psychology, 42(10), 2583-2605. doi: 10.1111/j.15591816.2012.00955.x

Waller, J. (1993). Correlation of need for cognition and modern racism. Psychological Reports, 73(2), 542.

Wanous, J. P., \& Reichers, A. E. (1996). Estimating the reliability of a single-item measure. Psychological Reports, 78, 631-634. doi: 10.2466/pr0.1996.78.2.631

Washington Post 2015 database of police shootings. (2016). Retrieved August 20, 2016, from https://www.washingtonpost.com/graphics/national/police-shootings/

Watts, R., Griffith, D., \& Abdul-Adil, J. (1999). Sociopolitical development as an antidote for oppression: Theory and action. American Journal of Community Psychology, 27, 255-272. 
Watts, R. J., \& Hipolito-Delgado, C. P. (2015). Thinking ourselves to liberation?: Advancing sociopolitical action in critical consciousness. Urban Review, 47(5), 847-867. doi: 10.1007/s11256-015-0341-x

Welch, S., \& Sigelman, L. (2011). The "Obama Effect” and White racial attitudes. Annals of the American Academy of Political and Social Science, 634(1), 207220. doi: $10.1177 / 0002716210386302$

White, D. G. (1999). Too heavy a load: Black women in defense of themselves, 18941994. WW Norton \& Company.

Wilson, G. (1978). The psychology of conservatism: Comment on Stacey. New Zealand Psychologist, 7(1), 21. doi: 10.2307/2062226

Wong, F., \& Halgin, R. (2006). The "model minority": Bane or blessing for Asian Americans? Journal of Multicultural Counseling and Development, 34(1), 38-49. doi: 10.1002/j.2161-1912.2006.tb00025.x

Wright, S. C. (2003). Changing intergroup relations strategic collective action: Social psychology and social change. In R. Brown \& S. L. Gaetner (Eds.), Blackwell Handbook of Social Psychology: Intergroup Processes (pp. 409-430). Blackwell Publishers Ltd.

Wright, S. C., \& Lubensky, M. (2009). The struggle for social equality: Collective action vs. prejudice reduction. In S. Demoulin, J. P. Leyens, \& J. F. Dovidio (Eds.), Intergroup misunderstandings: Impact of divergent social realities (pp. 291-310). New York: Psychology Press 
Wright, S. C., Taylor, D. M., \& Moghaddam, F. M. (1990). Responding to membership in a disadvantaged group: From acceptance to collective protest. Journal of Personality and Social Psychology, 58, 994-1003. doi: 10.1037/00223514.58.6.994

Wright, S. C., \& Tropp, L. R. (2002). Collective action in response to disadvantage. In I. Walker \& H. J. Smith (Eds.), Relative Deprivation: Specification, Development and Integration. New York: Cambridge University Press.

Xenos, M., \& Moy, P. (2007). Direct and differential effects of the internet on political and civic engagement. Journal of Communication, 57(4), 704-718. doi: $10.1111 /$ j.1460-2466.2007.00364.x

Zebrowitz, L. A., White, B., \& Wieneke, K. (2008). Mere exposure and racial prejudice: Exposure to other-race faces increases liking for strangers of that race. Social Cognition, 26(3), 259-275. Doi: 10.1521/soco.2008.26.3.259

Zenou, Y., \& Boccard, N. (2000). Racial discrimination and redlining in cities. Journal of Urban Economics, 48(2), 260-285. doi: 10.1006/juec.1999.2166 
Appendix A: List of measures used in analyses

Bolded measure items were used in the analyses for this study.

1. Gender

a. With what gender do you identify?

i. Female

ii. Male

iii. Transgender

iv. Other

v. Decline to state

2. Age

a. What is your age? (open-ended)

3. Race/ethnicity

a. With which racial/ethnic group do you identify?

i. White

ii. Black or African American

iii. American Indian or Alaska Native

iv. Latino/a

v. Asian, South, or Southeast Asian

vi. Middle Eastern

vii. Hawaiian Native and Pacific Islander

viii. Multiracial (Please specify :

ix. Other (Please specify :

4. SES/Occupation

a. Please estimate your socioeconomic status.
i. Very low
ii. Low
iii. Somewhat low
iv. Average
v. Somewhat high
vi. High
vii. Very high

5. Education Status

a. What is your major?

i. What is your student status?

ii. part-time

iii. full-time

b. What year in school are you?

i. First year

ii. Second year 
iii. Third year

iv. Fourth year or higher

v. Graduate student

6. First generation status

a. Were you born in the United States?

i. Yes

ii. No (if no: how many years have you lived here:

7. Political orientation

a. Which of the following best represents your political views?

i. Very conservative

ii. Conservative

iii. Slightly conservative

iv. Neither liberal or conservative

v. Slightly liberal

vi. Liberal

vii. Very Liberal

\section{Stereotypicality/Identity centrality}

a. SCORING: 1-5 scale, strongly agree to strongly disagree

i. People in the same racial, gender, or social groups can have very different experiences. We are interested in differences based on how you see yourself and how others see you.

ii. Other people think I physically look like a typical member of my racial/ethnic group.

iii. The racial group I belong to is an important reflection of who I am.

iv. In general, belonging to my racial group is an important part of my self-image.

v. Other people think I physically look like a typical member of my gender group.

vi. The gender I belong to is an important reflection of who I am.

vii. In general, belonging to my gender group is an important part of my self-image.

viii. My identity as a PSU student is an important reflection of who I am.

ix. In general, belonging to PSU students as a group is an important part of my self-image.

9. Stereotype threat

a. SCORING: 1-5 scale, strongly agree to strongly disagree

i. I worry that police may stereotype me because of my race or ethnicity. 
ii. I worry that the things I say may be misinterpreted as prejudiced by others.

iii. I never worry that someone will suspect me of being prejudiced just because of my race or ethnicity.

iv. I worry that police officers' evaluation of me might be affected by my race.

v. I worry that, because I know the racial stereotypes about my group, my anxiety about confirming that stereotype may negatively influence my interactions with police officers.

10. Pervasiveness of discrimination

a. SCORING: 1-7 scale

i. How often do you think that racial and ethnic minorities can expect to face discrimination?

ii. In how many contexts or situations do you think racial and ethnic minorities can expect to face racial discrimination in US society?

iii. In your estimate, what percentage of people are prejudiced against racial and ethnic minorities in US society?

11. Views on gun control

a. SCORING: 1-7 scale, strongly agree to strongly disagree

i. Citizen's rights and restrictions surround gun ownership have been a highly debated topic for a long time. Please indicate how much you agree or disagree with the following statements.

ii. I support stricter gun control laws in the United States.

iii. I do not support requiring background checks for all gun buyers.*

iv. More strict gun laws in the United States would help prevent gun violence.

v. There should not be laws to prevent people with mental illness from purchasing guns. ${ }^{*}$

12. Body camera use

a. SCORING: 1-7 scale, strongly agree to strongly disagree

i. There has been a growing national movement to require police officers to wear body cameras as part of their job. We are interested on your opinion on this topic. Please indicate how much you agree or disagree with the following statements.

ii. Police officers should be required to wear body cameras while on the job.

iii. Having police officers wear body cameras while on the job would not be effective in reducing excessive use of force with suspects. *

iv. Having police officers wear body cameras while on the job will not reduce racial profiling.*

v. Having police officers wear body cameras while on the job will improve community relations. 
b. Having police officers wear body cameras while on the job will not increase community trust.*

13. Views of armed security on campus

a. SCORING: 1-5 scale, strongly agree to strongly disagree

i. In December 2014, the Portland State Board of Trustees approved a plan to allow armed security on Portland State's campus. We would like to know more about your perceptions of this plan. Please indicate how much you agree or disagree with the following statements.

ii. I support the decision to arm PSU security officers.

iii. Having armed security officers at PSU will not reduce crime on campus.*

iv. The presence of armed security at PSU will not have an effect on race relations on campus. ${ }^{*}$

v. Armed security officers at PSU will make the campus safer.

vi. The presence of armed security at PSU will not increase racial profiling on campus.*

vii. The presence of armed security at PSU will have a negative impact on campus interactions.

14. Views of police/campus security

a. Please score the following statements about Portland Police and Campus

Security based on your opinions and experiences.

b. Legitimacy and Trust

c. SCORING: 1-5 scale, strongly agree to strongly disagree

i. Portland Police

ii. The Portland Police are trustworthy.

iii. Portland Police treat people like me respectfully.

iv. I think I would be treated fairly by Portland Police.

v. I think my values and the values of Portland Police are very similar.

vi. Portland Police treat people disrespectfully because of their race or ethnicity.

vii. If I saw a crime happening I would call the Portland Police to report it.

viii. I would work with the Portland Police to identify a person who committed a crime.

ix. Portland State Campus Security (current perceptions)

x. PSU's campus security officers are trustworthy.

xi. PSU's campus security officers treat people like me respectfully.

xii. I think I would be treated fairly by PSU's campus security officers.

xiii. If I saw a crime happening I would call PSU's campus security officers to report it. 
xiv. I would work with PSU's campus security officers to identify a person who committed a crime.

\section{Perceptions of Safety}

a. SCORING: 1-5 scale, very safe to very unsafe

i. How safe do you feel walking alone during the day

ii. On PSU's campus?

iii. Downtown Portland?

iv. How safe do you feel walking alone at night

v. On PSU's campus?

vi. Downtown Portland?

16. Police-Public Contact

a. In the past 12 months...

b. Have you been a victim of a crime in Portland?

i. No

ii. Yes

c. Did you contact the Portland Police / PSU Security to report a crime or ask for help? If "yes", were you treated fairly in your most recent interaction?

i. No (no contact)

ii. Yes (contact, treated fairly)

iii. Yes (contact, treated unfairly)

d. Did a Portland Police officer / PSU Security contact you? If "yes", were you treated fairly in your most recent interaction?

i. No (no contact)

ii. Yes (contact, treated fairly)

iii. Yes (contact, treated unfairly)

17. Views of who is at fault in Ferguson case

a. SCORING: 1-7 scale, strongly agree to strongly disagree

b. In August 2014, Michael Brown, an unarmed Black teenager, was fatally shot by Darren Wilson, a White police officer in Ferguson, Missouri. Based on your opinions of this event, please answer the following questions:

i. How much do you remember about the shooting of Michael Brown in Ferguson? (1-7 scale, not familiar at all to very familiar)

c. Please indicate how much you agree or disagree with the following statements.

i. This incident was the fault of Officer Darren Wilson.

ii. Michael Brown's behavior led to the outcome of this incident.

iii. Officer Darren Wilson acted in an unbiased manner during this incident.

iv. Officer Darren Wilson was justified in the amount of force used in this incident. 
v. I support Officer Darren Wilson's actions in this incident.

vi. Officer Darren Wilson was responsible for any injuries the suspect obtained.

vii. Michael Brown was to blame for the amount of force that was used.

viii. Officer Darren Wilson should receive disciplinary sanctions for this incident.

ix. This incident was the result of insufficient police training.

$\mathrm{x}$. This incident was the result of systemic racial discrimination in policing.

18. Many protests occurred after the shooting of Michael Brown and other similar events. Please indicate how much you agree or disagree with the following statements.

a. SCORING: 1-7 scale, strongly agree to strongly disagree

i. I support the protests in Ferguson, Missouri after the shooting of Michael Brown.

ii. I understand the reasons why people protested after the shooting of Michael Brown.

iii. The protests after the shooting of Michael Brown, and similar cases, are effective in promoting social change.

19. BlackLivesMatter, a collective movement that stemmed from perceived excessive use of force by police officers on racial minorities, is a nationwide movement that has been involved in some of the protests after the shooting of Michael Brown and similar events. Please indicate how much you agree or disagree with the following statements.

a. SCORING: 1-7 scale, strongly agree to strongly disagree

i. The BlackLivesMatter movement....

ii. is necessary.

iii. is effective in increasing awareness of systemic racial bias.

iv. is promoting unlawful behavior.*

$v$. is justified.

vi. increases racial tensions in society.*

vii. I support the goals of the BlackLivesMatter movement.

viii. "AllLivesMatter" is a better term than "BlackLivesMatter".*

b. The protests and BlackLivesMatter movement has collectively brought Black people/minorities/all people together (for a common cause).

i. In the US

ii. Globally

c. How much were you, personally, involved in any of the protest efforts for Michael Brown or similar cases?

i. 1-5 scale; not at all to extremely 
20. Feelings towards Groups

a. "Thermometer scale": On this scale, a number between 0-1 would mean you feel no warmth towards the group, while a number between 9-10 would mean you feel extreme warmth towards the group. Please rate how favorable you feel towards each of the groups by indicating a number next to the desired response.

i. White people

ii. Black people

iii. Latino/a people

iv. Asian people

v. Police officers

vi. Portland State campus security

\section{Modern Racism Scale}

a. SCORING: 1-5 scale, strongly agree to strongly disagree

b. Following are a number of opinion statements about public issues, politics, and your beliefs about the world in general. Please use the following scale to indicate your degree of agreement with each item.

i. Over the past few years, the government and news media have shown more respect to Black people than they deserve.

ii. It's easy to understand the anger of Black people in America.*

iii. Discrimination against Black people is no longer a problem in the United States.

iv. Over the past few years, Black people have gotten more economically than they deserve.

v. Black people are getting too demanding in their push for equal rights.

vi. Black people should not push themselves where they are not wanted.

22. Social Dominance Orientation Scale

a. SCORING: $1-7$ scale; very negative to very positive

b. Which of the following statements do you have a positive or negative feeling towards?

i. Some groups of people are simply inferior to other groups.

ii. In getting what you want, it is sometimes necessary to use force against groups.

iii. Superior groups should dominate inferior groups.

iv. To get ahead in life, it is sometimes necessary to step on other groups.

v. It would be good if groups could be equal.

vi. Group equality should be our ideal.

vii. All groups should be given an equal chance in life. 
viii. We should do what we can to equalize conditions for different groups.

\section{Belief in a Just World}

a. SCORING: 1-6 scale; strongly disagree to strongly agree

i. I think basically the world is a just place.

ii. I believe that, by and large, people get what they deserve.

iii. I am confident that justice always prevails over injustice.

iv. I am convinced that in the long run people will be compensated for injustices.

v. I firmly believe that injustices in all areas of life (e.g., professional, family, politic) are the exception rather than the rule.

vi. I think people try to be fair when making important decisions.

24. Social Networking Site Use

a. Are you a member of a social networking site like Facebook or Twitter?

i. Yes

ii. No

b. Which social networking site do you use for MOST of your online social networking?

i. Facebook

ii. Twitter

iii. Instagram

iv. Tumblr

v. Snapchat

vi. Other (fill in item)

c. How many times do you visit your favored site per week?

i. $0-2$ times

ii. 3-5 times

iii. 6-10 times

iv. More than 10 times

d. Please indicate your agreement with the following statements

e. SCORING: 1-7 scale, strongly agree to strongly disagree

i. I use social networking sites to share political information with my friends

ii. I have participated in "real world" political activities (like attending a rally or meeting) because I heard about them on a social networking site

iii. I was more likely to protest excessive police use of force because of information I saw on a social networking site

iv. I use/have used social networking sites to share my views about policing in the United States

v. I have found additional sources of information regarding policing in the United States through social networking sites 
25. Protective Paternalism

a. SCORING: 1-6 scale; strongly disagree to strongly agree

i. In a disaster, women should not necessarily be rescued before men. *

ii. Women should be cherished and protected by men.

iii. A good woman should be set on a pedestal by her man.

iv. Men should be willing to sacrifice their own well being in order to provide financially for the women in their lives.

26. Awareness of Privilege and Oppression Scale - 2

a. SCORING: 1-6 scale; strongly disagree to strongly agree

i. Racial and ethnic minorities are more likely to suffer from mental illness because of the way society treats them, compared to White individuals.

ii. Most history books accurately show how racial and ethnic minorities helped America become the country it is.*

iii. Being poor has no bearing on a person's opportunity to earn a college degree. *

iv. Racial and ethnic minorities and White people have to worry equally about their credibility when addressing a group. *

v. Racial minorities with lighter skin color are more likely to be promoted within corporations than racial minorities with darker skin color.

vi. Growing up in a middle class family improves your chances for obtaining a job that will be satisfying.

\section{General Comments}

a. (open ended) 
Appendix B: Conceptual model and statistical diagrams

\section{Conceptual Model: H2}

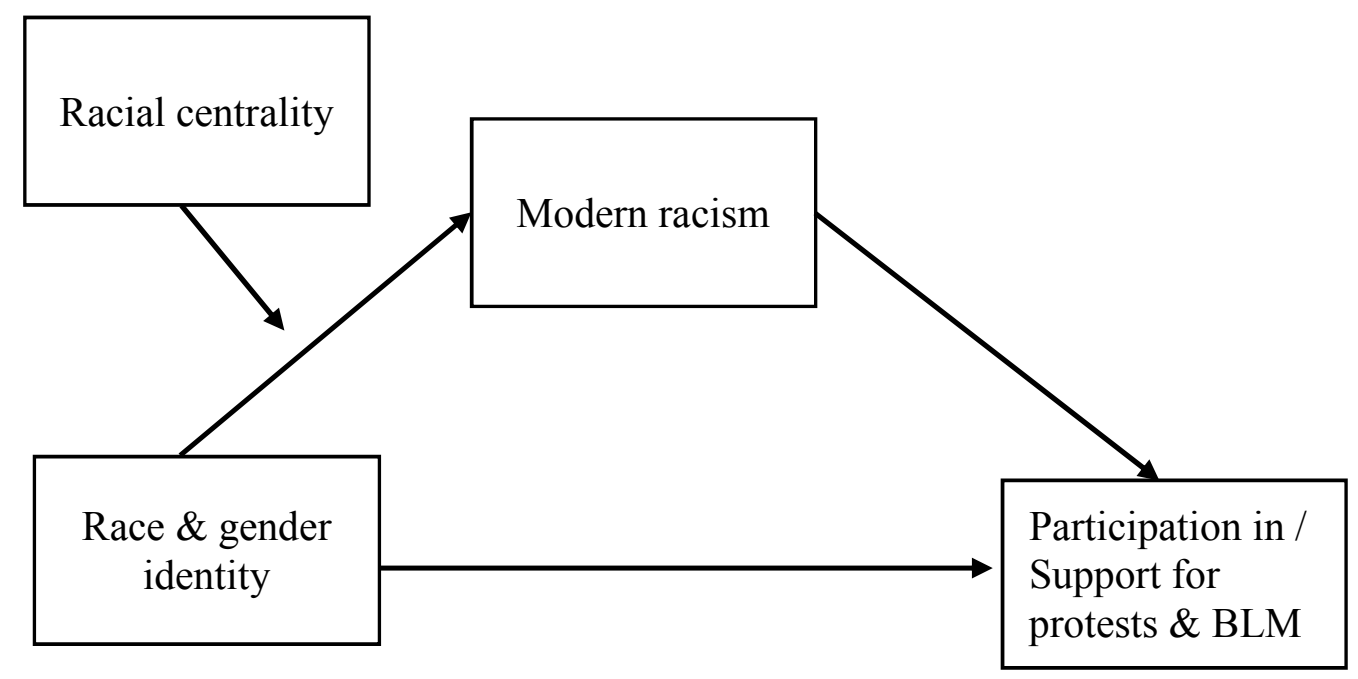


Tested regression: Equation 1

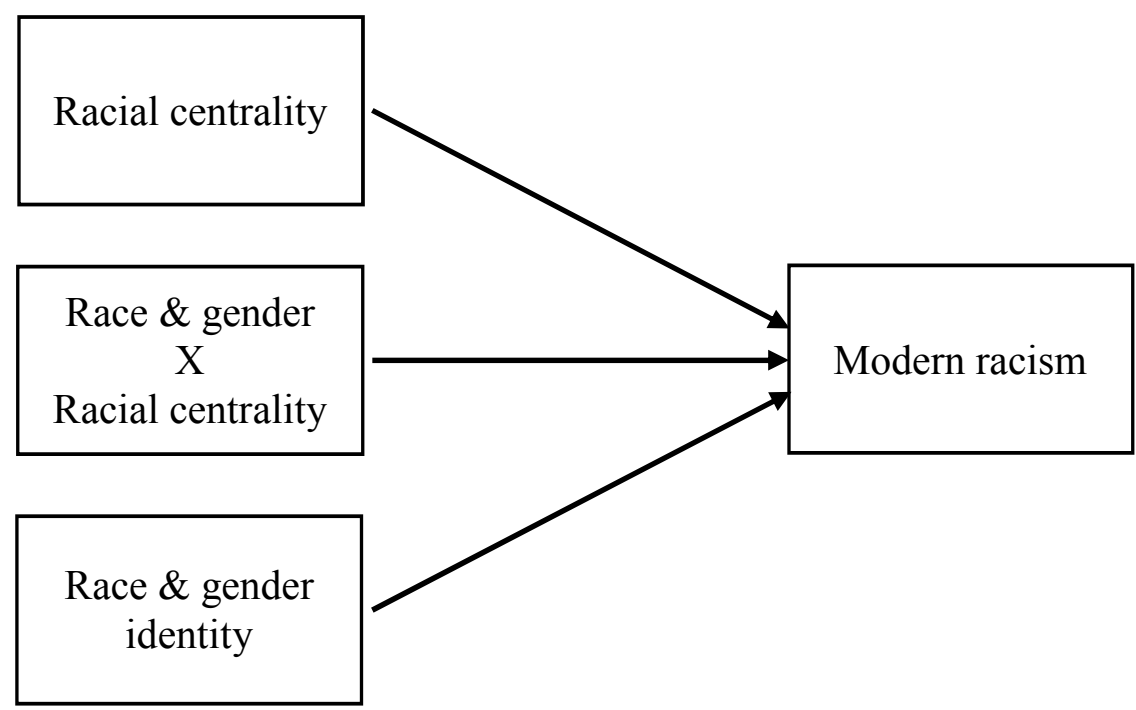

Tested regression: Equation 2

\begin{tabular}{|l|l|}
\hline Modern racism $\longrightarrow \begin{array}{l}\text { Participation in / } \\
\text { Support for } \\
\text { protests \& BLM }\end{array}$ \\
\hline
\end{tabular}


Tested regression: Equation 3

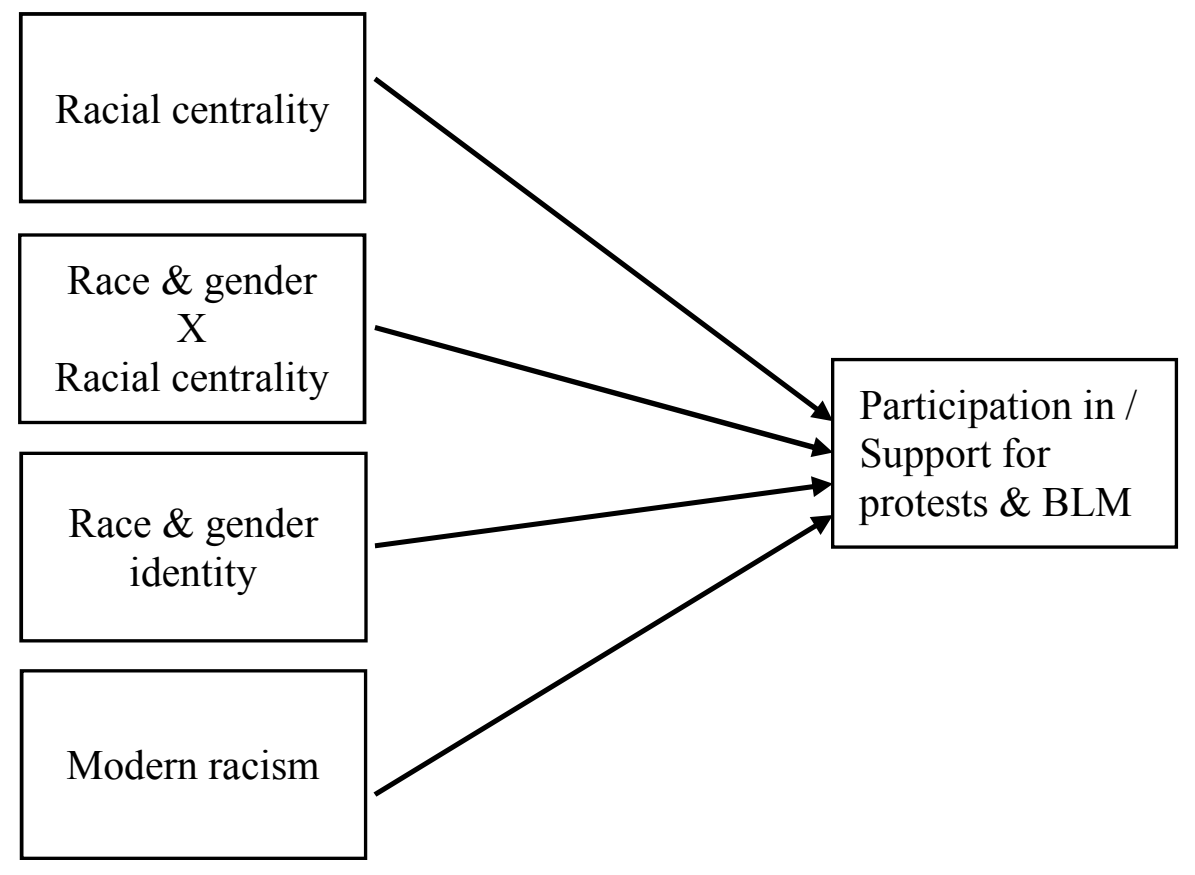




\section{Appendix C: Results from previously conducted EFA and CFAs}

\section{Measure Items}

Support for protests and Black Lives Matter

Scoring: 1-7 Likert scale, strongly disagree-strongly agree

Protest items instructions: Many protests occurred after the shooting of Michael Brown and other similar events. Please indicate how much you agree or disagree with the following statements.

1. $\left(\mathrm{P}_{1}\right)$ I support the protests in Ferguson, Missouri in response to the shooting of Michael Brown.

2. $\left(\mathrm{P}_{2}\right)$ The protests in response to the shooting of Michael Brown, and similar cases, are effective in promoting social change.

BLM items instructions: Black Lives Matter is a collective movement that stemmed from perceived excessive use of force by police officers on racial minorities. This is a nationwide movement that has been involved in some of the protests in response to the shooting of Michael Brown and similar events. Please indicate how much you agree or disagree with the following statements.

1. $\left(\mathrm{B}_{1}\right)$ I support the goals of the Black Lives Matter movement.

2. $\left(B_{2}\right)$ The Black Lives Matter movement is necessary.

3. $\left(\mathrm{B}_{3}\right)$ The Black Lives Matter movement is effective in increasing awareness of systemic racial bias.

4. $\left(\mathrm{B}_{4}\right)$ The Black Lives Matter movement is justified.

5. $\left(\mathrm{B}_{5}\right)$ The Black Lives Matter movement unnecessarily increases racial tension in society.*

*item was reverse-coded

Table C1.

Item residual correlations from EFA with oblimin rotation for the 7 items constructed to measure support for racial protests and the Black Lives Matter movement.

\begin{tabular}{lllllll}
\hline & $\mathrm{P}_{1}$ & $\mathrm{P}_{2}$ & $\mathrm{~B}_{1}$ & $\mathrm{~B}_{2}$ & $\mathrm{~B}_{3}$ & $\mathrm{~B}_{4}$ \\
\hline $\mathrm{P}_{1}$ & & & & & & \\
$\mathrm{P}_{2}$ & .18 & & & & & \\
$\mathrm{~B}_{1}$ & -.07 & -.08 & & & & \\
$\mathrm{~B}_{2}$ & -.05 & -.05 & .06 & & & \\
$\mathrm{~B}_{3}$ & -.06 & .05 & .06 & .05 & & \\
$\mathrm{~B}_{4}$ & -.05 & -.08 & .06 & .06 & -.00 & \\
$\mathrm{~B}_{5}$ & .03 & -.01 & -.04 & -.02 & -.02 & -.03 \\
\hline
\end{tabular}


Table C2.

Factor loadings and communalities from EFA with oblimin rotation for the 7 items constructed to measure support for racial protests and the Black Lives Matter movement.

\begin{tabular}{ccccc}
\hline & Mean & SD & $\begin{array}{c}\text { Factor } \\
\text { loadings }\end{array}$ & Communalities \\
\hline $\mathrm{P}_{1}$ & 4.83 & 1.97 & .76 & .63 \\
$\mathrm{P}_{2}$ & 4.62 & 1.88 & .72 & .51 \\
$\mathrm{~B}_{1}$ & 5.56 & 1.51 & .86 & .74 \\
$\mathrm{~B}_{2}$ & 5.46 & 1.51 & .89 & .80 \\
$\mathrm{~B}_{3}$ & 5.27 & 1.58 & .81 & .66 \\
$\mathrm{~B}_{4}$ & 5.50 & 1.45 & .85 & .72 \\
$\mathrm{~B}_{5}$ & 4.69 & 1.93 & .77 & .59 \\
\hline
\end{tabular}

Table C3.

Model fit statistics from a confirmatory factor analysis for seven items to measure support for protests and Black Lives Matter.

\begin{tabular}{ll}
\hline \multicolumn{1}{c}{ Fit test } & \multicolumn{1}{c}{ Tested model } \\
\hline$\chi^{2}(d f)$ & $99.649(13)$ \\
cfi & .970 \\
tli & .952 \\
aic & 10821.021 \\
bic & 10884.291 \\
RMSEA $(90 \% \mathrm{CI})$ & $.115(.09-.14)$ \\
SRMR & .035 \\
\hline
\end{tabular}

